Illinois State University

ISU ReD: Research and eData

Theses and Dissertations

$1-23-2018$

\title{
The Look Of Pedagogical Content Knowledge In Middle School Statistics
}

Dhimitraq Duni

Illinois State University, pduni@yahoo.com

Follow this and additional works at: https://ir.library.illinoisstate.edu/etd

Part of the Science and Mathematics Education Commons

\section{Recommended Citation}

Duni, Dhimitraq, "The Look Of Pedagogical Content Knowledge In Middle School Statistics" (2018).

Theses and Dissertations. 952.

https://ir.library.illinoisstate.edu/etd/952

This Dissertation is brought to you for free and open access by ISU ReD: Research and eData. It has been accepted for inclusion in Theses and Dissertations by an authorized administrator of ISU ReD: Research and eData. For more information, please contact ISUReD@ilstu.edu. 


\title{
THE LOOK OF PEDAGOGICAL CONTENT KNOWLEDGE IN MIDDLE SCHOOL
}

\section{STATISTICS}

\author{
Dhimitraq Duni
}

\section{Pages}

In this study, I attempt to examine the nature of pedagogical content knowledge (Shulman, 1986) that teachers exhibit while observing computer-generated animations that bring up pedagogical issues in the classroom. In-service teachers were asked to view different animations and react to different prompts about the animations. Later, teachers were interviewed to prompt more discussion of pedagogical issues with the intention of clarifying their stance and their knowledge of pedagogy. The computer animations were utilized as a surrogate for classroom teaching, highlighting issues that could be otherwise overlooked during live teaching observation.

KEYWORDS: Statistics; Pedagogical Content Knowledge; In-service Teacher Knowledge; Computer Generated Animations 
THE LOOK OF PEDAGOGICAL CONTENT KNOWLEDGE IN MIDDLE SCHOOL

STATISTICS

DHIMITRAQ DUNI

\begin{abstract}
A Dissertation Submitted in Partial
Fulfillment of the Requirements

for the Degree of

DOCTOR OF PHILOSOPHY

Department of Mathematics

ILLINOIS STATE UNIVERSITY
\end{abstract}

2018 
(C) 2018 Dhimitraq Duni 
THE LOOK OF PEDAGOGICAL CONTENT KNOWLEDGE IN MIDDLE SCHOOL STATISTICS

DHIMITRAQ DUNI

COMMITTEE MEMBERS:

Edward S Mooney, Chair

David D Barker

Matthew S Winsor

Beth Hatt 


\section{ACKNOWLEDGMENTS}

As it is with most accomplishments in life, this dissertation has been supported and guided along by many people. This is a good place to try and give thanks and credit to some of these people.

I would first like to thank Dr. Edward Mooney, dissertation chair, for his patience in guiding me through this process. He has been remarkably understanding and insightful of my expectations while still parting knowledge through constructive criticism.

To my committee members, Dr. Barker, Dr. Winsor, I would like to thank for their insight in refining the prompts and the content used in the study. I also want to thank Dr. Hatt for her help in shaping my methodology and helping me become aware of my biases. I also wanted to thank Dr. Langrall, who while not on my committee, has been a source of inspiration through these years.

I dedicate this dissertation to my family, since none of this work could have been possible without their support and encouragement. My mother, Leonora has always been the one person to whom I could pour my heart out and who could support me without reservations. My father Perikli has been the rock that never wavered in his support of me and my work. My sister, Sandra, and brother in law, Burak, who have given me an example of excellence in academic scholarship. My nephews, Deniz, Erol and Eren, have been a welcome distraction and a source of energy and happiness.

D. D. 


\section{CONTENTS}

Page

ACKNOWLEDGMENTS

$\begin{array}{lll}\text { CONTENTS } & \text { ii }\end{array}$

TABLES - vi

FIGURES

CHAPTER I: BACKGROUND AND RATIONALE 1

$\begin{array}{ll}\text { Statistics } & 1\end{array}$

Recommendations for Statistics in K-12 Mathematics Curriculum 2

NCTM Standards $\quad 2$

GAISE Report $\quad 4$

$\operatorname{CCSSM}(2010)+5$

$\begin{array}{ll}\text { Statistical Education of Teachers } & 6\end{array}$

Teachers' Statistical Knowledge for Teaching 9

$\begin{array}{ll}\text { Problem Statement and Research Questions } & 15\end{array}$

CHAPTER II: REVIEW OF RELATED LITERATURE 18

$\begin{array}{ll}\text { Introduction } & 18\end{array}$

$\begin{array}{ll}\text { Pedagogical Content Knowledge } & 19\end{array}$

$\begin{array}{ll}\text { Statistical Knowledge for Teaching } & 22\end{array}$

$\begin{array}{ll}\text { Models and Frameworks } & 23\end{array}$

Research on Teacher's Statistical Knowledge for Teaching 30

$\begin{array}{ll}\text { Summary } & 39\end{array}$

Development of the Conceptual Framework 39 
Knowledge of Content and Curriculum $\quad 41$

Knowledge of Content and Students

Knowledge of Content and Teaching $\quad 63$

Expected Statistical Knowledge for Teaching Framework 76

$\begin{array}{ll}\text { Research on Animations } & 78\end{array}$

$\begin{array}{lr}\text { Chapter Summary } & 80\end{array}$

CHAPTER III: METHODOLOGY

$\begin{array}{ll}\text { Introduction } & 82\end{array}$

$\begin{array}{ll}\text { Research Paradigm } & 82\end{array}$

$\begin{array}{ll}\text { Participants } & 83\end{array}$

$\begin{array}{ll}\text { Procedure } & 84\end{array}$

$\begin{array}{ll}\text { Instruments } & 85\end{array}$

Development of Computer-Generated Animation Protocol 87

Creation of Computer Generated Animations (CGA) 92

$\begin{array}{ll}\text { Pilot Study } & 95\end{array}$

$\begin{array}{ll}\text { Data Analysis } & 96\end{array}$

Knowledge of Content and Curriculum $\quad 97$

Knowledge of Content and Students 99

Knowledge of Content and Teaching 101

$\begin{array}{ll}\text { Second Cycle of Coding } & 103\end{array}$

$\begin{array}{ll}\text { Ethical Issues } & 105\end{array}$

Validity, Reliability, and Credibility 106

$\begin{array}{ll}\text { Chapter Summary } & 107\end{array}$ 
$\begin{array}{ll}\text { Introduction } & 108\end{array}$

Pedagogical Content Knowledge Through the Computer-Generated Animations 108

$\begin{array}{ll}\text { Knowledge of Content and Curriculum } & 109\end{array}$

Knowledge of Content and Students 113

$\begin{array}{ll}\text { Knowledge of Content and Teaching } & 121\end{array}$

$\begin{array}{ll}\text { Summary } & 125\end{array}$

$\begin{array}{ll}\text { Three Teachers' Profiles } & 125\end{array}$

$\begin{array}{ll}\text { Jonathan's PCK } & 126\end{array}$

Kasy's Profile 135

$\begin{array}{ll}\text { Monika's Profile } & 143\end{array}$

CHAPTER V: CONCLUSIONS AND RECOMENDATIONS 152

$\begin{array}{lr}\text { Introduction } & 152\end{array}$

Summary of the Study 152

Discussion on Teacher's Pedagogical Content Knowledge 156

$\begin{array}{ll}\text { Knowledge of Content and Curriculum } & 157\end{array}$

Knowledge of Content and Students 159

$\begin{array}{ll}\text { Knowledge of Content and Teaching } & 161\end{array}$

$\begin{array}{ll}\text { Limitations } & 162\end{array}$

Discussion on Extending the Conceptual Framework 163

$\begin{array}{ll}\text { Recommendations } & 164\end{array}$

Thoughts on Professional Development 164

Recommendations for Research 166 
Significance and Contributions of the Study

Concluding Thought

168

REFERENCES

170

APPENDIX A: ANIMATION VIGNETTES

186

APPENDIX B: INITIAL SURVEY QUESTIONS

194 


\section{TABLES}

Table

Page

1. Expected Framework Components of Knowledge of Content and Curriculum

2. Expected Framework Components for Knowledge of Content and Students

3. Expected Framework Components of Knowledge of Content and Teaching

4. Expected Statistical Knowledge for Teaching Measures of Center

5. Responses to Initial Survey Questions

6. Vignettes to Framework Chart

7. Codes as Related to Framework

8. Expected Knowledge of Content and Curriculum Components

9. Components of Curriculum Other

112

10. Knowledge of Content and Students

11. Components of Student Other

12. Components of Knowledge of Content and Teaching

13. Components of Teaching Other

14. Jonathan's Profile Summary Chart

15. Kasy's Profile Summary Chart

16. Monika's Profile Summary Chart

17. Expected Statistical Knowledge for Teaching Measures of Center 2 


\section{FIGURES}

Figure Page

1. Framework for teacher knowledge in relation to statistical thinking $\begin{array}{ll}\text { and investigation. } & 11\end{array}$

2. Summary of John's teaching knowledge. 11

3. Summary profile sections and types of knowledge covered. 23

4. Hypothetical SKT elements and developmental structure. 26

5. Framework for teacher knowledge in relation to statistical thinking $\begin{array}{ll}\text { and investigation. } & 27\end{array}$

6. Facets and levels of teachers' knowledge. 28

7. Summary of Linda's reaching knowledge. 32

8. Levels of response to NAEP-based assessment task on mean and $\begin{array}{ll}\text { median. } & 36\end{array}$

9. Levels of knowledge of content and teaching apparent in individualized support suggested for student $1 . \quad 37$

10. Distribution graph for CGA 7. 90

11. Classroom used in the fourth CGA. 93

12. Classroom used in the first three CGAs. 93

13. Platform with which the teachers interacted. 94 


\section{CHAPTER I: BACKGROUND AND RATIONALE}

\section{Statistics}

Shaughnessy (1992) claimed that statistics is one of the most important subjects for college-bound or non-college-bound students. Statistics, a relatively new subject, has been gaining momentum within the last 30 years in the curriculum of school mathematics (Franklin et al., 2007; National Council of Teachers of Mathematics [NCTM], 1989, 2000, 2006; National Governors Association Center for Best Practices [NGA] \& Council of Chief State School Officers [CCSSO], 2010; Shaughnessy, 1992, 2007). This shift was first felt from the National Council of Teachers of Mathematics (NCTM) in 1989, when they first placed statistics in the national curriculum. Statistics and probability was one of the five major strands of study (Number \& Operations, Algebra, Geometry, Measurement, Data Analysis \& Probability) recommended for students as early as the elementary grades all the way to high school. The subsequent NCTM $(2000,2006)$ documents kept advocating for statistics by keeping the subject as a large part of the curriculum. Following those documents, the Guidelines for Assessment and Instruction in Statistics Education (GAISE) Report (Franklin et al., 2007) introduced a curriculum framework to further specify the level of understanding that students needed to have at different developmental milestones. Teacher preparation, on the other hand, has not been as quick in adapting to changes in curriculum, with Statistical Education of Teachers (Franklin et al., 2015) being the only document clarifying recommendations for teachers' statistics preparation. 


\section{Recommendations for Statistics in K-12 Mathematics Curriculum}

During the 1980s, after the publication of the report $A$ Nation at Risk (National

Commission on Excellence in Education, 1983), the U.S. Department of Education

recommended that schools and colleges set more rigorous standards for academic excellence.

Within mathematics, the National Council of Teachers of Mathematics (NCTM) was the first to set such rigorous standards, which were understood as statements of value. NCTM standards were followed by efforts in other school subjects such as science and reading. After the release of these standards both researchers and policy makers began to scrutinize and debate the standards. What followed were attempts at updating and enhancing the standards by acknowledging research and other scholarship in mathematics education.

\section{NCTM Standards}

The NCTM standards (1989) were the first curriculum document to include statistics in the content of teaching mathematics in elementary grades through high school. The standards encouraged teachers to include student experiences with data analysis and probability so that students can-

- collect, organize, and describe data;

- construct, read, and interpret displays of data;

- formulate and solve problems that involve collecting and analyzing data;

- explore concepts of chance. (NCTM, 1989, p. 54)

The authors of this curriculum document emphasized the idea that students should see statistics as a problem-solving tool and not just another computation algorithm. The emphasis was on students being able to make decisions and predictions based on the information gathered, and a 
spirit of investigation and exploration was associated with the learning of statistics. In the early grades, the authors concentrated on data displays and the types of questions the teachers could use to scaffold student learning.

In the standards for middle school (fifth through eighth grade), NCTM (1989) added to the elementary standard by requiring students to make inferences and arguments and to evaluate arguments based on data. These standards drew emphasis to the idea that students needed to learn to appreciate the process of statistical investigation. With respect to measures of central tendency, the authors concentrated on what the average student would be and how, for example, to find Mr. and Ms. Average, using random sampling while keeping in mind biases in data. At this grade level, the authors recommended that mode should be used to represent nonnumerical data.

A decade after their 1989 curriculum document, NCTM published a new document, the Principles and Standards for School Mathematics (NCTM, 2000). The authors envisioned students moving from formulating questions close to their experience, to formulating questions based on current issues and interests, and further to posing questions that require investigation and exploration of complex issues. Moving from simple data gathering plans (planning data collection and evaluating collection methods), to working with data gathered by others in the middle grades and further to understand the purpose of surveys, observational studies, and experiments. Developing from the early grades in which data can be organized or ordered in pictures to middle school in which data are displayed in bar graphs, tables, and line plots.

With respect to measures of center, NCTM (2000) made some simple recommendations about what knowledge students should exhibit. NCTM recommended that children as early as the third grade could start learning about concepts of statistics, specifically measures of center. In the 
recommendations for the third to fifth grade, the authors emphasized the need for students to see the measures of center in different context and that students needed to build on "their ideas of what is 'typical"'? The authors recommended that students needed to understand what the median told them about the data and that, in Grade 5, the best representation of the mean was the balance point.

In Grades 6-8, NCTM (2000) acknowledged that students did not understand the mean well, and they reiterated the fact that using balance point, the mean evens out or balances a set of data because the representation of the mean was the best practice. Students needed to see the median as the middle of the data. Also, when choosing the best average to represent the data, students needed to understand (through modeling) that the mean could be influenced by extreme values. In high school, the recommendations became more geared toward procedural understanding of the mean, adding the same constant to all observations would change the measure of center by the same constant but not the measure of spread, and claiming that "the mean score of a test was 50 percent" (p. 327) could cover several distributions of data. Keeping to the theme of choosing measures of center, they recommended that students should recognize that the sample mean and median could be greatly influenced by the skewness of the distribution.

\section{GAISE Report}

Within the NCTM $(1989,2000,2006)$ curriculum documents, there are recommendations on what students should know, and there are some recommendations about how mathematics should be taught (National Council of Teachers of Mathematics, Commission on Teaching Standards for School Mathematics, 1991). However, there initially were no documents that specifically discuss the way that statistics should be taught. With that in mind, Franklin et al. 
(2007) published the Guidelines for Assessment and Instruction in Statistics Education (GAISE)

Report. The guidelines were designed as a curriculum framework for all grades, preK-12, with the goal of statistical literacy for citizenship. The authors envisioned all high school students making sound decisions using statistics in order to cope with the daily challenges of life. Hence, the framework was designed to provide a conceptual structure for the teaching of statistics that gave a coherent picture of the curriculum during three different levels of development. The main methodology for teaching the concepts of statistics was through the investigative cycle combined with an emphasis on variability, progressing in sophistication through the three levels of development. This framework includes the following: formulate questions, collect data, analyze data, interpret results, and the nature of and focus on variability.

The progression of ownership of the investigative cycle was spelled out in the report (Franklin et al., 2007), with teachers having a more direct role at Level A and progressing toward a more passive role in Levels B and C. The report suggested that students act as the collectors of data in Level A, but teachers can help students take advantage of their innate curiosity and help them formulate statistical questions for investigation. At the early stages, another recommendation was for teachers to capitalize on natural occurring errors when collecting data to help students speculate about the impact on the final results. Because the authors suspected that teachers might not be prepared for some statistical procedures, they offered examples on simulations and other difficult concepts.

\section{$\operatorname{CCSSM~(2010)~}$}

From the recommendations of Foundations for Success: The Final Report of the National Mathematics Advisory Panel (National Mathematics Advisory Panel, 2008), the Common Core 
State Standards for Mathematics (CCSSM; NGA \& CCSSO, 2010) were born. The content of the CCSSM is important because even though it is designed as standards to be strived towards, most states have adopted it as the intended national curriculum document by which they base the choice of content being taught in the classroom (Porter, McMaken, Hwang, \& Yang, 2011). Until this point, previous NCTM documents had advocated for statistics to be a presence in the curriculum as early as first grade; however, the CCSSM pushed all that to sixth grade. Even though there are mentions of Measurement and Data in Grades 1-5, these standards have nothing to do with statistics or data analysis. At Grade 6 , students were encouraged to think of the median as the center of data and how it could be used to create a box and whiskers plot and consequently the interquartile range (IQR), explained as a measure of variability. Connecting statistics to mathematics, the authors expected students to use knowledge of fractions to calculate the arithmetic mean, recommending that students think of mean as leveling out or fair share. When comparing mean with median the authors recommended that the mean can be pulled by extreme values, and that context should be used in making these comparisons. For instances in which the mean is understood as the measure of center, the authors recommend using the mean absolute deviation (MAD) as the measure of variability; however, when the median was used and the data displays long tails, the IQR should be used as the measure of variability.

\section{Statistical Education of Teachers}

With direct implication for teachers, the American Statistics Association (Franklin et al., 2015) released the Statistical Education of Teachers (SET) report, which was designed as a companion to the Conference Board of the Mathematical Sciences' (2012) document, The Mathematical Education of Teachers II (MET II). Franklin (2014) commented that the American 
Statistical Association (ASA) and NCTM felt that the MET II had not gone deep enough on their recommendations for teaching of statistics. Even though there were some recommendations, they were concentrated on the teaching of mathematics, so the SET report was conceptualized as a detailed source for statistical pedagogy with a better map toward the understanding of the evolution of statistical topics and concepts from $\mathrm{K}-12$. Because the writing team for SET was headed by the same researchers as the GAISE report, SET was designed to build on existing K12 standards as recommended by the GAISE report, the NCTM standards, and the CCSSM. The authors of the SET report suggested that there were three different goals when designing the document: to reach the appropriate audience for teacher preparation, to make recommendations and provide details for content and pedagogy, and to make recommendations for improving the training of teachers. The intended audience for the document were mathematicians and statisticians, mathematics educators, and policy makers.

As with the GAISE report, the SET report (Franklin et al., 2015) recommended that the teaching of statistics should be done thorough the statistical problem-solving process so that statistics topics could be developed through meaningful experiences. Staying with meaningful experiences, it recommends that teachers preparation courses should be taught with an emphasis on active engagement and that lecture, direct/individual instruction, is not appropriate as a primary mode of teaching. With respect to pedagogy, the report emphasized the importance of connecting concepts in statistics with other areas in mathematics and how concepts in middle school built on elementary understanding.

The SET report also made more direct recommendations for the teaching of statistics. One of the primary goals of teacher preparation in elementary school statistics is to "develop pedagogical content knowledge necessary for effective teaching of statistics. Pre-service and 
practicing teachers should be familiar with common student conceptions, content-specific teaching strategies, strategies for assessing statistical knowledge, and appropriate integration of technology for developing statistical concepts" (Franklin et al., 2015, p. 14). Following that, the authors recommended that teachers should attend to common misunderstandings that students have with regards to statistics and develop strategies to address students' conceptions. Further, it was recommended that teachers have pedagogical knowledge to assess students' levels of understanding and plan for the steps needed to advance and develop students' statistical thinking.

More precisely, and more pertinent to the teaching of statistics in middle school, the SET report (Franklin et al., 2015) gave some specific recommendations on the teaching of measures of center. Regarding the problem-solving cycle's analyze data component, the teachers were encouraged to recognize and use appropriate numerical summaries to describe characteristics of the distribution for quantitative data, such as mean or median for describing center, and range IQR or MAD to describe variability. Also, teachers should recognize that the shape of the distribution, for quantitative data, influences the numerical summary for center and that the median is resistant to outliers. Keeping to the theme of comparison, teachers should realize that distributions are compared with respect to similarities or differences in center, shape, and variability and that the context of the original question is paramount in the comparison.

In the elementary grades, it was expected that the teacher would help the students in writing a specific statistical question to investigate (Franklin et al., 2015). The teacher was then expected to facilitate the data collection process by helping students determine how data would be collected and design an appropriate and feasible experiment. In analyzing data, the teacher was expected to use graphical displays and numerical summaries to help students identify patterns present in the variability pertinent to the question at hand. In the last step of interpreting 
results, teachers were expected to help students use the results to answer the question investigated.

Recommendations for the education of prospective and in-service teachers also came from a joint policy paper published by ASA and NCTM (2013). The recommendations of this paper were not as detailed as the SET or GAISE reports; however, they encompassed every stakeholder in the education process. The paper emphasized the growing importance of statistics as a scientific field of study and that teachers must have deep knowledge and understanding of both content and pedagogy. The paper recommended that administrators support in-service teachers through opportunities for professional development (PD), and that educators create PD to model effective teaching pedagogies and deeper understanding of statistical concepts, boosting their knowledge of content, statistical thinking, and problem solving. For preservice-teacher educators, recommendations revolved around creating courses that familiarize future teachers with pedagogies appropriate for the classroom, as outlined by policy documents. Similar recommendations were given for faculty members who teach statistics and for state departments of education.

\section{Teachers' Statistical Knowledge for Teaching}

Cobb and Moore (1997), and later Groth (2007), argued that the knowledge that is needed to teach statistics is different from the knowledge that it takes to teach mathematics. In an attempt to differentiate between mathematics and statistics, Groth (2007) used statistical knowledge for teaching (SKT) instead of mathematical knowledge for teaching (MKT; Hill, Schilling, \& Ball, 2004) to talk about the knowledge needed to teach statistics. Groth (2007) following Cobb and Moore (1997) advocated for the need of mathematics to take context away 
from doing mathematics and the standardization of mathematical thinking and computation free from context. Mathematics is more interested in finding the correct answer to a question, no matter if that question has real-life applications or not. On the other hand, statistics thrives in, and requires, context from real-life situations because context decides what questions to ask, how to collect data, and more importantly how to analyze and interpret the data. Another difference is exemplified in question posing: Although mathematics poses questions with deterministic answers, statistics often poses questions to form conditional conclusions (Groth, 2007).

Although scholarship on different embodiments of MKT is vast, there also exists research on the understanding of SKT. SKT became a subject of research projects with in-service teachers outside of the United States (Burgess 2007, 2009a; Estrella, Olfos, \& Mena-Lorca, 2015; Watson, 2001; Watson, Callingham, \& Donne, 2008; Watson \& Nathan, 2010) as well as research done with preservice teachers (PSTs) in the United States (Groth, 2014). Much of the research on SKT with in-service teachers outside of the United States is concentrated around Australia with Watson and colleagues (Watson, 2001; Watson et al., 2008; Watson \& Nathan, 2010), who have developed, and validated, different assessments in understanding teacher knowledge including pedagogical content knowledge (PCK) (Hill, Ball, and Schilling, 2008) within statistics. Another contribution to the research with in-service teachers has come from Estrella, Olfos, and Mena-Lorca (2015) in Chile, who also created an instrument to measure PCK that focuses on teachers' awareness of student statistical knowledge.

From New Zealand, Burgess $(2007,2009 a)$ gave a hybrid conceptualization of teacher knowledge by observing teachers while they taught. His framework (see Figure 1) was an amalgam of the four major components of MKT introduced by Hill, Schilling, and Ball (2004), and eight components of statistical thinking model by Wild and Pfannkuch (1999). With this 
model, Burgess (2007, 2009a) gave a more structured view of in-service teachers' knowledge through the investigative cycle. Burgess concluded his research by giving examples of what each box in the matrix looked like for his four participating teachers. In further publications, Burgess (2009b) introduced profiles of each teacher's knowledge (see Figure 2) by highlighting examples in which the teachers showed direct evidence (solid grey cells) or indirect evidence (checkered cells) of the hypothesized component of the framework, examples in which the teachers missed opportunities to show their knowledge (grey cells with an $M$ ), and examples in which the knowledge was not evident at all (white cells).

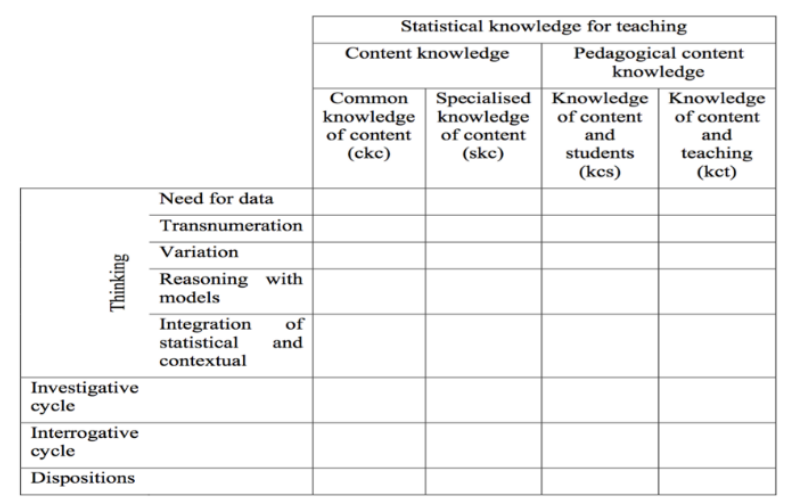

Figure 1. Framework for teacher knowledge in relation to statistical thinking and investigation. This figure shows the components of knowledge hypothesized by Burgess (2009a) with the intersections being the components.

\begin{tabular}{|c|c|c|c|c|c|}
\hline \multirow{3}{*}{\multicolumn{2}{|c|}{$\begin{array}{l}\text { Summary of John's } \\
\text { teaching knowledge }\end{array}$}} & \multicolumn{4}{|c|}{ Statistical knowledge for teaching } \\
\hline & & \multicolumn{2}{|c|}{ Content knowledge } & \multicolumn{2}{|c|}{$\begin{array}{c}\text { Pedagogical content } \\
\text { knowledge }\end{array}$} \\
\hline & & $\begin{array}{l}\text { Common } \\
\text { knowledge } \\
\text { of content } \\
\text { (CKC) }\end{array}$ & $\begin{array}{c}\text { Specialised } \\
\text { knowledge } \\
\text { of content } \\
\text { (SKC) }\end{array}$ & $\begin{array}{l}\text { Knowledge } \\
\text { of content \& } \\
\text { students } \\
\text { (KCS) }\end{array}$ & $\begin{array}{c}\text { Knowledge } \\
\text { of content \& } \\
\text { teaching } \\
\text { (KCT) }\end{array}$ \\
\hline \multirow{5}{*}{ 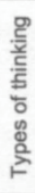 } & Need for data & & & & \\
\hline & Transnumeration & M & $\mathrm{M}$ & M & M \\
\hline & Variation & & & & \\
\hline & Reasoning with models & M & M & M & M \\
\hline & $\begin{array}{l}\text { Integration of statistical } \\
\text { and contextual }\end{array}$ & & & & \\
\hline \multicolumn{2}{|c|}{ Investigative cycle } & & M & & M \\
\hline \multicolumn{2}{|c|}{ Interrogative cycle } & & M & & M \\
\hline \multicolumn{2}{|c|}{ Dispositions } & & & & \\
\hline
\end{tabular}

Figure 2. Summary of John's teaching knowledge. This figure shows the knowledge that John displays in Burgess' (2009b) study. The solid grey indicates direct evidence of that knowledge component, shaded $\mathrm{M}$ indicates missed opportunities to show evidence, checkered indicates indirect knowledge, and unshaded indicates that no evidence of that component was given. 
So, if we look at Figure 2, we can see that John showed direct evidence of "Common content knowledge: integration of statistical and contextual" (Burgess, 2009b). This category was characterized by the ability to make sense of statistical measures and by understanding the relevance of statistical tools in real-life data. According to Burgess (2009b), John showed direct evidence of this knowledge by acknowledging that the reason all younger students could whistle (a finding in the experiment) was because they were taught by their older siblings. This displayed John's knowledge by relating statistical findings to real-life context. In another instance, John had the knowledge, but he missed the opportunity to show it in class, "knowledge of content and teaching: reasoning with models" (how a teacher structures teaching to encourage reasoning with models). The teacher commented that because the students had concentrated on one variable at a time during instruction, he intended to structure the next lesson to encourage students to consider two variable simulations.

Groth (2007) hypothesized about what SKT would look like, acknowledging that statistics is a different discipline from mathematics while still using some mathematical ideas. Groth introduced only two categories, common knowledge and specialized content knowledge, both of which had aspects of mathematical and nonmathematical concepts. He also made the point that when a teacher made a decision in the classroom, she or he could not divorce the mathematical and statistical thinking and that every decision made in the classroom had a component of both disciplines in it.

Later, Groth (2013) incorporated the ideas of Hill, Ball, and Schilling (2008) and their concepts of PCK for MKT into his construct of what SKT would look like. Groth (2013) reconciled that PCK for statistics would have similar aspects to PCK for mathematics and that knowledge of students and teaching still constituted the main concepts. Groth arrived at this 
conclusion by incorporating two concepts: key developmental understandings (KDUs; Simon, 2006) and pedagogically powerful ideas (PPIs; Silverman \& Thompson, 2008). At the base of his theoretical framework, Groth places KDUs, cognitive landmarks used in the learning of contextual concepts, and the need for decentering to transform these KDUs into PPIs. KDUs, as conceptualized by Simon (2006), are landmarks that a student reaches only after an extensive immersion in the major concept being taught. These KDUs cannot be reached by direct instruction alone; they have to be reinforced through different experiences in the classroom from the teacher and through peers. Pedagogically powerful ideas, as conceptualized by Silverman \& Thompson, were KDU's that the teachers would have, and the teachers would need to somehow become aware of these KDU's and use them in their teaching. So, after a teacher would become aware of her/his possession of particular KDU's for a subject, through decentering she/he would start to create these pedagogically powerful ideas about teaching.

After having laid out his theoretical perspective, Groth (2013) goes on to introduce a couple of KDUs as they relate to statistics and, more specifically, to the work he was doing with his PSTs in a statistics content course. Under "common content knowledge: experimental and theoretical probabilities," Groth theorized that "conceiving of theoretical probability as an anchor for predicting long-term behavior is a statistical KDU" (p. 169). This came from the responses his students gave when explaining differences between experimental and theoretical probability. His students kept concentrating on predicting individual outcomes rather that the long-term trends and kept thinking of theoretical probability as just a guess. Another KDU was presented in the context of MAD in which responses were solicited about differences of MAD to standard deviation. "Conceiving of the 'typical' deviation as a measure of spread can be considered a KDU” (p. 131). 
Existing research on PCK has shown that teachers, within statistics, are not adapt at responding well to student questions about proportional reasoning (Watson et al., 2008). Watson, Callingham, and Donne (2008) interviewed 42 teachers and asked them to solve a probability question. The authors then asked the teachers to think of the responses that their students would give and how they would use the item in their classroom. The authors found that most teachers gave only generic responses to developing instructional strategies, dependent on student knowledge. Using a similar instrument, Watson, Callingham, and Nathan (2009) found that more than a third of their teachers were quick at judging student responses about data analysis but were not able to use those responses to suggest activities to further student knowledge. Another third of their teachers only used a handful of specific questions about the task at hand without being able to make connections to previous knowledge. In the same group, some participants mentioned that the students needed experience with data collection.

In helping students improve their conceptions of statistics, Godino, Batanero, Roa, and Wilhelmi (2008) found that almost half of their participants made vague suggestions about improvements to a statistical question and were only sometimes able to use those suggestions in the classroom. Only $26 \%$ of their participants were able to make general statements and suggest improvements. Groth (2014) found that $85 \%$ of his participants were able to identify a student with a more sophisticated response about which measure of center to use; however, the majority of his participants were not able to give specific suggestions to the less sophisticated students on improving his understanding. Ijeh (2013) found that most of his participants taught the subject of statistics, particularly graphical representations of data, in a step-wise procedural fashion and linked that teaching to student misconceptions about graphical displays, analysis, and interpreting of scatter plots. 
As previously mentioned, research in SKT has been lacking, with most of the work done with PSTs and little work done with in-service teachers especially in the United States. The work done in the United States has concentrated mostly on PSTs (Groth, 2014). Because the CCSSM (NGA \& CCSSO, 2010) has been adopted as the new implemented curriculum in most states, there is a need for research to be done with in-service teachers to understand their knowledge of pedagogy. There is also a need for research to understand what component of PCK: teachers understanding of their students' knowledge of statistical concepts, and teachers' knowledge of the best representations to use in teaching statistical concepts, do teachers possess in statistics at the middle school and what does that knowledge look like.

\section{Problem Statement and Research Questions}

In the early stages of understanding teachers' knowledge researches started with observations of classroom teaching (Even, 1993; Even \& Tirosh, 1995; Wilson, 1994). Later, in lieu of observations researchers stated to introduce instruments for measuring teachers' knowledge of mathematics as well as statistics (Ball et al., 2008; Hill et al., 2008; Hill \& Lubienski, 2007; Watson, 2001). However, as argued in the same publications, these methods have had some shortcomings, hence as a field mathematics education has started to use different methods in understanding teacher knowledge. One of these methods is animations (comics) (Chazan \& Herbst, 2012; Herbst \& Chazan, 2015; Herbst, Chazan, Chen, Chieu, \& Weiss, 2011; Herbst \& Kosko, 2014). Herbst, Chazan, Chen, Chieu, and Weiss (2011) have argued that animations present a unique opportunity in understanding teacher's knowledge. Following Herbst and his colleagues' recommendations, I will be using Computer-Generated Animations as the main 
instrument to analyze the characteristics of participating teachers' knowledge when teaching measures of center in middle school.

The importance and use of statistics has gained momentum in the last 30 years with its inclusion in the curriculum (Franklin et al., 2007; NCTM, 1989, 2000, 2006; NGA \& CCSSO, 2010). Hence, it is important for teachers to know how to teach statistics in meaningful ways (Batanero, Godino, Vallecillos, Green, \& Holmes, 1994; Franklin et al., 2007; Shaughnessy, 1992, 2007). This means that teachers need to know what conceptions and misconceptions their students bring to the classroom environment so that they can correct the misconceptions and foster the correct conceptions. Teachers also need to have multiple representations of the concepts that they are going to teach so that students will be afforded different examples to relate the new concepts to. Also, teachers need to relate statistics to other concepts in mathematics so that the transition between the two disciplines can be integrated and seamless. All the concepts and knowledge that teachers need to have are part of what Ball and Bass (2003) conceptualized as components of PCK.

There is research that has been put forth regarding what PCK should look like in mathematics (Ball \& Bass, 2003; Ball \& Hill, 2005; Ball, Thames, \& Phelps, 2008; Even, 1993; Even \& Tirosh, 1995; Hill \& Lubienski, 2007; Hill, Ball, \& Schilling, 2008; Shulman, 1986, 1987; Wilson, 1994); however, research on what PCK looks like for teaching statistics, other than the research previously mentioned (Burgess, 2007; Groth, 2007, 2013; Watson et al., 2008; Watson \& Nathan, 2010), has been lacking and constricted. Other than Burgess, there is a chunk of research missing to tell us what PCK looks like in the environment in which it is being taught. In order for PD courses to be designed for in-service teachers, we need to understand the knowledge that they bring into instruction. 
The purpose of this study is to examine a small part of teachers' knowledge by examining their pedagogical content knowledge when teaching measures of center. The reason for the concentration in middle school is that it is the first time that teachers, according to the curriculum (NGA \& CCSSO, 2010), introduce students to the concepts of measures of center and statistics itself. The measures of center are important because, as mentioned by Batanero, Godino, Vallecillos, Green, and Holmes (1994), the mean is an important subject that is as simple as it is difficult for students. As Cai (1998) and Zawojewski and Shaughnessy $(1999,2000)$ reported, students in all grades were able to find the measures of center; however, they were not able to discern which measure is better to use for which situation. This shows that students can use the algorithm to find these measures, but they do not have the knowledge to relate their choice of measure to the shape or context of the data, a major recommendation in the CCSSM (NGA \& CCSSO, 2010). Therefore, it is important to understand the knowledge that teachers have when introducing the measures of center so that we, as educators, can have a baseline when helping teachers with future PD. For these reasons, I used the following questions to guide my research.

1. What characteristics of knowledge of content ad curriculum do middle school mathematics teachers exhibit when reflecting on teaching measures of center?

2. What characteristics of knowledge of content and students do middle school mathematics teachers exhibit when reflecting on teaching measures of center?

3. What characteristics of knowledge of content and teaching do middle school mathematics teachers exhibit when reflecting on teaching measures of center? 


\section{CHAPTER II: REVIEW OF RELATED LITERATURE}

\section{Introduction}

With the changes introduced in the curriculum, it is not clear if teachers are prepared to teach statistics meaningfully (Batanero, Godino, Vallecillos, Green \& Holmes, 1994;

Shaughnessy, 1992). Batanero et al. (1994) stated that many teachers needed to improve their knowledge of the subject matter, ways in which to teach statistics, and improve their knowledge of difficulties and errors that students experience. However, as noticed by Hashweh (1987) and by Carlsen (1993), in the teaching of biology and physics, teachers with low knowledge of content tend to not deviate or change the activities that are presented in books. The same teachers also tended to ask mostly recall questions, and tended to reinforce preconceptions and incorrectly criticized correct student answers. These shortcomings, point at the teachers' characteristics of knowledge of content and curriculum, knowledge of content and teaching as well as knowledge of content and students. Hence, it is important to place teachers in a position to where they can show us what characteristics their knowledge has, so that we can better inform their education through professional development and experiences in college classrooms.

In this chapter, I attempt to give some background information and situate my research in relation to work already assimilated by the field. I start this chapter by introducing the term PCK from its conception with Shulman (1986) to its later refinement and definition by Deborah Ball and her colleagues (Ball \& Bass, 2003; Ball \& Hill, 2005; Ball et al., 2008; Hill et al., 2008). I also include discussions of similarities and differences between the way PCK is theorized in mathematics to the way it is theorized in statistics. I share work done by both mathematics educators and statistics educators as it relates to the study at hand. Later, I lay out my 
development of a conceptual framework that I use in this study and recommendations for teacher knowledge from curriculum documents and research.

\section{Pedagogical Content Knowledge}

PCK, as identified by Shulman (1986), has been gaining momentum as a legitimate field of study for mathematics educators and researchers (Ball \& Bass, 2003; Ball \& Hill, 2005; Ball et al., 2008; Bergess, 2007, 2010; Ebert \& Risacher, 1996; Even, 1993, Even \& Tirosh, 1995;

Foss \& Kleinsasser, 1996; Groth, 2007, 2013; Hill et al., 2008; Lehrer \& Franke, 1992; Shulman, 1986, 1987; Watson, 2001; Watson et al., 2008; Watson \& Nathan, 2010; Wilson, 1994). Because of Begle's (1979) research report that questioned the merits of judging teacher performance solely on their content knowledge and content courses taken in college, Shulman (1986) introduced the idea that teachers' knowledge was not just content related but had a pedagogical component as well. In his article, Shulman advocated for the existence of a different type of knowledge, which he called PCK, on which teacher educators should concentrate their efforts.

For Shulman (1986), subject matter content knowledge not only had to do with the facts of the subject but also required the understanding of the structure of said subject. The structure was thought of as the different ways that the concepts of the subject were organized and the way that truth or falsehood is identified. PCK was thought of as the knowledge that went further into the subject matter pertaining to aspects of teaching. PCK consisted of the most useful forms or representations of that subject; the most powerful analogies, examples, formulations; and the ways of representing the subject to make it comprehensible to others. In Shulman's opinion, there was no single most powerful representation for a subject; hence, the teacher needed to have 
a plethora of alternative ways of representation derived from experience, research, and practice. Another important idea incorporated into PCK was the knowledge of conceptions and preconceptions that students brought into the classroom and how the teacher needed to be aware when these preconceptions were misconceptions. Knowledge of curriculum was especially a sore point with Shulman because he thought that teacher educators failed to prepare their students for the coming curriculum. In the following sections of this review, I first introduce the most dominant models conceptualizing what knowledge is needed to teach mathematics and statistics as well as research on the findings from these models.

Further elaborating on Shulman's (1986) original framework, Ball, Thames, and Phelps (2008) introduced their "egg" model of mathematical knowledge for teaching (MKT). This model was comprised of two equally important areas, subject matter knowledge (SMK) on the left and PCK on the right. SMK was comprised of three parts: common content knowledge (CCK), specialized content knowledge (SCK), and horizon knowledge. On the PCK side we find knowledge of content and students (KCS), knowledge of content and teaching (KCT), and knowledge of content and curriculum (KCC). Ball et al. (2008) conceptualized PCK as knowledge of students, the knowledge of teaching, and knowledge of curriculum, even though more attention was dedicated to the first two concepts. KCS was identified as the knowledge that combined knowledge about students and knowledge about mathematics. The authors were very careful in not confusing KCS with SCK, so they conceptualized KCS as the knowledge that allows teachers to recognize student thought processes and student misconceptions and to anticipate what students find confusing and are likely to think about a problem. So, in the subtraction problem, the teacher not only recognizes that the answer is correct but is also able to 
interpret the students' thinking and find obstacles that impede the student in generalizing the method for larger or more complex numbers (Hill et al., 2008).

The other important part of PCK, KCT, can also be identified in the process of analyzing student work (Ball et al., 2008; Hill et al., 2008; Hill \& Lubienski, 2007). After the teacher has understood the students' thinking and methodology, he needs to be able to capitalize in this teaching moment. KCT allows the teacher to identify the next step in instruction to take the student deeper into the content; hence, $\mathrm{KCT}$ connects knowledge about teaching with knowledge of mathematics. Teachers evaluate the instructional advantages of representations exhibited by individual students and then identify the best representations and methodology to model in the classroom for maximum results. The last component of PCK, the knowledge of content and curriculum, is not as well defined and developed as the other components of PCK. The only definition comes from Shulman (1987), who conceptualized KCC as "the grasp of the materials and programs that serve as 'tools of the trade' for teachers"' (Shulman, 1987, p. 8).

Within mathematics, the research has been abundant in the knowledge that teachers need to teach mathematics (MKT; Ball \& Bass, 2003; Ball \& Hill, 2005; Ball et al., 2008; Hill et al., 2008; Shulman, 1986, 1987). There has been research on what components of content knowledge and what components of pedagogical knowledge teachers need to teach mathematics at the elementary level and research on instruments for measuring MKT (Hill et al., 2008). It is easy to see, from the abundant scholarship undertaken, why the "egg" model is one of the most dominant model in mathematics and why it is still being researched today. However, in statistics, it is not easy to pinpoint to a singular model that is widely used to understand SKT; hence, what follows is a synthesis of what models exist in understanding SKT. 


\section{Statistical Knowledge for Teaching}

Although PCK is not the only component of SKT that has been researched (Casey, 2008), it is one of the more interesting areas in the education of new teachers. Within this dissertation, SKT is defined as the knowledge that teachers need to teach statistics, knowledge that might be different from the MKT. "Many teachers need to increase their knowledge of both the subject matter of statistics and appropriate ways to teach the subject" (Batanero et al., 1994, p. 528). Batanero et al. (1994) made the point that with the rise of interest in the teaching of statistics, educators should not lose the focus on helping teachers better themselves by increasing their knowledge of both subject matter and pedagogy. As the importance of PCK was gaining momentum in mathematics with proponents like Deborah Ball, statistics educators started showing interest in mapping out the components of PCK for the teaching of statistics (Burgess, 2007; Groth, 2007, 2013; Watson, 2001).

There have been several research agendas introducing frameworks with the intent of explaining and describing what PCK for teachers teaching statistics effectively should look like (Batanero \& Diaz, 2010; Burgess, 2007, 2009a, 2009b; Godino, Ortiz, Roa, \& Wilhelmi, 2011; González, 2016; Groth 2007, 2013; Watson, 2001; Watson, Callingham, \& Nathan 2009). However, when it comes to presenting evidence of what teacher knowledge looks like the research is fragmented at best (pre- and in-service teachers; Estrella et al., 2015; Groth, 2014; Ijeh, 2013; Mercimek \& Erbas 2017; Sorto \& White, 2004; Wessels, 2014). In this section, I introduce some of the most prevalent frameworks hypothesized and used in understanding and explaining PCK within statistics, and then I discuss some of the research that shows what teachers' PCK looks like within SKT. 


\section{Models and Frameworks}

One of the earliest conceptualizations of knowledge for teaching statistics came from Watson (2001). Watson created an assessment that would analyze teacher's knowledge through a survey-style questionnaire and a follow-up interview in which the answers were evaluated through a hierarchical rubric. This assessment was not specifically designed to measure teacher's PCK, but it was designed with Shulman's (1987) conceptualization of teacher knowledge as the overarching framework and with statistics as its main content (as seen in Figure 3).

\begin{tabular}{|c|c|c|c|c|c|c|c|c|c|}
\hline Profile section & $\begin{array}{l}\text { Contents } \\
\text { (S1) }\end{array}$ & $\begin{array}{l}\text { General } \\
\text { Pedagogical } \\
\text { (S2) }\end{array}$ & $\begin{array}{l}\text { Curriculum } \\
\text { (S3) }\end{array}$ & $\begin{array}{l}\text { Pedagogical } \\
\text { Content (S4) }\end{array}$ & $\begin{array}{l}\text { Learners' } \\
\text { Chartacter- } \\
\text { istics (S5) }\end{array}$ & $\begin{array}{l}\text { Contexts } \\
\text { (S6) }\end{array}$ & $\begin{array}{l}\text { Ends / } \\
\text { Values } \\
\text { (S7) }\end{array}$ & $\begin{array}{l}\text { Background / } \\
\text { Prof. Dev. } \\
\text { (P) }\end{array}$ & Reflection \\
\hline Significant Factors & $\sqrt{ }$ & $\sqrt{ }$ & $\sqrt{ }$ & $\sqrt{ }$ & $\sqrt{ }$ & $\sqrt{ }$ & $\sqrt{ }$ & $\sqrt{ }$ & $\sqrt{ }$ \\
\hline 2. Unit Planning & $\sqrt{ }$ & $\sqrt{ }$ & $\sqrt{ }$ & $\sqrt{ }$ & & $\sqrt{ }$ & & & $\sqrt{ }$ \\
\hline Lesson Planning & $\sqrt{ }$ & $\sqrt{ }$ & $\sqrt{ }$ & $\sqrt{ }$ & $\sqrt{ }$ & & & & $\sqrt{ }$ \\
\hline 4. Teaching Practices & $\sqrt{ }$ & & $\sqrt{ }$ & $\sqrt{ }$ & $\sqrt{ }$ & & & & $\sqrt{ }$ \\
\hline Average and Sample & $\sqrt{ }$ & & $\sqrt{ }$ & $\sqrt{ }$ & $\sqrt{ }$ & & & & $\sqrt{ }$ \\
\hline 6. Confidence & $\sqrt{ }$ & & & $\sqrt{ }$ & & & & & \\
\hline Beliefs in Everyday Life & $\sqrt{ }$ & & & & & $\sqrt{ }$ & $\sqrt{ }$ & & \\
\hline $\begin{array}{ll}\text { 8. } & \text { Student Survey Items } \\
\text { 9. } & \text { Background }\end{array}$ & $\sqrt{ }$ & & $\sqrt{ }$ & $\sqrt{ }$ & $\sqrt{ }$ & $\sqrt{ }$ & $\sqrt{ }$ & $\sqrt{ }$ & $\sqrt{ }$ \\
\hline 10. Professional Development & $\sqrt{ }$ & & $\sqrt{ }$ & $\sqrt{ }$ & & $\sqrt{ }$ & & $\sqrt{ }$ & $\sqrt{ }$ \\
\hline
\end{tabular}

Figure 3. Summary profile sections and types of knowledge covered. On top, there are the types of knowledge that the instrument was assessing, and on the side, there are the 10 sections of profiling for the teachers (Watson, 2001). The tick marks are the evidence shown by the teachers about their knowledge as it pertains to each section.

As seen in Figure 3, the profile selection is adhering to the major categories that Shulman (1987) hypothesized should be included in teacher knowledge. Watson et al. (2008) and Watson and Nathan (2010) continued the work started with Watson (2001) in the use of the assessment for profiling teachers. Watson and colleagues (Watson et al., 2008; Watson \& Nathan, 2010) expanded on the protocols used in order to understand teacher's knowledge of pedagogy when teaching statistics. Both articles were tailored toward the understanding of PCK with in-service 
teachers. Watson and colleagues found that PCK could be conceptualized into four categories: recognizes big ideas, anticipates student answers, employs content-specific strategies, and constructs shift to general, which they used as their framework for teacher knowledge of statistics.

For Watson, Callingham \& Nathan (2009), recognizing big ideas meant the teacher would have a clear idea for a sequence of related concepts, showing her/his knowledge of content. Anticipating student answers meant that the teacher would recognize appropriate and inappropriate student answers, as well as show an understanding of the way students reason about statistical concepts. Employs content-specific strategies, entailed the teacher directing questions towards clarification and explanations of students' answers, as well as promptly introducing alternative data to bring up similar previous issues. Construct shift to general, meant that the teacher exposes differences between similar topics in statistics, makes connections to statistical ideas, as well as exposing limitations and misuses of data.

Groth (2007) used the term SKT in contrast to MKT (Ball \& Bass, 2003). In his article, Groth explained how statistics was not a branch of mathematics and pointed out the differences between the two disciplines. The most poignant difference was about context and how, in mathematics, context is just background noise that you must filter through to get the pertinent information. However, in statistics context makes all the difference in terms of interpreting results and making decisions. Groth also hypothesized about what SKT would look like; the main components were common knowledge and specialized knowledge:

Common knowledge relates to competencies developed in conventional mathematics courses, such as computing accurately, making correct mathematical statements, and solving problems. Specialized knowledge is developed by carefully attending to 
mathematical issues and dilemmas that arise in teaching contexts. It relates to such tasks as providing understandable explanations, appraising students' unconventional methods for solving problems, and constructing and evaluating multiple representations for concepts. (Groth, 2007, p. 428)

Both categories could have mathematical and nonmathematical components to them. The difference was that Groth hypothesized that both mathematical and nonmathematical aspects of knowledge had to be activated for many statistical activities.

Later, Groth (2013) was able to see the benefits of having a more unified theoretical perspective with Ball and colleagues (Hill, Ball, \& Schilling, 2008) and with the pedagogically powerful ideas conceived by Silverman and Thompson (2008). Simon (2006) introduced KDUs as a conceptual advance that is needed in order for the student to develop a new concept. He thought of KDUs as abilities, not as missing any knowledge that inhibited the students' achievement, and that KDUs may be related to the learning trajectories of the student. Simon conceptualized KDUs closer to Piaget's (1952) levels, which needed to be constructed through multiple experiences. Simon was adamant in the contradiction of Vygotsky's (1978) theory of the zone of proximal development: that KDUs could not be acquired through explanation or demonstration.

With his later research, Groth (2013) placed his earlier theory in question by trying to rethink the construct of SKT that he had presented previously. Hence, in his new work, Groth (2013) understood that his definition of common knowledge was a very close definition to what Hill et al. (2008) conceived of as CCK, except that their definition cut through professions, whereas Groth's was ingrained in mathematics. Groth's definition of specialized knowledge contains similar ideas with Hill et al.'s specialized content knowledge, Within KCS, Groth 
hypothesized his ideas of various representations and unusual student strategies. In Hill et al.'s conception of KCS, he also found his ideas of common difficulties that students have in understanding a subject.

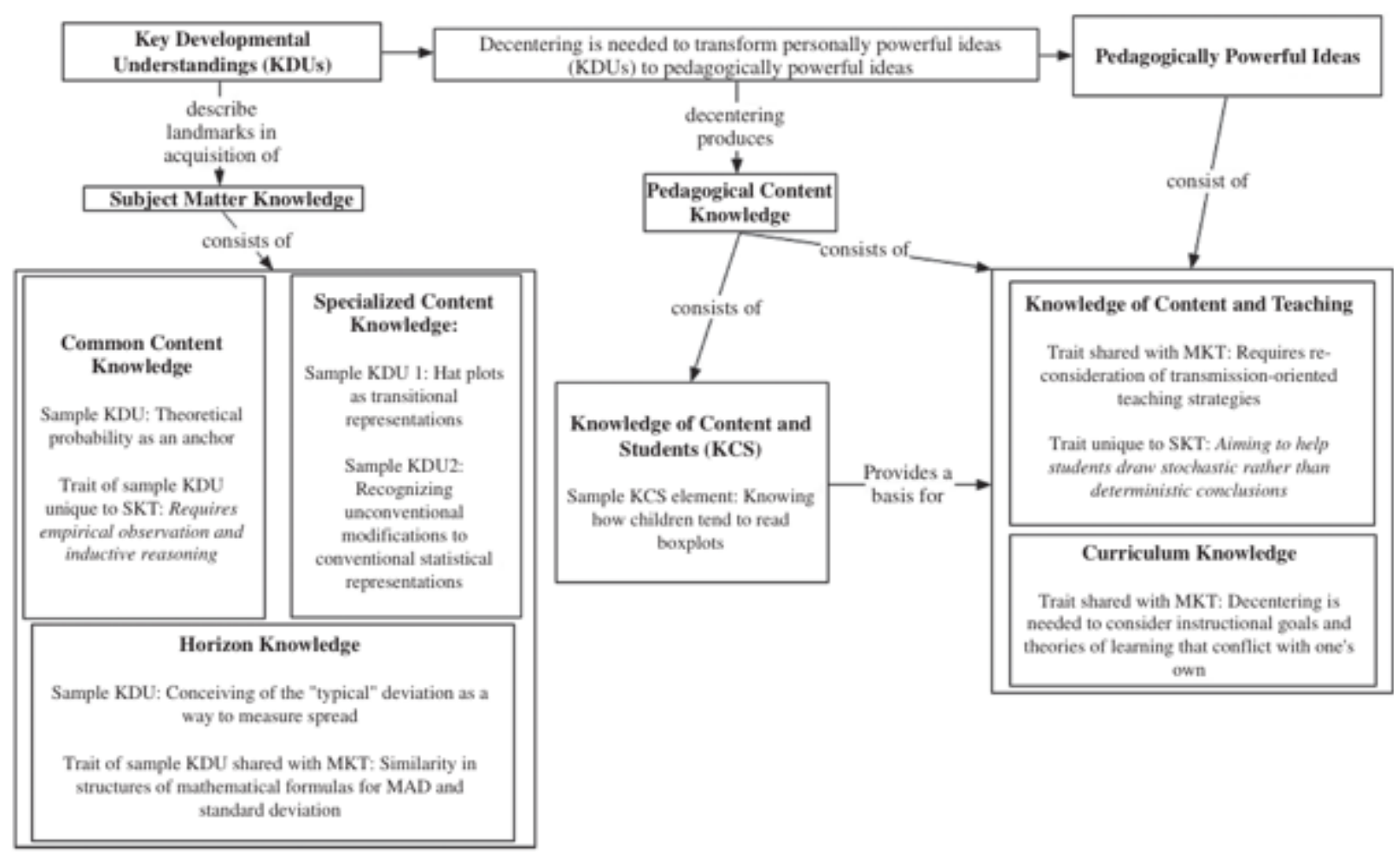

Figure 4. Hypothetical SKT elements and developmental structure. Shows the conceptualization of SKT as envisioned by Groth (2013). You can see the components of knowledge of content on the left and the components of PCK on the middle and right.

The next model in the conceptualization of SKT is offered by Burgess $(2007,2009$ a, 2011), who looked at in-service teachers in the environment of teaching, in the classroom, and characterized what PCK looks like. As his main components of teacher knowledge, Burgess (2009a) decided to concentrate on CKC, SKC, KCT, and KCS from Hill, Schilling, et al. (2004) and Ball, Thames, and Phelps (2008). These four categories were intertwined with the eight categories of statistical thinking put forth by Wild and Pfannkuch (1999)—namely; recognize the 
need for data, transnumeration (transforming data correctly in order to report it), variation (uncertainty in decision making), reasoning with models (different models used to make decisions), dispositions (that teachers hold pertaining to statistics), investigative cycle, interrogative cycle, and integration of contextual with statistical thinking.

Burgess hypothesized that when teaching statistics, teachers must use all four components of MKT while still addressing and keeping in mind the components of statistical thinking (see Figure 5). If you look at "common knowledge of content: transnumeration," Burgess hypothesized that this intersection would be the knowledge of content allowing the teacher to transform data to make more sense of it and the ability to recognize if a student used the correct procedures and rules in transforming the data.

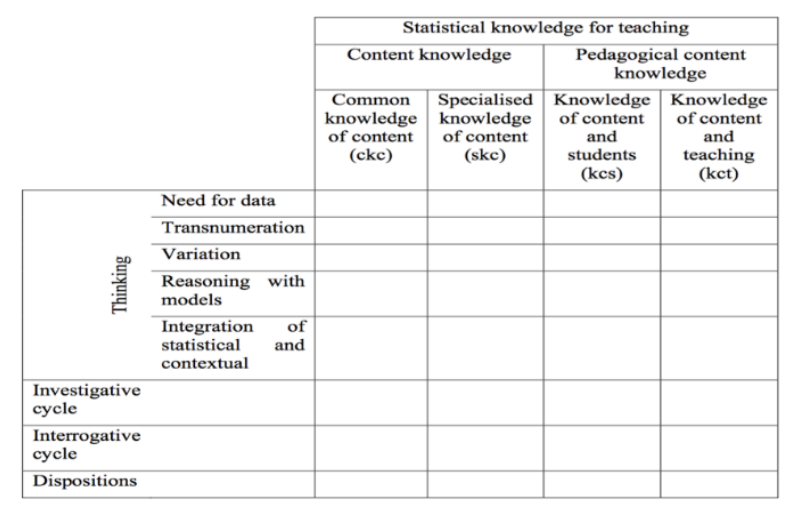

Figure 5. Framework for teacher knowledge in relation to statistical thinking and investigation. This figure shows the components of knowledge hypothesized by Burgess (2007) with the intersections being the components.

Godino, Ortiz, Roa, and Wilhelmi (2011) synthesized models for statistical pedagogical knowledge before they introduced their framework for PCK. They started by introducing the model laid out by Shulman (1986), then moved on to Hill et al.'s (2008) MKT, and then moved to the statistical models laid out by Burgess (2008) and Watson et al. (2008). Even though 
Godino et al. (2011) recognized that all the previous models for MKT and SKT were useful, they also stated that the categories on those models were too general and that there was room for improvement and more precise categories. They expanded on the didactical suitability model (epistemological and cognitive components) and added an instructional component based on social constructivism to construct their new model (as seen in Figure 6).

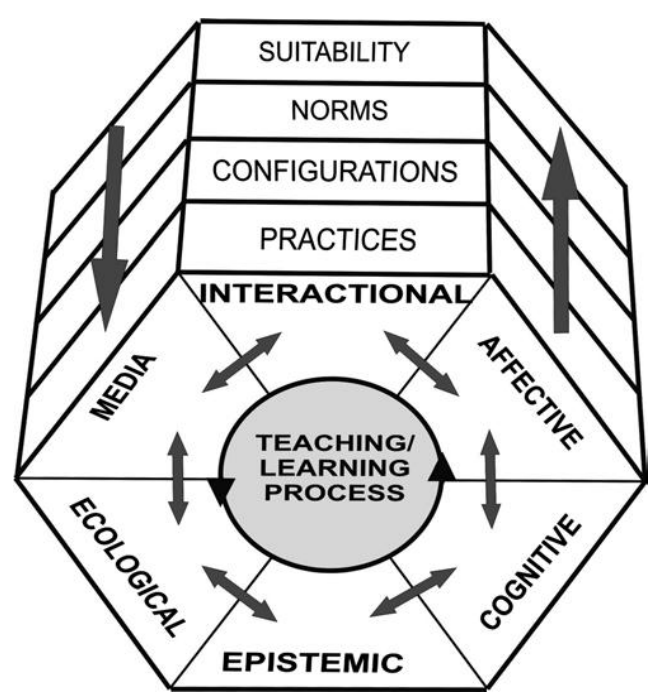

Figure 6. Facets and levels of teachers' knowledge. This figure shows the six different facets of knowledge that teachers must require (horizontal) interacting with four teaching and learning processes (vertical; Godino et al., 2011).

Godino et al. (2011) hypothesized that the epistemic facet was the intended and implemented instructional meaning for a given statistical content, the cognitive facet explains the level of students' development and understanding of the topic, the affective facet explains students' attitudes and emotions about the content, the media facet explains the technological resources available for teaching, the interactional facet explains possible organizations of classroom discourse, and the ecological facet is the relation of the topic with the official curriculum. On the vertical aspect of this framework, hypothesized that didactical practices 
explain the actions students take to solve problems, the configuration of statistical objects explains the processes that emerge in statistical practices, norms explain the rules and habits that make learning possible, and didactic suitability explains the criteria that helps improve the learning and teaching as well as the evaluation of said learning and teaching process.

González (2016) started by laying out the existing research on frameworks for SKT and then explained the four major arguments that were considered in in designing of his framework. The first argument considered that his framework would have to use the six components of MKT introduced by Ball et al. (2008). His second argument was that the six components of MKT would have to be redefined for use in statistics. For example, common content knowledge would have to be seen as statistical literacy, one of the major goals of statistics education. The third argument is that the teachers' beliefs about teaching and learning of statistics should also be considered. The last argument of his framework has to do with tasks used to get teachers thinking about their conception of variability. His framework was also followed by an instrument used to assess SKT, a pencil-and-paper assessment asking about important ideas in context and teaching strategies as well as asking teachers to discuss student thinking.

Summary. In this section, I have introduced some of the frameworks used in understanding what PCK looks like within statistics. Some of the models included are inspired and based on Shulman (1986; e.g., Watson, 2001; Watson et al., 2008), others based on work done within mathematics by Ball and her colleagues (Hill, Ball, \& Schilling, 2008) (e.g., Burgess, 2007; Groth, 2013), and others still by looking at existing models and creating new ones (e.g., Godino et al., 2011; Groth, 2007). However, there is some consensus: teachers should be aware of their students' understanding, teachers should be able to predict student answers, 
teachers should be able to develop instructional strategies based on student knowledge, and teachers should be knowledgeable of the available curriculum.

\section{Research on Teacher's Statistical Knowledge for Teaching}

In this section, I introduce some of the research that has been brought forth about the knowledge that teachers, in-service first then preservice, have with respect to statistics. As with frameworks, this section will start with the work done by Watson and her colleagues in Australian schools with in-service teachers. Watson (2001) found that when it came to the teaching of chance and data, although there were a lot of activity-based lesson plans at the primary level, there was almost no evidence of uniformity in curriculum through different schools. The opposite was evident at the secondary level; student difficulties were well documented, but teachers were reluctant to bring activities that would relate to simulations or actual sampling to reinforce theory. Interestingly, the authors found that the major curriculum document, in Australia at the time, was only used by a quarter of the secondary teachers.

Watson et al. (2008) worked with 40 teachers, from Grade 5 to Grade 12 teachers. They used a previous instrument (Watson, 2001) with 12 items specifically addressing PCK, using Rasch analysis to obtain a measure of teachers' ability. The Rasch analysis differentiated three different groups of teachers based on their ability, with a one-way ANOVA confirming significant differences between the groups. The instrument asked teachers a question about odds and then asked them to predict student answers (both correct and incorrect) and ways to use the items in the classroom.

In the "low" level (Watson et al., 2008) group, the 14 teachers were only able to predict student answers and to use some of the materials in the classroom. Watson et al. presented two 
teachers who were both at the low level, and their responses showed that they did not have any success with responding to student work or student questions about proportional reasoning. At the "middle" level, the 19 teachers suggested both correct and incorrect student answers as well as found errors and made suggestions to students about several items. At this "middle" level, however, teachers were only able to give the same single generic suggestion when using student responses to develop ideas for the classroom. At the "high" level, the nine teachers suggested both correct and incorrect student responses, focused on the mathematics of proportional reasoning; however, some of them still did not earn high grades when using student answers to suggest classroom activities.

Using the same instrument for understanding teachers' PCK (Watson, 2001), Watson et al. (2009) changed their methodology by taking a holistic approach in the analysis of the data. Forty in-service teachers, involved in a professional learning project in statistics for middle school, were interviewed. The teachers had to consider the variation and information given in a pictograph, and they also had to make predication of expectation couched in uncertainty. They found that nine teachers could be identified as having a high degree of PCK, 14 teachers were classified as medium, and 17 teachers were classified as low. Teachers in the "medium" group exhibited knowledge of some of the components of the framework but were not consistent across all four major categories of PCK as previously identified. When discussing ways of handling student responses, teachers focused on using specific questions about the task at hand and commented on the need for students to familiarize themselves with data collection. Teachers in the "low" group did not see the big ideas involved with the tasks presented, and they were quick at giving judgement on student responses, appropriate or otherwise. 
Burgess (2009b) conducted a study with four inexperienced primary teachers in their second year of teaching. He gave the teachers a teaching unit that had students investigate some multivariate data sets. He observed and videotaped the teaching of the lesson; the video was then edited to show only noteworthy episodes from the lesson. The teacher and the researcher (Burgess) then discussed the lesson, which was also audiotaped for further analysis. These videos and audiotapes were the main data source that was informed the profiles of each teacher's knowledge. He found that almost all four teachers had instances in which they showed direct evidence of the hypothesized knowledge (Figure 7, solid grey color), indirect evidence (checkered pattern), missed opportunities (M) and no evidence of the hypothesized knowledge (white solid color). None of the teachers displayed the components for "need for data" because all the activities started with the teachers giving students a set of data; also, dispositions were not evident because there was no questionnaire to determine them.

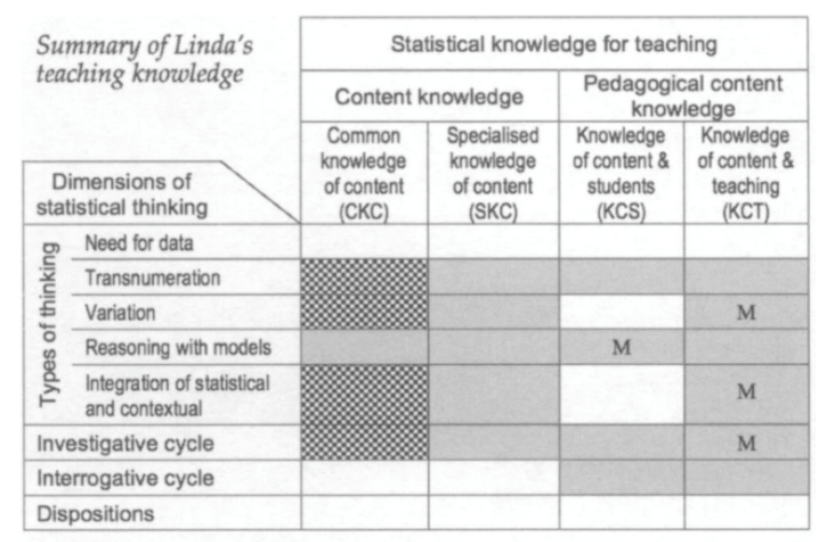

Figure 7. Summary of Linda's reaching knowledge. Solid grey shows direct evidence of that knowledge component, shaded M shows missed opportunities to show evidence, checkered shows indirect knowledge, and unshaded shows no evidence of that component was given.

If you look at "common knowledge of content: transnumeration," Burgess (2009a) hypothesized that this intersection would be the knowledge of content allowing the teacher to 
transform data to make more sense of it and the ability to recognize if a student used the correct procedures and rules in transforming the data. Burgess observed that (as in Figure 7) Linda did not show "direct common knowledge of content: transnumeration" because she did not transform the data she was given; however, when helping a student, she did help him sort the data, hence Burgess was able to observe "indirect common knowledge of content."

There also has been research with in-service teachers outside of the United States to give evidence of what PCK for statistics looks like (Estrella et al., 2015; Ijeh, 2013). Estrella et al. (2015) reported that of the second item, how to get students at a higher level of understanding, only $29 \%$ of teachers answered correctly, and $70 \%$ of teachers had issues with commenting on student difficulties about a graphical display item. Graphical displays of data were an important topic of the research reported by Ijeh (2013), who found that most teachers taught the topic in a step-wise and mostly procedural fashion. From analysis of student work, Ijeh (2013) found that learners experienced misconceptions confusing bar graphs and histograms and that some experienced misconceptions in analyzing and interpreting scatter plots and labeling the data axis. Estrella et al. (2015) found that only $51 \%$ of teachers were able to correctly answer a transnumeration process of counting to tabular representation task, with only $18 \%$ of fourthgrade and $15 \%$ of seventh-grade students answered correctly. The authors hypothesized that this lack of knowledge could be explained by the teachers' lack of study and teaching practice regarding this type of content.

Godino et al. (2008) started by introducing a framework of PCK:

a) Epistemology: Epistemological reflection on the meaning of concepts to be taught ...; b) Cognition: Prediction of students' learning difficulties ...; c) Teaching resources and 
techniques: Experience and good examples of teaching ...; d) Affect: Ability to engage students' interest. (p. 1)

The authors used this previous framework to create a formative cycle to improve their participants' PCK in statistics. There were 55 PSTs that were asked to work on a statistical project and then later to carry out a didactical analysis of the project. Two key elements in didactical analysis are the epistemic (mathematical content) and cognitive (students' learning). This analysis was designed to increase both the content knowledge and PCK of the prospective teachers. Teachers were asked to complete a project on their intuitions about chance with the aim of showing usefulness of statistics in checking conjectures and checking intuitions about randomness, with the secondary aim of realizing that sometimes intuitions are misleading. The authors found that a majority of the PSTs could use elementary statistics concepts, but they had issues with statistical variables, used inadequate graphs, and were not able to reach a conclusion about their intuitions. Most teachers showed some statistical knowledge but not literacy of statistics concepts.

Godino et al. (2008) used a cluster analysis to identify four levels of knowledge for both statistical content and pedagogy. At the first level of content knowledge (60\%), the PSTs only used their sample (instead of the whole class) as part of analysis, they built incorrect frequency tables, and they computed the mean but did not use it to reach a conclusion. At Level 2 (18.2\%), teachers produced tables and graphs for different statistical variables but did not compare the simulated and real distributions. At Level 3 (16.3\%), teachers plotted each pair of variables on the same graph, facilitating the comparison of distributions, but the comparison was limited to the averages without spread. At Level 4 (5.5\%), as in Level 3, the comparison of distributions was not limited to the averages, but it was extended to the spread. At Level 1 for pedagogical 
content (47\%), PSTs did not apply descriptors and were vague in ways to help student improve. At Level 2 (26\%), they listed all the components of the didactical analysis but were only sometimes able to use them, and improvements, for students, were sometimes specific. At Level $3(26 \%)$, they applied at least one component of the analysis, made global judgments, and even suggested some improvements. The authors concluded that there was a need to improve the training of PSTs in statistics.

Before hypothesizing about what content knowledge within SKT should look like, Batanero and Diaz (2010) decided to take a look at the existing literature on content needed in the teaching of statistics. The authors found that even though curriculum documents advocated for the development of statistical thinking, schools frequently reduced the teaching of statistics, and when it was taught, it was with few examples of real-life applications. The authors also mentioned that teachers did not consider themselves prepared to help their students with the difficulties that they faced. Batanero and Diaz also shared results from research that suggested that teachers struggled with the mean and median, incorrectly identified relevant variables, did not consider outliers when looking at mean and median, and failed to interpret data distributions as a whole. The authors concluded with some activities that could be influential in training teachers: promoting collaborative work among PSTs, analyzing student responses strategies and difficulties, project work or research projects, and working with technology.

Like Godino et al. (2008), Groth (2012, 2014), Mercimek and Erbas (2017), and Sorto and White (2004) also worked with PSTs. Groth (2012) used writing prompts to help asses and develop content and pedagogical knowledge of his students. Groth used SOLO Taxonomy (Biggs \& Collis, 1982) to evaluate student responses through which he was able to get a clear snapshot of his students' knowledge. In the posttest, Groth identified that at the prestructural 
level, the students did not exhibit evidence of understanding probability. At the unistructural level, the students showed a degree of progress in using probability to help student conception. At the multistructural level, students used relevant terminology and relevant aspects of what students will do during stimulations in statistics. At the relational level, students added by describing how elements of probability can be used to help with statistics. Using LMT and CAOS testing for PCK, Groth found significant differences from pre- to post-test.

Groth (2014) used his theoretical framework (Groth, 2013) to analyze PSTs' responses to student answers to National Assessment of Educational Progress (NAEP) tasks. Groth introduced his PSTs to questions and answers from three children taken directly from NAEP website. Groth then asked PSTs to rank the answers from least to most sophisticated and then explain what they would do to further support the students' thinking. Using his theoretical framework, Groth analyzed PSTs' thinking and understanding of statistics and was able to identify levels of knowledge that the PSTs possessed.

In the case of content knowledge of the mean and median, Groth (2014) classified his PSTs' responses as seen in Figures 8 and 9. Groth found that of the 20 students, 17 correctly observed that the second student was more sophisticated in his answer because he was paying attention to the outliers.

Response shows lack of
attention to statistical content
or to children's thinking
Response shows attention to statistical content and to children's thinking, but analysis of one of the two areas is flawed
Response shows coordination of statistical content knowledge and attention to children's thinking

Figure 8. Levels of response to NAEP-based assessment task on mean and median. This figure shows the three different levels of responses that Groth (2014) encountered with his PSTs when they were analyzing student work. 
To explain his PSTs' KCT when suggesting support for a specific student, Groth (2014) offered the classification shown in Figure 9.

\begin{tabular}{|c|c|c|}
\hline \multirow{2}{*}{$\begin{array}{l}\text { Response identifies a flaw in } \\
\text { the child's thinking but } \\
\text { suggests no teaching } \\
\text { strategies to remedy it }\end{array}$} & $\begin{array}{l}\text { Response suggests probing } \\
\text { the child's thinking by asking } \\
\text { for further explanation }\end{array}$ & \multirow{2}{*}{$\begin{array}{l}\text { Response includes content- } \\
\text { specific questions or tasks } \\
\text { likely to prompt the child to } \\
\text { notice key aspects of the data } \\
\text { set }\end{array}$} \\
\hline & $\begin{array}{l}\text { Response suggests pointing } \\
\text { the child directly toward a } \\
\text { key aspect of the data set }\end{array}$ & \\
\hline
\end{tabular}

Figure 9. Levels of knowledge of content and teaching apparent in individualized support suggested for student 1 . This figure shows the four levels of knowledge of content that Groth (2014) observed when PSTs were asked to comment on strategies in helping struggling students.

Three of the PSTs described what they thought the students could do to improve without offering any specific pedagogical strategies. Seven of the PSTs chose to ask the student to explain in more detail. Although asking probing questions can give insight, Groth also warns that such questions do not show evidence of how teachers will further the students' thinking. Three PSTs suggested pointing out the outlier to the student, which could lower the cognitive demand of the question.

Sorto and White (2004) used a written instrument and one-on-one interviews to assess the teachers' pure statistical knowledge and knowledge applied to teaching. Within pure statistical knowledge, the teachers had to respond to questions pertaining to reading, interpreting, and inferring data using a graphical display. They also had to recognize and use the shape of a data distribution as well as use and develop measures of center and variability. Within their knowledge applied to teaching, PSTs had to respond to student work, responses, and solutions by judging correctness or by explaining strategies used by the students.

Sorto and White (2004) found that PSTs performed better at pure statistical knowledge, with $65.72 \%$ accuracy, than when they had to apply statistical knowledge to teaching. PSTs 
perform better at the lower levels of statistical literacy, and at high levels of reasoning and thinking, they do progressively worse. Statistical literacy was defined as recognition, identification, computation, or basic understanding of concepts; reasoning referred to the ways that students reason with statistics; and thinking referred to the application of students' understanding to real-world problems. All teachers found the mean through an algorithm, and most teachers were bothered by non-whole-numbers as average. PSTs do not think of what the measures of center and spread tell you about the data when trying to find them. When applying their knowledge to teaching, PSTs performed worse, at $45.14 \%$, with only a third of teachers providing the ideal response of connecting algorithm of mean as balance point. At identifying student errors, no teacher received a top score. PSTs made up strategies for median of categorical data, and they could not recognize student errors about median or range of categorical data.

Mercimek and Erbas (2017) worked with 659 preservice middle school teachers in Turkey in order to assess their mathematical knowledge for teaching statistics and to identify any relations between the components of that knowledge. In that study, Mercimek and Erbas only looked at content knowledge and PCK. They took a previous instrument (TEDS-M, Tattoo et al., 2008) and adapted it for their use. They found that there was a statistically significant difference in the content and pedagogical knowledge between third-year and fourth-year scores, with fourth-year students receiving better scores. Another significant finding was that CK and PCK had a high correlation $(r=78, p<0.001)$. They also found that the gain from third to forth year was very small, suggesting that teachers are not gaining any new knowledge in the last year of their education. 


\section{Summary}

The key components of the pedagogical knowledge that teachers should bring to the teaching of statistics are their KCS, KCT, as well as knowledge of curriculum. However, as research shows (Watson et al., 2008), teachers have a hard time predicting student answers (correct and incorrect), and when they do have those student answers, they have a hard time using said answers to come up with activities to use in the classroom. When it comes to handling student responses (Watson et al., 2009), teachers focused on using specific questions about the task at hand. As Groth (2014) warned that such questions do not show evidence of how teachers will further the students' thinking, Godino et al. (2008) reported that almost half of their participants used vague ideas when helping their students.

With respect to KCT, Godino et al. (2008) reported that their participants had a hard time with statistical literacy and concepts and showed little statistical knowledge. In the same study, they reported that only $26 \%$ of their participants used activities and made suggestions for improvement. Similarly, Ijeh (2013) reported that most teachers taught the topic in a step-wise and mostly procedural fashion. As reported earlier, Watson (2001) found that only a quarter of the participating high school teachers used the prevailing curriculum document. In primary schools, activity-based lesson plans were available, but there was little evidence of coherent program planning. All of these studies paint a grim picture of the knowledge that teachers have with respect to statistical pedagogy and content.

\section{Development of the Conceptual Framework}

I am conducting this research to find out what the structure of teachers' knowledge about teaching statistics looks like within statistics in middle school. To do this, I look at the statistical 
knowledge that teachers have based on what is expected of them from research as well as curriculum documents. However, finding a theoretical perspective to rely on and to use in this study has not been a simple task. PCK is a subject that has been theorized about and researched for the last 30 years, and it is a subject that will keep being the center of attention for years to come. So, being able to pinpoint the best or most appropriate theoretical perspective to use can be a challenge. Since Shulman (1986) wrote his prolific paper, there have been a lot of researchers that have put forth models and theories about the construct and components of PCK for mathematics (Ball \& Bass, 2003; Ball \& Hill, 2005; Ball, Thames, \& Phelps, 2008; Even, 1993; Even \& Tirosh, 1995; Hill \& Lubienski, 2007; Hill, Ball, \& Schilling, 2008; Shulman, 1986, 1987; Wilson, 1994) and PCK for statistics (Burgess, 2007; Groth, 2007, 2013; Watson 2008). For this study, I chose to use the EGG Model (Hill et al., 2008) because it is a model that has endured through the last decade and because it is a model used by other researchers that are conducting scholarship in statistics (Burgess, 2009a; Groth, 2013, 2014). This model also gives me the ease of understanding how to classify the responses that my participating teachers give, where I can easily differentiate the statements offered into statements about students about teaching and about curriculum.

The egg model is divided into two parts: content knowledge and pedagogical content knowledge. PCK is partitioned into knowledge of curriculum, KCS, and KCT. These three components of PCK will become the three major components of my conceptual framework. But I still have to fill in the blanks and define what knowledge of curriculum, or the other two components, looks like for the teaching of statistics in middle school as it pertains to measures of center. This kind of detail has not been conceptualized in previous scholarship. This is the major reason why I cannot use an existing framework, but I have to conceive of my own conceptual 
framework. All the components of my framework will come from curriculum documents or from research done with students or with teachers.

For the purpose of this study PCK is conceived as being comprised of three different, yet overlapping, types of knowledge. Knowledge of content and curriculum will be the knowledge of what content the curriculum requires to teach, and how to use it. Knowledge of content and students will be conceived as the knowledge of student conceptions, misconceptions, and topics of issue. Knowledge of content and teaching will be conceived as the knowledge of different strategies to teach, different activities to use to transfer (discover) knowledge in the classroom. Within each part, I introduce components that are advocated for in research about what this knowledge should look like. For the first part, knowledge of curriculum, I introduce what existing curriculum documents have to say about the major ideas that need to be included in curriculum. Here, I introduce ideas about the conceptualization of the measures of center, what concepts should be introduced first, and what documents say should be related to measures of center in the curriculum. Within knowledge of students, I introduce some of the difficulties that students have and some of the successes that students have with measures of center. In knowledge of teaching, I introduce what research advocates for the teaching of measures of center.

\section{Knowledge of Content and Curriculum}

Curriculum was one of the main categories that Shulman (1986) introduced as part of what he theorized as content knowledge that teachers have. At that time, Shulman regarded educators as "delinquent" (p. 10) for the lack of teaching future teachers about knowledge of curriculum. Shulman defined curriculum as the full range of programs designed for teaching a 
particular subject at a given level. For the purpose of this study I will define curriculum as the major ideas and concepts, that are advocated and kept at the forefront of curriculum documents (NCTM, 1989, 2000, 2006) as well as standards (NGA \& CCSSO, 2010) that have been adopted as curriculum documents. In 1989, NCTM published a standards document to establish a framework to guide school mathematics. NCTM realized their vision of what curriculum should look like, what topics to include, and where to place their priorities by establishing a precedence for what a curriculum document should be. From that first standards document, NCTM has further explored their ideas about curriculum with consecutive documents in 2000 and 2006, later followed by National Governors Association Center for Best Practices (NGA) and Council of Chief State School Officers (CCSSO, 2010) with the establishment of the Common Core State Standards for Mathematics.

NCTM (1989). In 1989, NCTM published its first curriculum document, Curriculum and Evaluation Standards for School Mathematics, with the purpose of establishing a broad framework to guide reform in school mathematics. The standards included goals for teaching emphasizing the need to create: mathematically literate students, lifelong learners, provide opportunity for all students, and to create an informed electorate. They also included goals for students: learn to value mathematics, become confident in their ability to do mathematics, become mathematical problem solvers, learn to communicate mathematically, and learn to reason mathematically.

As explained by NCTM (1989), the standards were designed to establish a framework to guide reform in school mathematics and to make suggestions about what curriculum should 
include in terms of content. Without including all the details about the standards for middle school, the major ideas for probability and statistics (Grades 5-8) were:

- systematically collect, organize, and describe data;

- construct, read, and interpret tables, charts, and graphs;

- make inferences and convincing arguments that are based on data analysis;

- evaluate arguments that are based on data analysis;

- develop an appreciation for statistical methods as powerful means for decision making. (NCTM, 1989, p. 105)

The focus of the NCTM (1989) standards for middle school was on the students' exploration of probability and statistics in the real world. The writers of the standards envisioned students' interaction with real-world information in order to understand how data are processed and translated into usable information. The writers understood the need for students to cope with an ever-changing world of information, and they understood that probability and statistics could be that catalyst. They wanted students to understand trends in data and how to use such trends to make decisions; also, they wanted students to become active participants of the statistics cycle, all the way from articulating questions to the consumption of the results. The authors envisioned students interacting with computers in the recording, analysis, and displaying of data. So, the standards put forth a picture of an educated and well-versed citizen of the future with statistics as one of the tools in his arsenal.

NCTM (2000). There have been revisions and improvements to the standards with the publication of the Principles and Standards for School Mathematics (NCTM, 2000). The authors understood that in a quickly changing world, the need to understand and use mathematics in life 
and work would become greater (NCTM, 2000). With this document, the authors outlined the essential components of an advanced and quality school mathematics program, emphasizing the need for teachers and administrators that were prepared to tackle the challenges to come. The document was envisioned as a guide for focused, sustained effort to improve school mathematics aiming to: set a comprehensive and coherent set of learning goals for mathematics; serve as a recourse for teachers, educators, and policymakers; guide the development of curriculum frameworks, assessments, and instructional materials; and stimulate ideas and ongoing conversations both at the national and state level about how best to help students understand important mathematics.

NCTM (2000) situated the standards for Data Analysis and Probability as early as the third grade all the way up to the twelfth grade. The authors envisioned students moving from formulating questions close to their experience, because young children are naturally curious, to formulating questions based on current issues and interests, and further to posing questions that investigate and explore complex issues. Moving from simple data gathering plans (planning data collection and evaluating collection methods) to working with data gathered by others in the middle grades and further to understand the purpose of surveys, observational studies, and experiments. Developing from the early grades in which data can be organized or ordered in pictures to middle school in which data are displayed in bar graphs, tables, and line plots. In later grades, students would start to compare the effectiveness of different displays in organizing data for further analysis, or presentation, and move on to record and represent data using technology in order to analyze and understand the results.

With respect to measures of center, NCTM (2000) made some simple recommendations about what knowledge students should exhibit. With respect to the timing, NCTM (2000) 
recommended that children as early as the third grade could start learning about concepts of statistics and specifically measures of center. In the recommendations for the third to fifth grade, the authors emphasized the need for students to see the measures of center in different context, and that students needed to build on their ideas of "typical." The authors recommended that students needed to understand what the median told them about the data, and that in Grade 5 the best representation of the mean was the balance point.

In Grades 6-8, NCTM (2000) acknowledged that students did not understand the mean well, and they reiterated the fact that using balance point, the mean evens out or balances a set of data because the representation of the mean was the best practice. Students needed to see the median as the middle of the data. Also, when choosing the best average to represent the data, students needed to understand (through modeling) that the mean could be influenced by extreme values.

In high school, the recommendations became more geared toward the procedural understanding of the mean, adding the same constant to all observations would change the measure of center by the same constant but not the measure of spread, and that claiming that "the mean score of a test was 50 percent" (p. 327) could cover several distributions of data. Keeping to the theme of choosing measures of center, they recommended that students should recognize that the sample mean and median could be greatly influenced by the skewness of the distribution.

GAISE (2007). The next avenue for the standardization of teaching statistics came from the GAISE report (Franklin et al., 2007) that put forth some major areas that students need to develop in school. The report is designed as a framework, and as a document to compliment the Principles and Standards for School Mathematics (NCTM, 2000), on what to teach and how to teach statistics, giving recommendations on what to teach at each level. There are three levels of 
teaching explained in the framework; the lowest level, Level A, is thought of as the introductory level, continuing to Level B and finally Level C as the pinnacle of statistics education of students in school. The framework recommends that students start at Level A and then progress through the other levels to Level C. At all levels, the students should learn statistics through investigations, which, as explained by the authors, will empower students by giving them tools to think for themselves and ask intelligent questions, skills required to excel in the modern world.

The report (Franklin et al., 2007) recommends that at all levels, students should through the statistical investigation cycle to: formulate questions, collect data, analyze data, and interpret results while focusing on the nature of variability. At Level A, the report recommends that teaches pose questions of interest restricted to the classroom, taking census of the classroom and designing simple experiments. Teachers should use properties of distributions in context, display variability within a group, and observe association between two variables. In the context of interpreting results, the report recommends that students do not look beyond the data, do not make generalizations beyond the classroom, note differences between two individuals, and observe associations in displays. With regard to measures of center, at Level A, the authors recommend that students should recognize mode as a way to describe what is typical or representative of a distribution. With regards to the mean and median, students are recommended to see the mean as a fair share and the median as the middle of the data with $50 \%$ of the data above and $50 \%$ of the data below the median. It is cautioned that students should be careful and purposeful in choosing the mean or median to describe numerical data and not categorical data.

In the GAISE report (Franklin et al., 2007), Level B is conceptualized as the second level that students come to with some conception of both summarized data and displaying it for analysis. For the purpose of this study, I thought of Level B as the middle school 
recommendations, which is what this study will be concentrating on. At this level, it is recommended that students start posing their own questions for investigation and that they start paying attention to differences in the samples chosen to answer the questions. Attention to the distribution properties as tools for analysis is another recommendation along with acknowledging sampling error, comparing groups in graphical displays, and noting the difference between two groups with differing conditions. The conception of the mean is recommended to be developed from fair share to balance point. This is done through several dot plots showing the original data then changed all to one point, pivot or balancing point, as the mean and moving values to the left and right to keep the pivot from tilting in either direction. Building from Level A in which median was the middle point, measure of central location of the data, the authors use the dot-plot activity to show that the mean also is to be considered a measure of central location.

In Level C, all the previous ideas on the investigative cycle are revisited, but the studies are of a deeper statistical nature. At this level, the students are encouraged to develop additional strategies for all the four steps of the investigative cycle and to explain their statistical reasoning to others. Students are still expected to come up with their own questions to investigate, but at this step, they have to take into account the data collection and analysis that will help provide an answer. Students are expected to understand what constitutes good practice for different types of data collection strategies and identify appropriate ways to summarize and analyze numerical or categorical data. At this level, students are expected to use the measures of center as tools for their data analysis, but they are expected to have the concepts developed from previous levels. The distinction between mean and median is more about the position in the graphical displays and not focused so much on which measure to use to represent the data. 
CCSSM (2010). The next and final curriculum document has a more conventional and more gubernatorial pedigree. From the recommendations of Foundations for Success: The Final Report of the National Mathematics Advisory Panel (National Mathematics Advisory Panel, 2008), the Common Core State Standards for Mathematics (NGA \& CCSSO, 2010) were born. The content of the CCSSM is important because it has been adapted by most states as the national curriculum document by which they decide the content in their classes. The recommended standards were designed to outline what students should be able to understand and be able to do at the end of a particular grade level. Even though the five major strands were never the same during the middle grades, probability and statistics was always one of the five. In the sixth grade, recommendations were aligned with students developing understanding of statistical variability and summarizing and describing distributions. In the seventh grade, the statistics and probability strand concentrated on probability, using random sampling to draw inferences about populations and to draw informal comparative inferences about two populations as well as investigating chance processes and develop probability models. In Grade 8, the students should be able to investigate patterns of association in bivariate data.

CCSSM (NGA \& CCSSO, 2010), and its accompanying Progressions (NGA \& CCSSO, 2011) document, has recommendations for data analysis from as early as kindergarten; however, on closer review, the recommendations have no connections to statistics or statistical thinking. The first instance of recommendations for statistic happen in the sixth-grade standards in which students are expected to understand variability, describe distributions, and use graphical displays to analyze and represent data. Aside from my bias on the enormity of the burden to sixth-grade content, students are expected, through investigations, to understand variability and, through graphics, to look for symmetry in the data. 
At this grade level, students are encouraged to think of the median as the center of data and how it can be used to create a box and whiskers plot and consequently the IQR, explained as a measure of variability. Connecting statistics to mathematics, the authors expect students to use knowledge of fractions to calculate the arithmetic mean, recommending that students think of the mean as leveling out or fair share. When comparing mean with median, the authors recommend that the mean can be pulled by extreme values and that context should be used in making these comparisons. For instances in which the mean is understood as the measure of center, the authors recommend using the MAD as the measure of variability; however, when the median is used and the data displays long tails, then the IQR should be used as the measure of variability.

In the seventh grade, students are expected to understand the inherent variability in data collection and that random sampling is the best way to avoid bias. With that in mind, the seventh grade is designed around the principles of probability in which random sampling and repeated sampling will pave the road for better designs in data collection. There are no recommendations about the conception of measures of center; however, there are instances in which sample statistics, center or variability, are linked to population justified through random sampling. At this point, students are also encouraged to think of comparisons of different populations can be done through comparison of samples and their statistics.

Eighth grade recommendations are based on the same ideas of progressing through the investigative cycle only more advanced with concentration on associations and data displays of bivariate data. Students are pushed to plot bivariate data as points on a plane, investigate questions through linear functions, and to build statistical models to explore relationships between variables. Still, quantitative data can be represented by its characteristics such as center, 
variability, and shape, and the comparison, choice, of mean or median should be appropriate to the shape of the data distribution.

Conclusions. From this review of the curriculum documents, there has been a change in the way that statistics has been conceptualized from procedures (NCTM 1989) to investigations (Franklin et al., 2007; NCTM, 2000; NGA \& CCSSO, 2010). The importance of the investigative cycle is evident in the mathematics and the statistics envisioned curriculum documents in which students are encouraged to ask statistical questions for investigation, to find appropriate ways to collect data, to analyze the data, and finally to interpret the findings and draw valid conclusions while keeping in mind variability and context. The last three documents, reviewed in detail here, all envision a knowledgeable student who is curious about her or his surroundings and willing to use technology and to understand the real world in order to become a better more informed citizen in our society.

Numerous researchers (Cai, 1998; Mathews \& Clark, 2003; Zawojewski \& Shaughnessy, 2000) have reported that students have issues with the conception of the mean and that students can use the algorithm to find the mean but have no conceptual understanding of the mean. In this regard, the GAISE report (Franklin et al., 2007), NCTM (2000), and the CCSSM (NGA \& CCSSO, 2010) have given some recommendations of different conceptions, fair share and balance point, of the mean that might help students understand the concept better. Interestingly, the authors have also recommended using the algorithm to find the mean by combining all data values and sharing fairly. The authors (Franklin et al., 2007) also recommend that the algorithm can be introduced to the introductory students at Level A and then later on in Levels B and C the students can develop a more sophisticated interpretation of the mean. The CCSSM (NGA \& CCSSO, 2010) mentioned that for an odd number of data points, the median is the middle 
number and that for an even number of data points, the average of the two middle values would be the median.

The review has also revealed that all four of these curriculum documents agree with Makar (2014), who understood that the aim of statistics was for students to think of the average as representative of the data. Both NCTM (2000) and the NGA and CCSSO (2010) advocated for the analysis of the shape of the distribution when comparing the mean and median. NCTM recognized that students would have issue choosing the mean versus median and that students needed to see that the mean can be influenced by extreme values, with the NGA and CCSSO (2011) encouraging the analysis of the shape of the distribution when deciding not only the measure of center but also the measure of variability. Echoing the same sentiment, the GAISE report (Franklin et al., 2007) reiterated the need for students to understand the proper use of the mean and median as appropriate measures for numerical but not categorical data.

Knowledge of curriculum and its components were derived from the available literature and curriculum documents (NGA \& CCSSO, 2010; Franklin et al., 2007; Kader, Jacobbe, Wilson, \& Zbiek, 2013; NCTM, 2000; Strauss \& Bichler, 1998). The first two components focus on the "correct" way of conceiving the meaning of measures of center. Both curriculum documents (the GAISE report and the NCTM standards) present the mean as a leveling of data or fair share. These are two of the most prevailing conceptions of the mean and the best ways for the students to understand the mean before we introduce the algorithm of add-and-divide. In both documents, there are examples that teachers can use to introduce the mean to students.

As per CCSSM (NGA \& CCSSO, 2010) recommendations, students should understand that mean, median, and mode are ways of representing the data using a single number (p. 43). Another recommendation that made it to the framework was the idea that teachers should make 
connections between measures of center and variability (p. 43). The idea of the mean being sensitive to extreme values comes forth in the fourth recommendation: that students should relate the choice of measure of center to the shape of the distribution (Kader et al., 2013; NCTM, 200; NGA \& CCSSO, 2010). This is a major concept that students need to understand; it is also a major concept of which students usually tend do not have the right conception (Tarr \& Shaughnessy, 2003; Zawojewski \& Shaughnessy, 2000). What follows is a table showing the components of the framework and where they came from.

Table 1

Expected Framework Components of Knowledge of Content and Curriculum

Code Description

C1 Students should understand the median as a central point (Franklin et al., 2007).

C2 Students should have a conceptual understanding of the mean: fair share, balance point (Kader et al., 2013; NCTM, 2000).

C3 Students should understand that mean, median, mode is a way of representing the data using a single number (NGA \& CCSSO, 2010).

C4 Students should relate the choice of measure of center to the shape of the distribution and context the data were gathered (Kader et al., 2013; NCTM, 2000; NGA \& CCSSO, 2010).

C5 Students should make connections between measures of center and variability through IQR and MAD (NGA \& CCSSO, 2010).

\section{Knowledge of Content and Students}

Research on knowledge of students, related to measures of center, has concentrated around three major areas: conception of average (Mokros \& Russell, 1995; Russell \& Mokros, 1990; Leon \& Zawojewski, 1990; Watson \& Moritz, 2000), conception of the algorithm for finding the average (Cai, 1998; García Cruz \& Garrett, 2008; Zazkis, 2013), and which measure of center best represents the data (Cooper \& Shore, 2008; García Cruz \& Garrett, 2008; 
Zawojewski \& Shaughnessy, 2000). This part of the review is organized into three parts in which I try to present the research in a way that shows what knowledge students have and in what knowledge they might need more instruction.

Conception of average. Leon and Zawojewski (1990) and Watson and Moritz (2000) all have concluded that students encounter difficulties with the conception of the average. The prevalent answer, among third to fifth graders, when asked about the average was bafflement, whereas with sixth or higher grade students, the answer was median or mode (Watson \& Moritz, 2000). In their work with 145 fourth, eighth, and college grade students, Leon and Zawojewski (1990) found that the statistical aspects of the mean were better understood by students than the abstract and representative aspects. Mevarech (1983) similarly found that the mean as a representative value was a difficult concept to grasp, but the mean as a computational construct was easier for students to understand.

Mokros and Russell (1995) asked their participants to place prices in nine bags of potatoes chips so that the "typical or usual or average" price would be $\$ 1.38$. The next question asked students to construct the distribution while taking into account data that were already placed by the interviewer. The authors found five dominant approaches to solving the problem: average as mode (5 students), average as algorithm (3 students), average as reasonable (4 students), average as midpoint ( 6 students), and average as mathematical point of balance ( 2 students). The authors found that students who thought of the average as mode constructed a distribution that was built around the center and that these students had issues constructing a distribution when the average value was not allowed to be part of the data. These particular students were not flexible with their problem solving and, at times, created algorithms and procedures that made little sense. Similar findings were previously reported by Russell and 
Mokros (1990) that students in this category (modal) even though they knew the algorithm (addand-divide) no student tried to use it.

Students that thought of the average as an algorithm were successful when they used the algorithm properly (Russell \& Mokros, 1990); however, of the three students using this strategy, none used the algorithm effectively (Mokros \& Russell, 1995). Russell and Mokros (1990) found that all three students using this strategy became confused, tangled in numbers, usually found unreasonable measures, and had issues reversing the algorithm to construct the data. These students understood that finding the average had to do with adding up and dividing, and they were eager to use this algorithm, but they "overtrusted the algorithm, and, blinded by this trust, they were willing to give up what they knew about reality" (p. 311).

Students in the reasonable group used values that were based on their understanding, and they had a concept that the average was representative of the data (Mokros \& Russell, 1990). Their concept was not connected to a precise construct, but the authors still believed it a critical foundation for students' future development. These students indicated an average centered roughly within the rest of the data, made good use of the algorithm, and intertwined mathematics with real life (Russell \& Mokros, 1995). Similarly, Makar (2014), working with 26 age eight students, found that the concept of reasonable helped students with their conception of average. However, this endorsement comes with the caveat that although reasonable conception of average is a good start, the aim of statistics should be to move the students toward a more aggregate reasoning such as: modal clump, signal and noise, balance point, and fair share.

Students that conceived of the average as midpoint used strategies that were flexible and understood the place of the average in the distribution, and their strategies were such that mean, median, and mode were the same (Mokros \& Russell, 1990). Most students in this group did not 
use formal definitions but constructed their distributions to appear symmetrical, even at times suggesting that the median could be used as a shortcut for finding the mean. These students knew the algorithm for finding the mean and used it to check their answers; however, it seemed simpler to think that a higher value in the data had to be balanced by a smaller value. There was, however, a drawback to this method, the authors feared that these students would choose the middle of the range (between 0 and 9 , it would be 5) rather than the middle of the data, finding the median.

As discussed by Cai (1998), another conception of the average is the leveling off of the data. In his study with 250 sixth graders in the Pittsburg metropolitan area, Cai, with the help of a graph, asked students to find the number of hats needed to be sold the next day so that the average would be seven. Students used the average formulae and guess and check to find the answer; however, a small percentage $(6 \%)$ of the students used the leveling off method. These students argued that because the average needed to be seven then the additional hats (over seven from each day) could be moved to the day in question, and then they would find the number of hats that still needs to be sold so that the day would have seven hats sold. Cai argued that the students were leveling off the data, so the average was 7 .

Knowledge of algorithm. As documented by Russell and Mokros (1995), students know the algorithm to find the mean, but they also documented that students do not have a conceptual knowledge of that algorithm. The fact that no student was able to use the algorithm backwards to construct the distribution could suggest that students only have a limited procedural knowledge of the algorithm for finding the mean. Both Cai (1998) and Watson and Moritz (2000) reported that the majority of sixth grade students knew the "add-and-divide" averaging algorithm or at 
least were familiar with it, but only half (or fewer) of them were able to apply the algorithm to solve more complex problem-solving tasks.

Several researchers have commented that for students from elementary school (Cai, 1998; Capraro, Kulm, \& Capraro, 2005; Mokros \& Russell, 1995; Watson \& Mositz, 2000) to college (García Cruz \& Garrett, 2008; Mathews \& Clark, 2003; Pollatsek, Lima, \& Well, 1981), dealing with the mean is a computational rather than a conceptual act. When asked to find the typical value of data presented in graph form, 134 sixth-grade students failed to use the graph but felt that the algorithm was more important and that the graph was useless (Capraro et al., 2005). When working with high school students, Zazkis (2013) found that when asked "what is the mean," half of the students responded with just description of the algorithm, showing a lack of conceptual understanding. Similarly, Mathews and Clark (2003) reported that their college students could only find the mean through the algorithm with no conceptual understanding. Working with 186 undergraduate students, Cooper and Shore (2008) confirmed that only 44\% of students were able to find the mean when data were presented in bar graph form, noting that students had difficulties maintaining the link between values on the horizontal axis and corresponding frequencies.

Problems using the algorithm for finding the mean led Strauss and Bichler (1998) to investigate which properties of the average do students understand: (a) the average is located between the extreme values; (b) the sum of the deviations from the average is zero; (c) the average is influenced by values other than the average; (d) the mean does not equal one of the values added; (e) the average can be a fraction that has no counterpart in physical reality; (f) when one calculates the average, a value of 0 , if it appears, must be taken into account; and (g) the average value is representative of the values that were averaged. In their study, the authors 
included a total of 80 Israeli students ages eight, ten, twelve, and fourteen. For each property (a total of 8) the authors asked the children individually to answer five questions in story format. Here is an example of a story problem for Property A:

Story medium for discontinuous quantity. "The children in a class decided to have a party at the beach. Everyone brought potatoes to put in the bonfire for a snack during the party. Yael brought the most potatoes-3. When they were ready to be eaten, the children decided to hand out all of the potatoes so that everyone would have the same number. When they were handed out, each child received 4 potatoes. Do you think this could happen? Why do you think this could [could not] happen?" (p. 69) It was reported that students performed poorly with Properties B, F, G. Because they could not ask an appropriate question, Property E was emitted from the data.

Strauss and Bichler (1998) found that few children in each age group could conceptualize why the sum of the deviations was equal to zero and that the most used correct explanation was that the surplus should equal the deficit. With respect to Property G-the average is representative of the values that were averaged - the authors found that this was the most difficult property for students to understand. No 8-year-olds were able to answer the question related to Property G, and only $25 \%$ of 10 -year-olds, $60 \%$ of 12 -year-olds, and $65 \%$ of 14 -yearolds were successful. The lack of justifications prompted the authors to believe that students had difficulty understanding the task. Similarly, García Cruz and Garrett (2008), when working with college students, confirmed issues with Property G. They reported that no student showed relational understanding of the algorithm, failing to exclude outliers when finding the mean.

With respect to Property F-when one calculates the average, a value of zero, if it appears, must be taken into account— the students were as troubled as with Property G, with less 
than half the students correctly answering this question. The most prevalent justification was that "you don't have to take the zero into account because when you add or subtract, you don't add or subtract the zero." (p. 77). Similar results were reported by Mevaresh (1983) when working with college students and by Mooney (2002) when working with sixth graders. Mevaresh reported that $30 \%$ of students thought that 0 was the identity element and that when added to the scores, it would not change the mean (p. 419). On the other hand, Mooney (2002) reported that students used flawed procedures when finding measures of center and that one student ignored a data point of 0 when calculating the mean.

It would be expected that if students have issue with the computation of the mean, then students surely will have issues with calculating the weighted mean (Gattuso \& Mary, 1998; Mokros \& Russell, 1995; Mevaresh, 1983; Pollatsek et al., 1981). When working with 37 undergraduate students, Pollatsek, Lima, and Well (1981) found that a large proportion of students did not understand the concept of the weighted mean when asked the following question:

A student attended college A for two semesters and earned a 3.2 GPA (grade-pointaverage). The same student attended college B for three semesters and earned a 3.8 GPA. What is the student's GPA for all his college work? (p. 192)

Students either added the two means and divided by two or added the means and divided by five semesters. The authors went so far as to say that "knowledge of the computational rule may inhibit the acquisition of more adequate (relational) understanding” (p. 202). Similar findings were reported by Mevaresh (1983), whose students, at a rate of $65 \%$, thought that the average was a closed operation, getting the weighted means questions wrong. Gattuso and Mary (1998), when working with high school students, reported that students invented false formulas when 
working with weighted means and that similar issues with ignoring weights of data were encountered in every problem.

Although all previous authors reported issues with calculations, Russell and Mokros (1990) and Mokros and Russell (1995) reported issues with their students' conceptions. Students that used the add-and-divide algorithm were generally successful; however, this strategy led others to confusion, hopeless entanglement in numbers, and unreasonable measures. The authors commented that even when the weighted mean was correctly found, the students did not believe that you could find the overall average because average was thought of as an approximation. Mokros and Russell (1995) reported that they could see a student "giving up what she knows about the world in order to apply a procedure that resulted in unreasonable (and unrepresentative) results" (p. 29).

Mean vs. median. This title is not meant to conjure visions of war; however, it does cause most students to cringe because this is a question (which measure of center best represents the data) that students have trouble answering (Cooper \& Shore, 2008; García Cruz \& Garrett, 2008; Zawojewski \& Shaughnessy, 2000). Makar (2104) suggests that one aim in statistics is for students to think about average as representative of a data set when comparing groups. Mean vs. median asks the students to make a decision on which measure of center better represents the data, and although the mode is missing from the title, it does not mean that the mode is not part of this debate. As early as 1986, question items about statistics have appeared in the National Assessment of Educational Progress (NAEP), and as reported by Zawojewski and Shaughnessy (2000), the percentage of these items is increasing. This assessment is used to measure the progress of students at fourth, eighth, and twelfth grade in mathematics. According to Zawojewski and Shaughnessy (2000) and Tarr and Shaughnessy (2007), these assessments have 
always included questions about measures of center, with the choice of mean or median as best representative of the data as a persistent presence among the questions.

There were five questions in the 1996 NAEP that pertained to the choice between mean and median to represent data (Zawojewski \& Shaughnessy, 2000); of these five, only the last two asked students to justify their responses. In the first three questions, only $22 \%$ of 8 th graders and $46 \%$ of 12 graders were able to find the mean from a frequency distribution. Similar difficulties with graphical displays of data were reported by Cooper and Shore (2008) and Capraro, Kulm, and Capraro (2005), whose students thought that the algorithm was more important that the shape of the data in the display. On the second question, only $31 \%$ of Grade 8 and $33 \%$ of Grade 12 students responded correctly when prompted to find the median of nonsequential numbers. Similar findings have been found for PSTs as well: $25 \%$ of the teachers in Groth and Bergner's (2006) study did not mention ordering data to find the median.

The third question in the 1996 NAEP (as reported by Zawojewski \& Shaughnessy, 2000) prompts students to choose the mean versus median, with $19 \%$ of 8 th and $28 \%$ of 12 th graders being able to answer the first multiple-choice question. On question four, explain your thinking, only $2 \%$ of 8 th graders were able to correctly answer, and on the fifth question, only $4 \%$ of 12 th graders were successful. The authors hypothesized that when faced with the choice of mean or median, students would choose the mean without regard to context or distribution. Taking a sample of 200 responses, the authors found that students believed that the mean was the better choice regardless of the data, that the mean was what they considered average or typical, or that the mean was more accurate.

In their study of the 2003 NAEP, Tarr and Shaughnessy (2007) reported similar findings to Zawojewski and Shaughnessy (2000) with a couple of difference. The 2003 NAEP 
assessment: had increased the number of data and analysis questions by one, had larger emphasis on computation, and included only one question asking the students to explain their thinking when choosing the typical value of the data. On the multiple-choice question, the eighth-grade students went from $20 \%$ accuracy to $19 \%$ accuracy, a trend that followed the 2000 NAEP results. On the explanation question, the students had a 4\% accuracy in 1996 and 2000 but had increased to only $5 \%$ by 2003 . In this study, Tarr and Shaughnessy documented issues with outliers: Students still chose the mean even though the median would be a better choice, cementing the idea that students prefer the mean over the median.

Conclusion. Two different curriculum documents (NCTM, 2000; NGA \&CCSSO, 2010) and one curriculum framework specific to statistics (Franklin et al., 2007) were analyzed for their recommendations about what and how to teach measures of center in statistics at the middle school. Although the question of "which measures of center to teach" was not the issue, what knowledge students needed to have was the main focus of this synthesis. It was unanimously agreed that the median should be thought of as the middle of a data set and that the mode could be used early on as a typical value of the data. It was more difficult to get agreement on how to teach and conceptualize the mean. Although the CCSSM only gave computational reasoning as the conception of the mean, both Franklin et al. (2007) and NCTM (2000) gave at least one other way that students could think of the mean other than the algorithm. Franklin et al. conceptualized the mean as the fair share, whereas NCTM (2000) thought of the balance point as the best practice.

Another conclusion was the acceptance that students would have issue choosing an appropriate measure of center to describe the distribution of the data. In this aspect, only NCTM (2000) was able to give a concrete method on how to tackle the issue, and they did it by trying to 
get students, through modeling, to see that the mean was heavily influence by extreme values. These conclusions make the choice of topics for my vignettes a little easier, because it seems that I have to have a vignette that tackles the issue of which measure of center to use. A vignette needs to bring up the conflict between choosing the mean or the median with numerical data. Another overarching idea for a vignette needs to be the conception of the mean, having teachers think about the best practices while introducing the mean. Also, a couple of vignettes need to contrast the algorithm for finding the mean to the balance point and to the fair share.

All components came from my review of literature and curriculum documents, and as seen in Table 2, every recommendation has a citation. Most of the components are stem from the misconceptions that students have about the mean and nature of data. If students had the right conception of the mean as fair share, balance point, evening out, then there would be no issue with considering an observation of 0 in the calculations or accepting the mean when it is not representative of the data. The reason that knowing the mean procedurally is in this list is because procedures need to be able to be reversed. They can be forgotten if not practiced, so if the student does not have a correct conception of the mean, then the procedure alone is not enough. If the procedure is all the student knows about the mean, then they are not able to answer simple questions about reversing the procedure (constructing a distribution when given the number of data and the mean) or justifying why one measure of center is better than another for a certain data distribution (Mokros \& Russel, 1995; Tarr \& Shaughnessy, 2003; Zawojewski \& Shaughnessy, 2000).

What follows KCS is the knowledge that teachers should have about their students' thinking and learning of the content. For this study, KCS is the ability of teachers to identify what conceptions, misconceptions, or issues students have about the content and being able to 
identify ways and strategies that students will use in answering questions. Keeping these ideas in mind, Table 2 shows my conceptualization (components) of what KCS is all about.

Table 2

Expected Framework Components for Knowledge of Content and Students

\begin{tabular}{|c|c|}
\hline Code & Description \\
\hline S1 & Students tend to think of minimums and maximums as outliers (Kader et al., 2013). \\
\hline $\mathrm{S} 2$ & $\begin{array}{l}\text { Students tend to ignore } 0 \text { in the data set when computing measures of center } \\
\text { (Mooney, 2002; Strauss \& Bichler, 1998). }\end{array}$ \\
\hline $\mathrm{S} 3$ & $\begin{array}{l}\text { Students tend to not order data before finding the median (Groth \& Bergner, 2006; } \\
\text { NCTM 2000). }\end{array}$ \\
\hline S4 & $\begin{array}{l}\text { Students tend to use the mode in the beginning to represent typicality (Franklin et } \\
\text { al., 2007). }\end{array}$ \\
\hline S5 & $\begin{array}{l}\text { Students tend to ignore mean when it is not part of the data (Strauss \& Bichler, } \\
\text { 1998, Cooper \& Shore, 2008). }\end{array}$ \\
\hline S6 & $\begin{array}{l}\text { Students tend to have difficulty calculating weighted means (Gattuso \& Mary, } \\
\text { 1998; Mokros \& Russell, 1995; Mevaresh, 1983; Pollatsek et al., 1981). }\end{array}$ \\
\hline S7 & $\begin{array}{l}\text { Students tend to only know the mean procedurally (Cai, 1995; Cai, 2000; Mokros } \\
\text { \& Russell, 1995). }\end{array}$ \\
\hline
\end{tabular}

\section{Knowledge of Content and Teaching}

This part of the framework will focus on recommendations about how statistics should be taught from the perspective of curriculum and policy materials as well as the knowledge that teacher's exhibit on the topic of measures of center. The same curriculum materials that have made recommended about what students should know, also introduce some recommendations about how the subject should be taught and what is expected of the teachers (NGA \& CCSSO, 2010; NCTM, 2000). With the introduction of the GAISE report (Franklin et al., 20007) and the release of a joint position statement from ASA and NCTM (2013), the statistics education community has offered recommendations and augmentations to both the CCSSM (2010) and NCTM (2000) recommendations. The ASA released the Statistical Teacher Education (SET) 
report, designed as a companion to the MET II (Conference Board of the Mathematics Sciences [CBMS], 2012), that had direct implication for teachers. The MET II had identified statistics preparation of teachers as an area of concern, a feeling that was echoed by Batanero, Burrrill, and Reading (2011), suggesting that teachers are not likely to be prepared to teach statistics at levels suggested by the GAISE report (Franklin et al., 2007).

Recommendations. With respect to the GAISE report (Franklin et al., 2007) the authors acknowledged that statistics is a relatively new subject and that many teachers may not have the necessary knowledge to teach it. The authors also mentioned that teachers do not clearly understand the difference between statistics and mathematics and what role context plays in doing and teaching statistics. Hence, the framework was designed to provide a conceptual structure for the teaching of statistics that gave a coherent picture of the curriculum. The main methodology for teaching the concepts of statistics was through the investigative cycle:

- formulate questions that can be addressed with data and collect, organize, and display relevant data to answer them;

- $\quad$ select and use appropriate statistical methods to analyze data;

- develop and evaluate inferences and predictions that are based on data; and - understand and apply basic concepts of probability. (Franklin et al., 2007, p. 5) The progression of the ownership of the investigative cycle was something that was spelled out in the report, with teachers having a more direct role at Level A and progressing toward a more passive role in Levels B and C. The report suggested that students act as the collectors of data in Level A but that teachers can help students take advantage of their innate curiosity and help them formulate statistical questions for investigation. Another recommendation, at the early stages, was for teachers to capitalize on natural occurring errors, when collecting data, to help students 
speculate about the impact on the final results. Because the authors suspected that teachers might not be prepared for some statistical procedures, they offer examples on simulations and other difficult concepts.

As a direct reaction to the creation of MET II (CBMS, 2012), the ASA-NCTM Committee released the SET report (Franklin et al., 2015) not only as a companion but also as a supplementary resource. Franklin (2014) commented that the ASA-NCTM felt that the MET II had not gone deep enough on their recommendations for teaching of statistics. Even though there were some recommendations, they were concentrated on the teaching of mathematics, so SET was conceptualized as a detailed source for statistical pedagogy with a better map toward understanding of the evolution of statistical topics and concepts from $\mathrm{K}-12$. Because the writing team for SET was headed by the same researchers as the GAISE report, SET was designed to build on existing $\mathrm{K}-12$ standards as recommended by the GAISE report, the NCTM standards, and the CCSSM.

The authors of SET (Franklin et al., 2015) suggested that there were three different goals when designing the document: to reach the appropriate audience for teacher preparation, to make recommendations and provide details for content and pedagogy, and to make recommendations for improving the training of teachers. The intended audience for the document was mathematicians and statisticians, mathematics educators, and policy makers. As reported by Franklin (2014), the writing team (Franklin et al., 2015) took the following six major recommendations from MET II (CBMS, 2012) as a beginning foundation for their work.

1. Prospective teachers need mathematics (statistics) courses that develop a solid understanding of the mathematics (statistics) they will teach. 
2. Coursework that allows time to engage in reasoning, explaining, and making sense of the mathematics (statistics) that prospective teachers will teach is needed to produce well-started beginning teachers.

3. Throughout their careers, teachers need opportunities for continued professional growth in their mathematical (statistical) knowledge.

4. All courses and professional development experiences for mathematics teachers should develop the habits of mind of a mathematical thinker, such as reasoning and explaining, modeling, seeing structure, and generalizing. Courses should also use the flexible, interactive styles of teaching that will enable teachers to develop these habits of mind in their students.

5. At institutions that educate teachers, teacher education must be recognized as an important part of a mathematics (statistics) department's mission and should be undertaken in collaboration with mathematics (statistics) education faculty. More mathematics (statistics) faculty need to become deeply involved in PreK-12 mathematics (and statistical) education by participating in preparation and professional development for teachers and becoming involved with local schools or districts.

6. Mathematicians (statisticians) should recognize the need for improving mathematics (statistics) teaching at all levels. Mathematics (statistics) education, including the mathematical (statistical) education of teachers, can be greatly strengthened by the growth of a mathematics (statistics) education community that includes mathematicians (statisticians) as one of many constituencies committed to working 
together to improve mathematics (statistics) instruction at all levels and to raise professional standards in teaching. (Franklin, 2014, p. 3)

As with the GAISE report, SET (Franklin et al., 2015) recommended that the teaching of statistics should be done thorough the statistical problem-solving process so that statistics topics could be developed through meaningful experiences. Staying with meaningful experiences, SET recommends that teachers preparation courses should be taught with an emphasis on active engagement and that lecture is not appropriate as a primary mode of instruction. With respect to pedagogy, the report emphasized the importance of connecting concepts in statistics with other areas in mathematics and how concepts in middle school built on elementary understanding. It is a little disconcerting that the report also recognized that at that time, there were no institutions offering courses specifically designed for preservice or in-service elementary teachers.

A more direct recommendation was that teachers develop pedagogical content knowledge necessary for effective teaching of statistics. Preservice and practicing teachers should be familiar with common student conceptions, content-specific teaching strategies, content-specific teaching strategies, strategies for assessing statistical knowledge, and appropriate integration of technology for developing statistical concepts. (p. 14)

Following that, the authors recommended that teachers should attend to common misunderstandings that students have with regards to statistics and develop strategies to address students' conceptions. Further, it was recommended that teachers have pedagogical knowledge to assess students' levels of understanding and plan for the steps needed to be taken to advance and develop students' statistical thinking. 
More precisely, and more pertinent to the teaching of statistics in middle school, the SET report (Franklin et al., 2015) gave some specific recommendations on the teaching of measures of center. In the problem-solving cycle, analyze data, the teachers were encouraged to recognize and use appropriate numerical summaries to describe characteristics of the distribution for quantitative data, such as mean or median for describing center, and range and IQR or MAD to describe variability. Also, teachers should recognize that the shape of the distribution, for quantitative data, influences the numerical summary for center and that the median is resistant to outliers. Keeping to the theme of comparison, teachers should realize that distributions are compared with respect to similarities or differences in center, shape, and variability and that the context of the original question is paramount in the comparison.

Following the recommendations for each grade level, the SET report (Franklin et al., 2015) gave examples of what an activity that brings up all the concepts previously discussed would look like. In the elementary example, it was expected that the teacher would help the students in writing a specific statistical question to investigate. The teacher was then expected to facilitate the data collection process by helping students determine how data would be collected and design an appropriate and feasible experiment. In analyzing data, the teacher was expected to use graphical displays and numerical summaries to help students identify patterns present in the variability pertinent to the question at hand. In the last step of interpreting results, teachers should help students using the results to answer the question investigated. In this example there was an example of the data collected, so the SET report gave actual recommendations for that specific situation and different ways to look at the data with graphical displays and numerical summaries. 
The recommendations put forth by the ASA and NCTM joint policy paper (2013) were not as detailed as the SET or GAISE reports; however, they encompassed every stakeholder in the education of PSTs and continued education of in-service teachers. The paper emphasized the growing importance of statistics as a scientific field of study, and that teachers must have deep knowledge and understanding of both content and pedagogy. The paper recommended supporting in-service teachers by their administrators through opportunities for PD, and support by professionals creating PD to model effective teaching pedagogies and deeper understanding of statistical concepts, both boosting their knowledge of content, statistical thinking, and problem solving. For preservice-teacher educators, recommendations revolved around creating courses that familiarize future teachers with pedagogies appropriate for the classroom, as outlined by policy documents. Similar recommendations were given for faculty members who teach statistics and for state departments of education.

Teacher knowledge of content. As mentioned by Russell and Mokros (1990) teachers have similar knowledge, or lack thereof, that their students have. This part of the review will concentrate on teachers' (both preservice and in-service) knowledge and conception of the average and its incarnations as mean, median, and mode (Aemah, Asiedu-Addo, 2014; Begg \& Edwards, 1999; Callingham, 1997; Gfeller, Niess, \& Lederman, 1999; Groth \& Bergner, 2006; Leavy, O’Loughlin, 2006); knowledge of the algorithm (Chatzivasileiou, Michalis, Tsaliki, \& Sakellariou, 2011; Jacobbe, 2008); and the conflict that arise deciding on which measure of center better represents the data (Jacobbe, 2012).

Conception of the average has been tested in two different ways: directly by asking participants to find the average from a set of data (Callingham, 1997; Chatzivasileiou et al., 2011; Jacobbe, 2008) and indirectly (Mokros \& Russell, 1990, Leavy \& O’Loughlin, 2006; 
Russell \& Mokros, 1995) by asking participants to create the distribution once they are given the average. These two different methodologies give different results for what teacher's knowledge looks like, but they offer similarly gloomy prognosis on the state of teachers' content knowledge of measures of center.

When directly asking participants to find a mean, median, or mode, researchers have found an appreciation of the add-and-divide algorithm without finding any evidence of conceptual understanding (Aemah \& Asiedu-Addo, 2014). With 140 Ghanaian PSTs in two consecutive academic years, the authors found that most students could use the algorithm to find the mean of the data; however, when given the mean and asked what it meant, as many as $60 \%$ of students gave wrong answers, and less than $3 \%$ of students described the average as a representative value for the data set. Begg and Edwards (1999) asked their participants (22 elementary in-service teachers and 12 PSTs): "What is average" and "what comes to mind when you think of average?” (p. 3). Results suggested a general lack of familiarity with the terms of mean, median, mode and suggested that there was a difference between the groups with PSTs coming out on top. With recognition of the mean, $55 \%$ of in-service and $67 \%$ of PSTs had the correct conception, with the mean only $33 \%$ and $83 \%$, respectively, and mode only $37 \%$ of inservice and $75 \%$ of PSTs.

Similarly, when Groth and Burgner (2006) asked 46 PSTs to discuss similarities and differences between mean, median, and mode, they found that eight of them gave answers that only contained definition-telling, no strategies or comparisons between the measures. In their analysis, the authors thought of those eight PSTs' answers as unistructural responses, at the multistructural level (21 PSTs) added a vague notion that mean, median, and more were tools utilized in analysis of data. At the relational level (13 PSTs), the authors saw responses that also 
included recognition that those were measures of center of data or what is typical of the data in some manner. At the highest level, extended abstract (three PSTs), responses included a discussion about when one measure of center would be better than another.

Indirect methodology was first conceived by Mokros and Russell (1990) and Russel and Mokros (1995) and expanded upon by Leavy and O'Loughlin (2006). Connections between Mokros and Russell and Leavy and O'Loughlin come in the identification of the strategies that participants (teachers) used in constructing the distribution. Although Mokros and Russell (1990) indicated four main strategies for solving the problem, the Leavy and O'Loughlin (2006) only identified three different strategies. However, there are similarities in the way that participants used mean to construct the distribution. When Mokros and Russell identified the first strategy as "average as mode," Leavy and O'Loughlin used "strategies based on some manipulation of the mean algorithm." From the excerpts, it can be seen that both groups of students used the mean as the mode and median and constructed the distribution by adding numbers around the mean.

Because Leavy and O'Loughlin (2006) did not prompt the participants to not use the mean as a value of the distribution in the first task, they only had 3\% of responses that did not use the mean, with $88 \%$ correct responses. In the second task, results changed from $88 \%$ to only $64 \%$ correct answers. Incorrect responses increased from $5 \%$ in the unrestricted task to $16 \%$, and the number of participants who did not attempt the task rose from $7 \%$ to $20 \%$. An interesting finding was that it may be concluded that the understanding of mean as "middle" was certainly more dominant than the understanding of mean as "balancing point." The notion of the mean as the middle of a distribution in which values were distributed evenly around the mean was demonstrated in $26 \%$ of the responses. 
Knowledge of the algorithm is an important subject and has been researched by many (Begg \& Edwards, 1999; Callingham, 1997; Chatzivasileiou et al., 2011; Jacobbe, 2008). Working with 130 Greek in-service elementary school teachers, Chatzivasileiou, Michalis, Tsaliki, and Sakellariou (2011) used Strauss and Bichler's (1998) eight properties (previously explained in this review) to understand teachers' knowledge. However, where this study differs is that the methodology used was that of Mokros and Russell (1995) in which they asked a similar question to the potatoes chip problem, asking teachers to create a distribution when the average was given. The authors confirmed the findings that Strauss and Bichler (1998) reported with 12- to 14 -year-olds: that $26 \%$ of these teachers had similar difficulties when a value of 0 was introduced in the data. The authors reported that their findings implied that teachers, even though they could apply the algorithm, had conceptual weakness with understanding of average as a measure that summarizes data that is representative of the values. The replies indicated that teachers were familiar with the terminology but had difficulties in using measures of center to solve real-life situations.

Working with 100 PSTs and 36 in-service middle and high school teachers, Callingham (1997) asked his participants to find the average of a measurement data set with one clear outlier. The author found that only one teacher mentioned the outlier in calculating the average and that two teachers had eliminated the lowest and highest observations, competitive diving methodology, when finding the average. It is disconcerting that four teachers found a mean outside the range of values and made no attempt to correct their mistake. That fact prompted the author to suggest that these teachers had little understanding of the meaning of their calculations but applied the procedure without taking into account the question or the answer (Jacobbe, 2008). Similar findings were reported by Begg and Edwards (1999): that all teachers showed 
understanding of the algorithm but either partially understood it or did not notice mistakes in its application by students.

Choosing the best measure of center is a concept that has its own recommendation for both teachers and students as well as a good chunk of the literature on the understanding of the conception of the average (Callingham, 1997; Groth \& Bergner, 2006; Zawojewski \& Shaughnessy, 2000). In the work that I just introduced from Callingham (1997), it is interesting that none of the teachers, when choosing the average of data with a clear outlier, chose to find the median; instead, they all chose to find the mean. Similarly, Jacobbe (2008) reported that when asked to comment on the differences between the mean and median, two of the three teachers could not explain what these measures represented, with one of them not even realizing there was a difference between these measures of center.

Similar findings to Callingham (1997) were reported by Chatzivasileiou et al. (2011). When asked to choose the method that gave the more accurate results for measure of center, only $33 \%$ of teachers chose the mean while excluding outliers. With $25 \%$ of the teachers choosing the mean of all values, $16 \%$ the mode, $13 \%$ the more detailed value (where all values had a one digit after the decimal, the chosen value had two digits after the decimal), and only $9 \%$ of 130 teachers chose the median of the data as the average. While working with the results from the National Assessment of Educational Progress (NAEP), Zawojewski and Shaughnessy (2000) found that when given a choice, eighth- and 12th-grade students chose the mean over the median without consideration of the distribution of the data.

Conclusions. It is easy to despair and to throw one's hands up and say that teachers are just not prepared to teach statistics, and the evidence would surely support such claims. However, I see that there is a movement toward getting teachers better prepared, which is 
evident from the ASA-NCTM collaboration on the Joint Position Paper and the publication of the GAISE and SET reports. So, from the recommendations, it is clear that statistics should not be taught as separate algorithms or just as lectures and that statistics should be taught through investigations and the use of the problem-solving process. Both elementary and middle school teachers need to have a better understanding of the concepts behind the measures of center, and they also need to be better prepared through pedagogy. Teachers need to learn what conceptions their students have, how best to improve students learning, and what strategies would best work.

This review of teachers' knowledge helps me understand the kinds of vignettes that I have to include in order to try to understand their knowledge of pedagogy. It seems realistic to think that a vignette needs to bring up the question of representativeness of the mean and what better way to do that than to use the Mokros and Russell (1995) ideas and use a vignette to create a distribution given the typical value. It would be easy to see that a prompt would have to ask teachers how we can change the problem to get at the misconception of mean as mode. I want the teachers to suggest not being able to use the mean as a point in the data. The idea of using a vignette to bring up the conflict between mean and median needs to happen, and also the inclusion of 0 as one of the points in the data, to bring up the issues both teachers and students had with Property F from Strauss and Bichler (1998). The concept of weighted means was well documented with the students, and it came up with the teachers, even though less often, so a vignette that brings up the calculation of the weighted mean should be part of the vignettes.

This study was designed to understand what pedagogical knowledge middle school teachers bring to the teaching of statistics. Aspects of teachers' KCS will be solicited through questions about student misconceptions and solving strategies. Aspects of teachers' KCT will be brought up, analyzing procedural and conceptual teaching and talking about specific strategies 
for teaching. Knowledge of curriculum will be analyzed through curriculum questions in the focus group interviews. All this is done to get a clear picture of what PCK in statistics looks like with in-service teachers, something that has not been done in the United States.

These components were taken directly from the literature, curriculum documents, and recommendations in which the prevailing content was the investigative process. Starting with the GAISE report (Franklin et al., 2007), the main recommendation for the teaching of statistics was through "data collection design, exploration of data, and interpretation of results should be emphasized in statistics education for statistical literacy ... [which] are heavily dependent on context” (p. 9). Franklin et al. (2007) recommended that the teaching of statistics should revolve around the investigative process: formulate questions, collect data, analyze data, and interpret results. From those recommendations come the first set of components of my framework. I concentrated on the first two levels because that is when measures of center are introduced and because those levels coincide with teaching in the elementary and middle school recommendations.

It is logical to think that the recommendations that were put forth in the GAISE report (Franklin et al., 2007) would coincide with and be supported by the later recommendations from the SET report (Franklin et al., 2015). Hence the last two components speak to the point that teachings statistics should be through the investigative cycle while keeping in mind that teachers should always make connections to other areas of mathematics and that real data should be used. Making connections to other areas of mathematics would be beneficial in students realizing that statistics is related to mathematics and to give students a way to scaffold their learning from something that they are already familiar with. Real data would allow the students to be more 
involved (active learning) and invested in the results and the recommendations of the investigation.

$\mathrm{KCT}$ is the knowledge that combines the knowledge the teacher has about teaching and their knowledge about the content (statistics). For this study, KCT will refer to the teaching strategies (types of questions, activities, examples, statements) that teachers use during instruction. The creation of these components was easier because there are several documents that advocate for the teaching of statistics (CCSSI, 2010; Franklin et al., 2007, 2015; Kader et al., 2013; NCTM, 2000). What follows in Table 3 is the conceptualization of the framework for KCT.

Table 3

Expected Framework Components of Knowledge of Content and Teaching

\begin{tabular}{ll}
\hline \multicolumn{1}{c}{ Code } & \multicolumn{1}{c}{ Description } \\
\hline T1 & Teach statistics through the investigative process. \\
T1a & - Formulate Questions \\
T1b & - Collect Data \\
T1c & - Analyze data \\
T1d & - Interpret results \\
T2 & Connect statistics to other areas in mathematics. \\
T3 & Relying on exploration of real data. \\
T4 & Making effective use of technology and assessment. \\
\hline
\end{tabular}

\section{Expected Statistical Knowledge for Teaching Framework}

What follows is the complete framework for the conceptualization of PCK needed for teaching measures of center in middle school. I have to note that this might not be all the knowledge needed nor is it the only knowledge needed to teach. However, this framework is 
derived from the research, which means that this is the knowledge that I examine in relation to the expected knowledge for teaching statistics.

Table 4

Expected Statistical Knowledge for Teaching Measures of Center

Code Description

Knowledge of Curriculum

C1 Students should understand the median as a central point.

C2 Students should have a conceptual understanding of the mean: fair share, balance point

C3 Students should understand that mean, median, mode is a way of representing the data using a single number.

C4 Students should relate the choice of measure of center to the shape of the distribution and context the data were gathered.

C5 Students should make connections between measures of center and variability.

Knowledge of Content and Students

S1 Students tend to think of minimums and maximums as outliers.

S2 Students tend to ignore 0 in the data set when computing measures of center.

S3 Students tend to not order data before finding the median.

S4 Students tend to use the mode in the beginning to represent typicality.

S5 Students tend to ignore mean when it is not part of the data.

S6 Students tend to have difficulty calculating weighted means.

S7 Students tend to only know the mean procedurally.

Knowledge of Content and Teaching

T1 Teach statistics through the investigative process.

T1a - Formulate Questions

T1b - Collect Data

T1c - Analyze data

T1d - Interpret results

T2 Connect statistics to other areas in mathematics.

T3 Relying on exploration of real data.

T4 Making effective use of technology and assessment. 


\section{Research on Animations}

As computing power (capturing, viewing, and sharing videos) has grown and become more sophisticated, so have the ways that teacher educators use videos in their practice (Danielowich, 2014). Videos have been incorporated from PD programs (Borko, Jacobs, Eiteljorg, \& Pittman, 2006), methods courses (Gaudin, Flandin, Ria, \& Chalies, 2014; Liston, 2015; Santagata \& Guarino, 2011), and computer learning environments (Meyer, Lampron, \& Gazé, 2014) to the field of teacher noticing (Jacobs, Lamb, \& Philipp, 2010; Star, Lynch, \& Perova, 2011; Star \& Strickland, 2008). Primarily, videos have been used in two different ways: as an artifact to be analyzed and as a tool to help develop knowledge. In the subsequent paragraphs, I synthesize the research on videos and explain the natural progression from videos to computer-generated animations for use in research.

Videos as tools to be analyzed have been used since the Third International Mathematics and Science Video Study (1999; Hiebert et al., 2004), which gave video evidence of different teaching styles around the world. Jacobs, Lamb, and Philipp (2010) used video clips of teaching to study the noticing of children's mathematical thinking through the eyes of $\mathrm{K}-3$ teachers. Kersting, Givvin, Thompson, Santagata, and Stigler (2012) used classroom video clips of fractions to analyze teachers' usable knowledge. Konig et al. (2014) presented video clips to be analyzed and interpreted by teachers with the goal of confirming that video analysis was as good as paper-and-pencil tests to assess general pedagogical knowledge. Similarly, Liston (2015) used video of a PST's lesson to confirm the potential of videos and the "Knowledge Quartet" (p. 3) in framing teacher education programs.

Videos have also been used widely in teacher education programs, be it PD or methods courses. Meyer, Lampron, and Gazé (2014) used videos, in a distant learning teacher training 
program, to study the evolution of the teachers' interaction with each other when analyzing videos. Santagata and Guarino (2011) examined ways that they used videos to develop elementary PSTs' knowledge through teaching. Santagata and Guarino commented that the main purpose was for teachers to learn to appreciate the complexities of students' thinking and ability with mathematics and that videos were a great vehicle for such teaching. Borko, Jacobs, Eiteljorg, and Pittman (2006) used videos as a tool to foster productive discussions about teaching in a PD program. In this program, the videos were from the participating teachers' classroom and were used to create a community in which teachers felt comfortable discussing their own teaching and learning from others' feedback. In a similar spirit, Danielovich (2014) used videos of teachers themselves teaching, to provide support for PSTs and to advance their thinking associated with goals they had for their own practice.

It has been argued that videos are a great way to elicit teachers' knowledge in general and pedagogy in particular (Kersting, 2008; Kersting, Givvin, Sotelo, \& Stigler, 2010; Liston, 2015). These authors have argued that analyzing videos can be as powerful, if not more so, than the results that are achieved through the Learning Mathematics for Teaching (LMT; Ball et al., 2008; Hill et al., 2008; Hill \& Lubienski, 2007) items alone. Another leap comes from Herbst, Chazan, Chen, Chieu, and Weiss (2011), who argued that comic-based representations of teaching can be powerful substitutions of videos, in seeing the mathematics taught in the lessons that were observed, allowing PST's to explore decisions made in the classroom while teaching and supporting teachers in acting out classroom situations. Furthermore, Herbst et al. argued that comics could enable a high degree of control over the content as well as the possibility of highlighting issues that might not show up in most videos. 
In their research, Herbst and colleagues (Chazan \& Herbst, 2012; Herbst \& Chazan, 2015; Herbst \& Kosko, 2014) have argued that comics can be used instead of videos in analyzing and helping teachers develop knowledge. The authors argue that comics allow the researcher to craft a situation that would otherwise not be found in videos. Another issue that was brought up by researchers in teacher noticing, teachers being distracted by situations other that the mathematics being assessed, can be alleviated through comics. Star, Lynch, and Perova (2011) and Star and Strickland (2008) found that PSTs were able to improve their noticing of a mathematics classroom; however, they still had issues with noticing tasks and with the actual mathematical content being discussed. Keeping in mind the ideas of Herbst and colleagues, I am using a comic, CGAs, in order to elicit teachers' knowledge of pedagogy. As Herbst advocated, I am using comics because it gives me the opportunity to control the narrative and what teachers pay attention to. These CGAs concentrate on eliciting different aspects of teachers' PCK when introducing the measures of center in middle school statistics.

\section{Chapter Summary}

The literature review is designed for me to give some evidence of the need for this study. I started this chapter by discussing where we, as researchers, started with the idea of PCK (Shulman, 1986). I discussed how Shulman did not think that content knowledge was the only knowledge needed to teach school mathematics. That mantle was taken by Deborah Ball and her colleagues at the University of Michigan, who later conceptualized the Egg Model (Ball \& Bass, 2003) for the knowledge needed to teach mathematics and called it MKT. This model showed the two major components of MKT: knowledge of content and PCK. 
Later on, when conceptualizing the knowledge needed to teach statistics, researchers like Groth (2007) gave some evidence about why statistics was different from mathematics and that maybe the PCK models for teaching mathematics might need to be reconceptualized for the teaching of statistics. Several models (Batanero \& Diaz, 2010; Burgess, 2007; Godino et al., 2011; González, 2016; Groth 2007, 2013; Watson, 2001; Watson et al., 2009) have been put forth for what SKT should look like, and again knowledge of content and PCK for teaching statistics are major components.

After a discussion of what all these models look like, I put forth my argument as to why I needed to create a framework that took the major components of PCK from Ball and Bass (2003) and the research present for teaching statistics. As Groth (2013) and other researchers have concluded, the framework for PCK (Ball \& Bass, 2003) needs to be adapted to statistics, which is what I did with my conceptualization of the expected statistical knowledge needed to teach measures of center framework. I gave evidence of the curriculum recommendations put forth by research, and I laid out the research on the knowledge of measures of center that students have to support the components of the framework. I also have given evidence of what knowledge teachers have and the ways that research and other documents recommend that statistics be taught in school mathematics. That research has given birth to the components of the framework on teacher KCT. What I hope to have done with this chapter is to give some evidence supporting the need for this study and the decisions that I made that directed the methodology of this study. 


\section{CHAPTER III: METHODOLOGY}

\section{Introduction}

In the previous chapter, I have highlighted some of the literature and, thus, situated this study in the context of PCK as it relates to statistics in middle school. With this study, I sought to understand the PCK that teachers bring to the teaching of statistics in middle school, specifically the introduction of measures of center. This chapter provides descriptions of the data sources, the methods used to analyze the data, and the rationale behind these decisions. I used a case study design in which the data were analyzed using qualitative methodology to look for themes and patterns.

\section{Research Paradigm}

My research paradigm for this study will be a postpositivist approach (Ernest, 1994). The field of mathematics education has been experiencing a paradigm shift in the last quarter century. We have moved away from the positivist approach of scientific research and random samples in order to validate our research and toward a more holistic view of research (Schoenfeld, 2007). With my research, I reveal a glimpse of the reality that the teacher experiences in the classroom through their interpretation and criticism of classroom situations. The teachers will have the opportunity to reflect on their own teaching, consider their students' knowledge, and be exposed to at least one different interpretation of the measures of center that they might use in their classroom. Within this paradigm, I am not trying to present generalizations about the subject of my query; however, I am trying to give one possible vision of the reality of teaching statistics in middle school. 


\section{Participants}

In this study, I used purposeful sampling (Ernest, 1994) because I was looking for middle school teachers of mathematics who had taught statistics at least once in their career. The sample of teachers was derived from several school districts in the Midwest. All teachers volunteered for the study. Teachers were certified to teach middle school, and most of them had a specialization in mathematics, which was not required. I did not differentiate on the perceived competency of the teachers. Two different methods were used to solicit teachers to take part in the study. An email was sent asking for teachers who had taught the subject of statistics at least once who were interested in taking part in the study. Interested teachers then received a consent form to fill out and confirm their participation in the study. I also solicited participants at a mathematics conference for in-service teachers.

The sample included eight teachers (see Table 5). Five of these teachers were solicited for participation at a mathematics teacher conference, one was just starting her graduate studies at a Midwestern university, and two were solicited from an email invitation sent to middle school teachers in the Midwest. Two of the teachers did not experience any coursework including data analysis during their undergraduate studies, three of these teachers did not have any methods course in their education that included data analysis, and three of them had not had any PD that included data analysis. The teachers were given a \$30 Amazon gift card for participating in the online CGA portion of the data gathering. Only three of the teachers were available to take part in the second portion of the study, the semi-structured individual interviews, and they were again compensated for their time. 
Table 5

Responses to Initial Survey Questions

\begin{tabular}{lcccc}
\hline & $\begin{array}{r}\text { Taught at } \\
\text { least twice }\end{array}$ & Content courses & Methods courses & $\begin{array}{c}\text { Professional } \\
\text { development }\end{array}$ \\
\hline Angela & Yes & Yes & No & No \\
Jonathan & Yes & No & No & Yes \\
Susan & Yes & No & No & No \\
Jennifer & Yes & Yes & Yes & Yes \\
Monika & Yes & Yes & Yes & Yes \\
Brenda & Yes & Yes & Yes & Yes \\
Miranda & Yes & Yes & Yes & No \\
Kasy & Yes & Yes & Yes & Yes \\
\hline
\end{tabular}

\section{Procedure}

The data that were analyzed in this study were collected from the participants in three different stages, not every teacher participated in all three stages. The first stage of the data collection was the initial survey, which was designed to get the teachers thinking about the subject of statistics and to gather some background data (as shown in Table 5); all eight teachers completed the initial survey. The second (main) data source was a set of seven computergenerated animations (CGAs), which all eight teachers completed. The last data source was the individual interviews, which only three teachers were able to complete. After I finished gathering data from the main data source, I took 2 weeks to look at the data available so that I could better design the questions in the individual interviews. For the first two stages, initial survey and responding to seven CGAs, the teachers could have been finished in one session; however, the interviews were conducted at least 3 weeks after the initial survey because of scheduling conflicts, as well as to give time to the researcher to conduct a cursory analysis of the data. This analysis was used to inform the questions that were used in the semi-structured interviews. 


\section{Instruments}

In the initial survey, aside from the background questions, I also included three additional questions (see Appendix B for the complete script). This initial questionnaire was designed to solicit teachers' knowledge of content, students, and teaching. The first question asked teachers "What major ideas do you want to bring across when teaching measures of center to your students?" This question was designed to get teachers thinking of important content and curriculum ideas that they would want their students to remember when leaving the classroom. The second question asked teachers "What challenges, have you seen, or do you expect your students will have in learning the content?" This second question was designed not only to get teachers thinking of their students' struggles but also to bring up any persisting misconceptions that their students have. The last question asked: "How have you, or how do you plan to address those challenges?" In keeping with PCK ideas, this question prompts teachers to talk about their KCT by discussing ways they have addressed issues with teaching statistics.

As mentioned above, the main source of data collection was responses to prompts from seven CGAs. These animations were designed to present teachers with several situations that could be encountered in the classroom. Animations were used because it gave me the opportunity to present teachers with the exact situation that I wanted with no distractions. Each animation starts with the teacher posing a question and giving students time to solve the question, and then students present solutions and pose their own questions. Once the animation

ends, the teachers are prompted to answer questions designed to solicit knowledge related to curriculum, students, and teaching. One prompt asks teachers to evaluate which students has the most sophisticated answer, soliciting their KCS. One prompt asks teachers to respond to specific 
student comments, soliciting their knowledge of students (recognizing student strategies) and their knowledge of teaching (responding with teaching strategies).

The last data gathering opportunity came from the post-CGA responses in the form of the semi-structured interviews. An interview protocol was designed to ask the teachers about the three major components of the framework. This was done by reminding the participants of their responses and asking for clarifications or additions. It was seen fit to not repeat all the responses to the videos because there would arise the need to see all the videos again. So, I created one more video with three distinct sections, which were designed to bring up some of the more interesting situations encountered in the CGA's, but the context was changed a little to not seem repetitive. In the first section, the teacher presents two very different distributions with the same mean and median, and then a student makes the observation and asks how this could be possible. All three teachers were asked if they had encountered the situation in their teaching and, if so, how they handled it.

The second section asked the students to create a distribution when the mean was known. Again, there were two questions: "Have you ever tried this activity in your classroom," and "How did or would your students answer this question?" The last section of the video introduced the students to 11 pieces of data representing the number of books that students read during the summer. A student quickly calculates the mean, and the teacher then introduces two more students (the first student has read eight books), and she asks: "How many books should this last student have read in order for the mean to stay the same?" The participants again were asked if they had done this activity in the classroom; then, they were asked how their students answered or how would their students answer. 


\section{Development of Computer-Generated Animation Protocol}

In this section, I introduce the different steps for creating the main instrument for data collection, including design and piloting. The main data collection instrument was developed in three steps: writing the script for the vignettes from research literature, creation of CGAs, and two piloting cycles. The vignettes were designed with the idea that the teacher in the animation would pose a question or an activity, and the students would respond to the questions. The prompt that are used after each vignette were specifically designed with the intention of assessing different aspects of teacher knowledge with regard to the teaching and learning of measures of center. The problems posed, as well as the students' comments, were typical of examples from research on students' knowledge of statistics (Cai, 1998; Russell \& Makros, 1990; Strauss \& Bichler, 1998). A complete transcript of all vignettes with their corresponding prompts is available in Appendix A.

In the first vignette, the teacher first introduces a set of data and then introduces a procedure for finding the mean, and uses the data to find an answer, then students are given data and asked to repeat the procedure to independently find an answer. The first vignette was divided into three portions in which the teacher introduced the procedures finding mean, median, and mode. The reason for the introduction of this style was so that teachers could have the opportunity to negate, or validate, this style of teaching and to discuss how they themselves taught the subject. The prompt, asked in all three portions of this vignette, asked the teachers to "comment on differences or similarities between the way you introduce the measures of center (mean, median, mode) and the way the teacher in this video did."

The content, of the second vignette was to discuss measures of center as "typical" instead of mean, median, mode. In this vignette, the teacher introduces data gathered from the students 
(shoes) and ask students to find the typical weight. The data are not ordered, and at the end, there is a piece of data that seems like an outlier. One of the students finds the mean of the data, and another student eliminates the supposed outlier (with no comment on identifying the outlier) and finds the mean. A third student eliminates the smallest and largest data points and then finds the mean, and the fourth student, who considers the outliers, chooses to use the median (wrongly identified). Lastly, the first student comments on his confusion about always using the mean without consideration of distribution. Student responses and issues with the content were consistent with previous research (Tarr \& Shaughnessy, 2003; Zawojewski \& Shaughnessy, 2000). The corresponding prompts were:

1. Please identify which student or students seem to be struggling with the idea of measures of center and explain why.

2. How would you help these students improve their conception (please talk about each child individually)?

In the third vignette, the teacher gives data (again gathered from students) and asks students to find the representative number of pets for the class. The student responses are the main focus of the vignette, with issues related to the concepts of not including 0 in the calculations and not accepting a mean that is not representative of the data. In this vignette, students are also struggling with choosing the best measure of central tendency, with Sallie not accepting the mean because it was a rational (2.375) number that was not representative of the data and Joey calculating the mean without including a piece of data ( 0 pets for a student). All these issues and struggles are derived from the literature on students' knowledge of measures of center (Cai, 1998; Russell \& Makros, 1990; Strauss \& Bichler, 1998; Tarr \& Shaughnessy, 2003). The corresponding prompts were: 
1. How would you respond to Sallie's comment?

2. How would you respond Joey's question about whether to include 0 in the calculation of the mean?

In vignettes two and three, the prompts were designed to solicit teachers' KCS, by identifying weak responses, and to solicit their KCT, by identifying strategies to help students.

The fourth vignette was specifically designed with the goal of introducing teaching styles that were discussed in the literature. The fourth vignette introduced the idea of mean as fair share (NGA \& CCSSO, 2010; Progressions, 2013; NCTM, 2000). The teacher allocates a set number of cubes $(7,6,10,9)$, representing money, to each of four students then asks the students to redistribute the cubes so that all had the same amount (8). The corresponding prompts asked:

1. What concept of measures of center would you connect this activity to?

2. Explain how you would make that connection.

The fifth vignette highlighted the struggles that students have when calculating weighted means (Gattuso \& Mary, 1998; Leavy \& O'Loughlin, 2006). The teacher introduces a situation in which four men and two women are in an elevator, gives the average age of the men and the women, and then asks the students to find the average age of the people in the elevator. The prompts following this vignette asked the teachers how they would respond to specific student answers. The reasoning behind the prompts was for teachers to talk about their knowledge of teaching and to volunteer ways to help the students. Another reason was also for teachers to exhibit their KCS, by recognizing that some students had wrong conceptions.

The sixth vignette asked a question adapted from the literature: If you have seven boxes of pencils with a mean of 15 pencils, what seven numbers could represent the number of pencils in each box? Students' initial answers were also taken from the literature, with students 
constructing the distribution modally (all seven observations were 15$)$ or symmetrically $(12,13$, $14,15,16,17,18,19)$. The prompts asked the teachers to comment on students' thinking. The second part of this vignette followed the situation from Makros and Russell (1995), asking the students what they would do if the value 15 was not allowed to be used. The two prompts that followed this part of the vignette asked teachers to help students with the new development.

The last vignette introduced a distribution (Figure 10) and its mean of $\$ 13.60$, median $\$ 12$, and mode as $\$ 11$. The students were asked to decide which measure of center would appropriately represent the data.

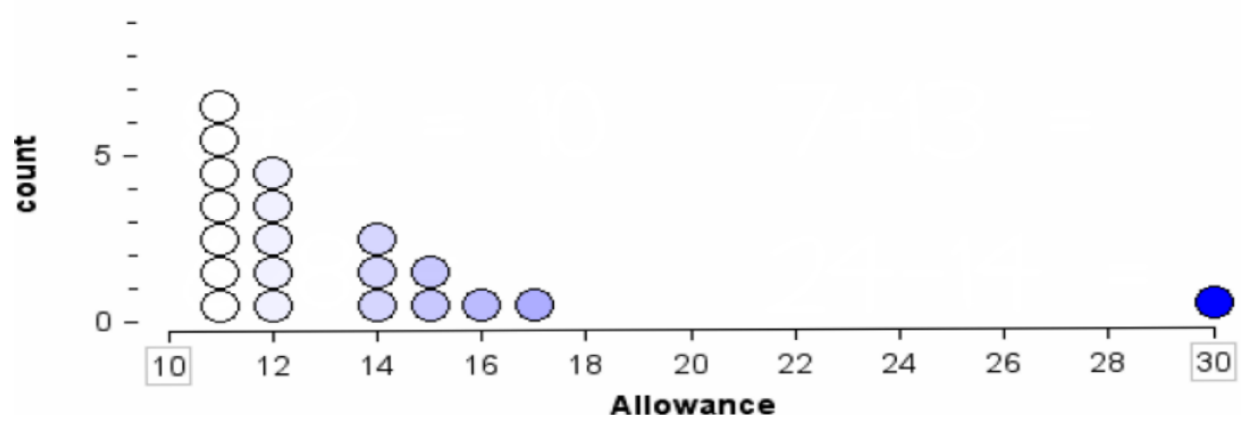

Figure 10. Distribution graph for CGA 7. Graph showing a distribution presented to the teachers in the seventh CGA. It shows how many students reported a given allowence.

Issues with choosing the correct measure of center were identified by the literature (Tarr \& Shaughnessy, 2003; Zawojewski \& Shaughnessy, 2000). The corresponding prompts are:

Prompt 1: Please identify which student/students seem to be struggling with the idea of measures of center, and explain why.

Prompt 2: How would you help these students improve their conception (please talk about each child individually)?

The first prompt was designed to get participating teachers talking about the students' knowledge, conceptions, and responses individually, soliciting their knowledge of content and 
students. The second prompt was designed to get teachers discussing ways to help students better understand the concepts of measure of center, this prompt was designed to solicit the teachers' knowledge of content and teaching.

Table 6 shows which component of the expected framework knowledge was solicited from each vignette. As an example, the second vignette, finding typicality from data of weight of shoes, could have solicited teachers to discuss their students' understanding of the mean as well as which measure of center to choose, depending on characteristics of the distribution. The second vignette could have also prompted teachers to discuss their students understanding of outliers, issues with finding median, and the idea that students tend to ignore the mean when it is not part of the data.

Table 6

Vignettes to Framework Chart

\begin{tabular}{|c|c|c|c|c|c|c|c|c|}
\hline \multirow[b]{2}{*}{ Code } & \multirow[b]{2}{*}{ Description } & \multicolumn{7}{|c|}{ Vignettes } \\
\hline & & V1 & $\mathrm{V} 2$ & V3 & V4 & V5 & V6 & V7 \\
\hline \multicolumn{9}{|c|}{ Knowledge of Content and Curriculum } \\
\hline $\mathrm{C} 1$ & $\begin{array}{l}\text { Students should understand the median as } \\
\text { a central point. }\end{array}$ & $\checkmark$ & & & & & $\checkmark$ & $\checkmark$ \\
\hline $\mathrm{C} 2$ & $\begin{array}{l}\text { Students should have a conceptual } \\
\text { understanding of the mean: fair share, } \\
\text { balance point }\end{array}$ & & $\checkmark$ & & $\checkmark$ & $\checkmark$ & $\checkmark$ & $\checkmark$ \\
\hline $\mathrm{C} 3$ & $\begin{array}{l}\text { Students should understand that mean, } \\
\text { median, mode is a way of representing the } \\
\text { data using a single number. }\end{array}$ & & & $\checkmark$ & & $\checkmark$ & & \\
\hline $\mathrm{C} 4$ & $\begin{array}{l}\text { Students should relate the choice of } \\
\text { measure of center to the shape of the } \\
\text { distribution and context the data were } \\
\text { gathered. }\end{array}$ & & $\checkmark$ & & & & & $\checkmark$ \\
\hline
\end{tabular}




\begin{tabular}{lllllllll}
\hline & \multicolumn{8}{c}{ Vignettes } \\
\cline { 2 - 7 } Code Description & V1 & V2 & V3 & V4 & V5 & V6 & V7 \\
\hline
\end{tabular}

C5 Students should make connections between measures of center and variability.

Knowledge of Content and Students

S1 Students tend to think of minimums and maximums as outliers.

S2 Students tend to ignore 0 in the data set when computing measures of center.

S3 Students tend to not order data before finding the median.

S4 Students tend to use the mode in the beginning to represent typicality.

S5 Students tend to ignore mean when it is not part of the data.

S6 Students tend to have difficulty calculating weighted means.

S7 Students tend to only know the mean procedurally.

Knowledge of Content and Teaching

T1 Teach statistics through the investigative process.

T1a - Formulate Questions

T1b - Collect Data

T1c - Analyze data

T1d - Interpret results

T2 Connect statistics to other areas in mathematics.

T3 Relying on exploration of real data.

T4 Making effective use of technology and assessment.

Note. Tick marks mean that that component of the framework was solicited by the corresponding vignette.

\section{Creation of Computer Generated Animations (CGA)}

In the next step, a web-based program (GoAnimate) was used to transform the vignettes into animations. I started looking online for different platforms, and GoAnimate was chosen for 
its ease of use, multiple character options, and ease of changing backgrounds and imbedding graphs, audio, and pictures from outside of the program.

The process of creating the animations became less daunting once I had finalized the vignettes. There were two different classrooms to choose from, lecture style and more private classroom, and I chose the classroom because I was able to see the teacher and the students in the same frame.

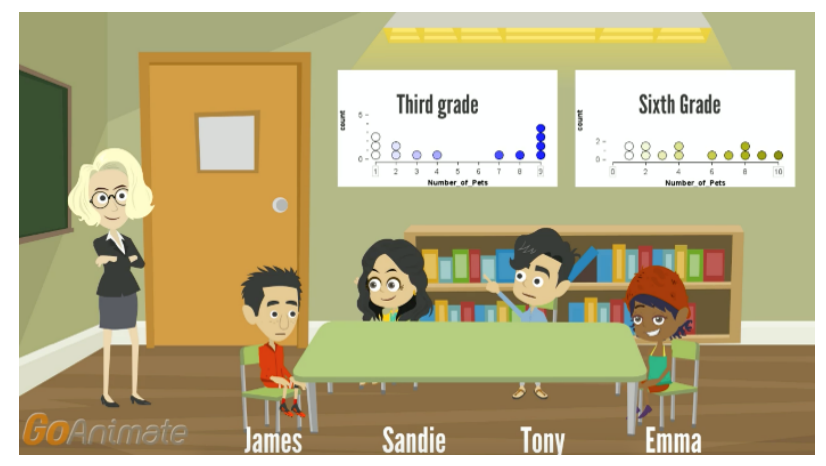

Figure 11. Classroom used in the fourth CGA. This was a screenshot from the fourth CGA, which includes the teacher (left) and four students. Tony (raised hand) is the one speaking.

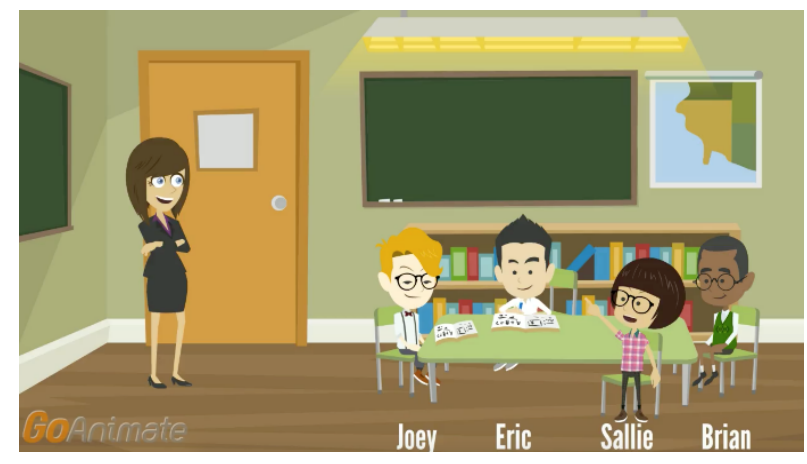

Figure 12. Classroom used in the first three CGAs. This figure is a screenshot from the first CGA. In this shot, Sallie (standing, raise hand) is the one talking.

This gave me the option of changing the teacher and changing the students, names, and what is in the background (as seen in Figures 11 and 12). The program allowed me to either include my 
own recording for what was being said, or to allow the computer to read the transcription with different voices. There were only three male voices, which was fortunate because I was using three males as students, and multiple female voices, which gave me some choices for the four female characters. The program also allowed me to change the students' actions within frames. I made the student talking get up and raise her or his hand in order for the viewer to distinguish which character was speaking. After the animations were finalized, I used Select Survey to create the platform with which the teachers would interact. Through Select Survey, I set up seven pages, each of which started by prompting the participants to watch a video (the animations) and then answer two to six prompts related to the animation. The following figure is a screenshot of what the teachers would have seen.

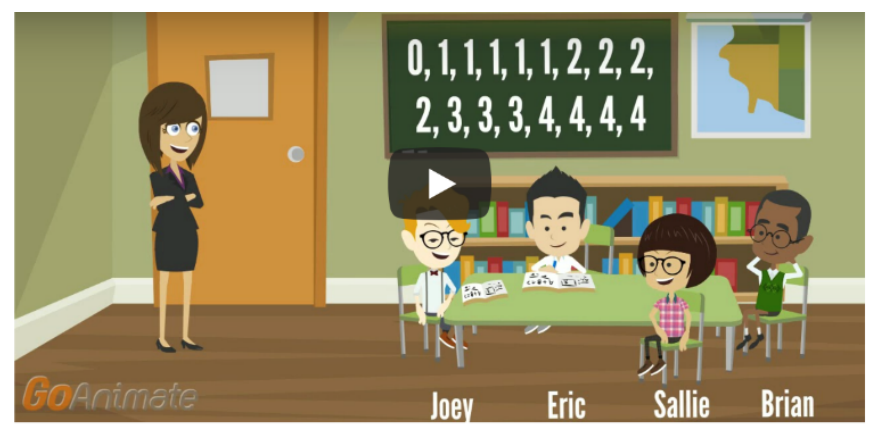

Characters left to right: Teacher, Joey, Eric, Sallie, Brian

If you want to see this video again please click on the link below, otherwise if you refresh your information (what you have done so far) will be lost.

https://goanimate.com/videos/OnhpwSbQQr7A

1. How would you respond to Sallie's comment?

Figure 13. Platform with which the teachers interacted. This is a screenshot of what the teachers interacted with when responding to prompts from the third CGA. As you can see on the top, 
there is a shot of the CGA, and then there are the two prompts that the teachers were presented with.

\section{Pilot Study}

The first cycle of the pilot study was conducted with three middle school teachers who were working on their graduate studies at a Midwestern university. The participants were prompted to go through the whole study and were then asked to give some feedback on the animations, the prompts, and the ease of movement through Select Survey. After this process, some changes were made to the animations to include the name of the students at the bottom of the video (because the prompts were asking questions on what students said). I imbedded the video into the page (instead of a link) to make it easier for the teachers to navigate and to eliminate distractions. One of the animations was too long, and the teachers forgot what the first child said by the time the prompts were introduced. So, page one was partitioned into three different videos with each having its own prompt. Issues with the animations skipping or not working well, spelling, and others were also addressed.

In the second cycle of piloting, the participants were two middle school teachers practicing somewhere in the Midwest. The purpose of this cycle was for final approval and practice with in-service teachers. After this cycle, I had to partition one more video, Video 5, into two parts to lessen the teachers' confusion. Also, a couple of the prompts were changed from "How would you respond to student's comment?" to "Explain how you would make that connection." The prompt for the fourth animation was also changed from "What should the teacher's next act be?" to "What concept of measure of center would you connect this activity to?" These changes were made because the participants seemed confused with what the question 
was asking or because they gave general answers that did not tell us anything about their knowledge.

\section{Data Analysis}

The conceptual framework, that I have previously outlined, was used in the initial, first cycle coding of the data that teachers gave through their responses to the CGAs. On this first cycle of the coding, looking for patterns, I used descriptive coding (Miles, Huberman, \& Saldana, 2014). Descriptive coding allowed me to assign a label to data to summarize the topic of a "chunk" of data. For the purpose of this study, the "chunk" of data that I used as the unit of analysis was a sentence or a collection of sentences. The teachers were themselves writing the answer to their responses, and they placed a period to represent that a thought has ended and to inform the reader that a new sentence, a new thought, is about to start. However, as I found in this analysis, a period is another way of taking a breather; therefore, multiple sentences were sometimes coded together. The coding, was done through Transana, a program similar to Envivo, which allows the researcher to attach codes to chunks of data and helps with analysis and display of data.

In the first cycle of coding, I coded all the responses to the CGAs by assigning them one of the codes from the framework ( $\mathrm{C} 1$ to $\mathrm{T} 4)$. This was done by first understanding if the teacher was talking about curriculum, students, or teaching then identifying which component of the framework the teacher was discussing. There were instances in which the teacher was discussing two topics in the same sentence; hence, some sentences had multiple codes. However, there were times that the teacher discussed specific content without mentioning any of the components of the framework. In these instances, the statements were coded as "other" ideas about curriculum, 
students, or teaching, and these statements were then analyzed in the second cycle of coding for patterns and themes.

\section{Knowledge of Content and Curriculum}

Statements that were coded as curriculum were statements in which the teacher was talking about the learning objectives that she or he wanted the students to have about the content of measures of center in middle school. These statements were not made in reference to what a particular student in the video was doing but were statements in which the teacher was talking about the curriculum of the class in general. There also was a question, Presurvey \# 5, that specifically asked the teachers about these major ideas; therefore, statements from this question was coded as knowledge of curriculum.

\section{C1: Students should understand the median as a central point (Franklin et al.,} 2007). The concept of the median is viewed as a quantity that has the same number of data values on either side of it, in an ordered set of data. Comments that will be coded as $\mathrm{C} 1$ are statements showing that the teacher understands that median is the middle value of an ordered data set. These statements have to include ideas of median as the middle of the data, median as a central point in the data, median as a location of the middle of the data, and median as a way of knowing that at most $50 \%$ of the data lie above or below the median value.

\section{C2: Students should have a conceptual understanding of the mean.}

C2a: Students should understand the mean as fair share (Kader et al., 2013; NCTM,

2000). Even though students might be adept at finding the mean procedurally, they also have some ways of understanding the mean conceptually. Mean as a fair share is the idea that the mean represents what a person, amongst some, would have if things were divided fairly among 
them. The GAISE report represents this with the length, in number of letters, of the name of a student by saying, "How long would our names be if they were all the same length?" In this case, a statement must show that the teacher understands the mean as a fair share by divided the quantity equally among several students and by the mean representing the number of things when equally shared.

\section{C2b: Students should understand the mean as balance point (Kader et al., 2013;}

NCTM, 2000). The mean is understood to be the point that balances all the data. If we were to place a data point two units to the left of the pivot (balance point), then the graph would tilt to the left; therefore, we need to place a data point two units to the right so that the graph would turn to balance. For statements to be coded as balance point, the teachers must understand that if the mean is $x$ then placing a data point $n$ spaces to the right must be countered with placing a data point $n$ spaces to the left.

\section{C3: Students should understand that mean, median, and mode are ways of} summarizing the data using a single number (NGA \& CCSSO, 2010). What this component eludes to is the idea that we do not have to use all the data points to understand what the data represents. We can look at the measure of central tendency so that we can summarize the data by using only a single number. Statements coded as C3 were statements in which the teacher showed understanding that the data can be represented by a single number (mean median or mode). When asking for a number to represent the data (as in one of the videos), teachers should show that the mean median or mode could be useful

C4: Students should relate the choice of measure of center to the shape of the distribution and context in which the data were gathered (NGA \& CCSSO, 2010; Kader et al., 2013; NCTM, 2000). Most of the literature points to the need for students to look at the 
distribution and context of the data when deciding which measure of center to use. Statements coded as C4 hinted at the teachers' understanding that students should look at the whole data to decide on mean, median, or mode. When there are outliers in the data, it would be best to use the median. When the data are categorical, students should use the mode. When the data are symmetrical and there seem to be no outliers, students can use the mean. When the minimum (or maximum) is so far away from most of the data, students should use the median. Any statement that recognizes outliers and their impact on the mean outside the context of students was coded as $\mathrm{C} 4$.

\section{C5: Students should make connections between measures of center and variability} through IQR and MAD (NGA \& CCSSO, 2010). Students should understand that the same way that measures of center represent the distribution of the data with one number, measures of variability also represent the variability in the data using one number. There should be connections between the median and IQR and how the idea of the median helps explain the IQR, and the idea of the mean helps explain the MAD. IQR is the difference between Q3 and Q1, which are the medians of the upper and lower half of the data (identified again by the median). MAD is the average distance from the data to the mean; again, the interdependence between the mean and MAD should be highlighted.

\section{Knowledge of Content and Students}

A response was coded as students when the participants (teachers) were discussing, explaining, or analyzing the knowledge that students have. If a statement (sentence or response to prompt) mentioned a student by name or referenced students in general, then the statement was looked at through the lens of KCS. Numerous prompts ask teachers to respond to students' 
thinking and to identify students that are struggling with the content; responses to these prompts were first viewed through the same lens of KCS then through other lenses if applicable. There also was a question, Presurvey \# 6, that asked teachers to identify challenges that students struggle with; this question was asked to solicit teachers' KCS.

\section{S1: Students tend to think of minimums and maximums as outliers (Kader et al.,} 2013). For a statement to be coded $\mathrm{S} 1$, the teacher must recognize, or acknowledge, the misconception or struggle that the students have by recognizing that students ignore min or max or classify them as outliers.

\section{S2: Students tend to ignore 0 in the data set when computing measures of center}

(Mooney, 2002; Strauss \& Bichler, 1998). Again, this must be recognized as a misconception or a struggle by mentioning that the student is miscalculating the mean by ignoring the outcome of 0 , or by recognizing that their (the teacher's) students make similar mistakes or struggle with similar issues.

\section{S3: Students tend to not order data before finding the median (Groth \& Bergner,} 2006; NCTM 2000). This should be recognized as a misconception or a struggle by mentioning that students make the mistake of not ordering the data before finding the median, or that that is a misconception that their students also have. Teachers might also recognize that they do bring up this idea, of ordering the data when finding median, with their students.

S4: Students tend to use the mode in the beginning to represent typicality (Franklin et al., 2007). This is not a misconception but a conception that students use when first working with representing or using measures of center. For a statement to be coded S4 teachers must recognize that students start by seeing mode first, or that students are comfortable with the idea 
of mode before getting to the mean and median, or by recognizing that they start with mode then mean and median because mode is easiest for students to see.

S5: Students tend to ignore mean when it is not part of the data (Strauss \& Bichler, 1998, Cooper \& Shore, 2008). Statements that were coded as S5 included ideas that students have issues accepting mean when it is a fraction, that students do not like to use the mean when it is a decimal, that students always try to recalculate when the mean is a decimal, or that students don't like to use a decimal for a mean of discrete numbers.

S6: Students tend to have difficulty calculating weighted mean (Gattuso \& Mary, 1998; Mokros \& Russell, 1995; Mevaresh, 1983; Pollatsek, Lima \& Well, 1981).Statements were coded as S6 when the teacher recognized that the weighted mean is a difficult concept for students.

S7: Students tend to only know the mean procedurally (Cai, 1995, 2000; Mokros \& Russell, 1995). As mentioned earlier (NCTM 2000), this is a struggle for teachers: that students tend to use a procedure to find the mean but do not have a conception of what the mean represents. Statements were coded S7 if they recognized that students have no issue with the procedure but do not know what the mean represents; that the procedure is not a problem for students, but they have issues with the conception of the mean; or that students can find the mean but do not know how to use it.

\section{Knowledge of Content and Teaching}

Statements coded as teaching were statements in which the teacher was discussing their teaching methodology, what they do in class, what they would do in certain situations, and how do they respond to student comments. There were three prompts that asked teachers to discuss 
similarities or differences in introducing measures of center, and several prompts asked teachers to comment on ways to help improve students' conception of measure of center. There was also a question, Presurvey \# 7, asking teachers to discuss how they planned to address challenges that students have. Answers to all these prompts were first viewed through the lens of KCT then through other lenses, as applicable.

T1: Teach statistics through the investigative process (Franklin et al., 2007, 2015). This is where teachers had the opportunity to show KCT through the investigative process. For statements coded as T1, teachers discussed how they would get students to make simple investigations by gathering data then analyzing it to make a decision, how they get students to talk about the mean through the statistical process of investigation, how students conduct investigations in class to understand statistics, how they get students to gather data about a subject then analyze it to make decisions, or how to use measures of central tendency to make decisions about data gathered in class.

T2: Connect statistics to other areas of mathematics (Franklin et al., 2015). The statements coded as T2 were statements that made connections between mathematics and statistics by connecting fractions to concepts of mean in statistics, by using algebraic thinking to help with statistical computations, by using fractions and probability to connect to statistics subjects, or how in class teachers use mathematical concepts that student know, like average, to connect to the mean and its meaning.

\section{T3: Relying on active learning and exploration of real data (Franklin et al., 2015).}

Statements coded as T3 included ideas about using real-life data to make the learning more active or to get the students more interested by use real-life data in class (exploring real-life data 
makes the investigation more interesting) or comments about students' being interested in the idea of using real data for their work.

T4: Making effective use of technology and assessment (Franklin et al., 2015). Here statements should have acknowledged that teachers use technology to get students more involved, how technology can help expedite the process and get to the interesting parts of making decisions or recommendations, or how technology helps students see the whole picture and make better decisions. Statements about the effective use of formative and summative assessment were also coded as T4.

\section{Second Cycle of Coding}

During the first cycle of coding, there were a lot of instances in which it was easy to discern what content the teachers were discussing but not as easy to identify a specific component of the framework. So, although it was easy to see that a teacher was discussing a student's thinking, components of the curriculum, or teaching strategies, it was not apparent which component of the framework the statement fit. Therefore, during that first cycle, I had to introduce three new codes: Curriculum Other, Student Other, and Teaching Other. Curriculum Other, for example, was given for instances in which the teacher was talking about the curriculum but did not use any of the components that were supported by research or curriculum documents; the same was true of the Student Other and Teaching Other codes.

The emergence of these three new codes made it necessary for me to look at all responses that were identified as "Other" to further analyze them. So, I took all the sentences that were coded as Curriculum Other and analyzed them to see what other components of curriculum teachers identified that were not evident in the literature. Similarly, I gathered all the Student 
Other and Teacher Other statements separately so that I could further understand how teachers thought of their students and their teaching, apart from the literature. The emergence of these new codes made it necessary to evaluate, check, the trustworthiness of my coding.

A fellow graduate student and researcher, who had experience in coding qualitative data and was familiar with teacher knowledge terminology and theory, was recruited to code some of the data for comparison. The data that this researcher was given was the initial responses to the CGA from four of the participating teachers, three of which were the data from the teachers who participated in the sem-istructured interviews. Even though the researcher is part of my IRB and has had the appropriate CITI training, the data that he received did not have any identifiers (pseudonyms were used in lieu of teacher names). After a discussion of what the components of the framework meant and a little background on the literature, the researcher started coding the data. The interviews were coded one at a time with the first transcript, as a practice, was one of the pilot study responses. With an initial agreement of $80 \%$, all four transcripts were validated, and data analysis continued.

From here, I continued the data analysis by first analyzing the Curriculum Other and finding patterns and general themes emerging. I combined all the sentences that were coded as Curriculum Other and started analyzing this data as a wholly new document. This coding was done similarly to the first cycle, through Transana, but this time, I was creating and assigning provisional codes to the data other than the framework. Later, by collapsing codes together, some codes emerged as the predominant ones. Because of the small amount of statements related to Curriculum Other, there was an instance in which a code was given for only two statements. Again, this only happened with Curriculum Other; the rest of the categories had at least eight 
statements that were collapsed to constitute a category. Similarly, I worked with Student Other and Teaching Other, assigning codes and later collapsing codes into dominant themes.

\section{Ethical Issues}

In this section, I discuss ethical issues regarding this study. To ensure privacy, I am the only one that knows the identity of the participating teachers. Pseudonyms were used in discussing individual participants, and original data were kept on password protected computers and jump drives. The teachers were compensated for their time, and questions were answered about both content and methodology. Issues of validity, reliability, and credibility were addressed by using the pilot study, triangulation, multiple sources of data, and member checking. In conducting this research, I did everything possible to perform research that is beneficial to the field overall and would not harm the participants.

As far as worthiness (Miles et al., 2014), I think that this study will be beneficial to teachers who are trying to improve their teaching. According to Shulman (1986), PCK is one of the main components of a teachers' knowledge, and knowing more about their PCK and ways to improve it should be a main component of every teachers' PD. My participants will have an opportunity to review my findings and to get information on how to better improve their PCK. As far as competence, having conducted previous work with statistics education research and having an advisor with more than 10 years of experience in statistics education research gives me enough experience to conduct this study.

As far as benefits are concerned, I will make sure to make myself and other recourses available to teachers who are interested in understanding more about what their PCK looks like and how to better their knowledge. I will offer to come back after the study and give PD to all 
the available teachers in the district about statistics education with a concentration on PCK. In terms of compensation of knowledge, all teachers who took part in responding to the CGA had the opportunity to think about their teaching and their knowledge of students. The teachers in the interviews were able to ask me questions, after we finished, about methodology and misconceptions.

\section{Validity, Reliability, and Credibility}

Validity is often defined as the quality and rigor of the data collected, reliability is defined as the dependability of the data, and credibility refers to the trustworthiness of the data (Simon, 2011). Regarding validity, the quality of the data collected was ensured by my piloting the CG's twice before it was presented to the participating teachers. The content in the animations was based on findings from the literature and was also vetted by an experienced and published researcher in the field of statistical education. The prompts used were also vetted by a researcher who conducts and publishes research on the mathematical knowledge of teachers.

Regarding reliability, or dependability of the data, a second researcher also coded the data. This second researcher was able to view the same animations and go through the prompts, just as teachers did, before he coded the data. After coding the data, we compared our coding, and an initial agreement of $80 \%$ was evident. This speaks to the validity of the coding and the reliability of my coding of the data from the teachers. Credibility of the data, or trustworthiness, was established by collaborating with one of the interviewed teachers: Analyzed data were presented to the teacher for reliability of interpretation. Only minor changes were made to the data after member checking, which speaks to the trustworthiness of the data presented. 


\section{Chapter Summary}

In this chapter, I put forth the method by which I conducted this study. I started by summarizing my research paradigm, postpositivist, and by introducing the participating teachers. These were eight practicing (in-service) teachers who had taught the subject of statistics in middle school at least twice, ranging in experience and education. Data collection was comprised of the development of the instruments used to collect the data and the pilot study conducted to improve and finalize the instrument. Data sources were discussed, including responses to prompts from the CGAs and the semi-structured interviews conducted. The analysis of data started with the explanation of the theoretical perspective and then the cycles of coding. Significance of the study was included, followed by ethical issues and validity, reliability, and credibility of the study. All this information was put forth so that the reader understands that this study is firmly grounded in theory and literature and to give arguments why this method was used. 


\section{CHAPTER IV: RESULTS}

\section{Introduction}

This chapter presents the results of this study. This chapter will be organized in two major parts. The first part will be the PCK that the participating teachers displayed when answering prompts to CGAs. This part will be divided into three sections: knowledge of curriculum, KCS, and KCT. The second part of this chapter will be the profiles of the three teachers who participated in the second phase of data collection, the individual interviews. In this part, each of the three teachers will be profiled as to their knowledge of content, students, and teaching.

\section{Pedagogical Content Knowledge Through the Computer-Generated Animations}

Before I get into the individual components, I want to introduce Table 7, which gives a snapshot of the components of the framework and the count for each category. This table is designed to show the differences in the discussion between expected knowledge, based on literature and curriculum documents, and other knowledge related to a specific topic. As can be seen, only $34.2 \%$ of the comments were aimed at KCS; of those comments almost, two thirds were under other knowledge of students. As previously mentioned, the unit of analysis was one or two sentences, which constituted a thought. Within the data from the CGA, there were 322 different statements. Eighty-two statements were coded within the framework, and the rest fell outside the framework. 
Table 7

Codes as Related to Framework

\begin{tabular}{lcc}
\hline \multicolumn{1}{c}{ Knowledge components } & $\begin{array}{c}\text { Number of statements } \\
(n=322)\end{array}$ & $\begin{array}{c}\text { Percent of total } \\
\text { statements }\end{array}$ \\
\hline $\begin{array}{l}\text { Expected Knowledge of Content and } \\
\text { Curriculum }\end{array}$ & 30 & $9.3 \%$ \\
Other Knowledge of Curriculum & 12 & $3.7 \%$ \\
Total Curriculum Statements & 42 & $13.0 \%$ \\
$\begin{array}{l}\text { Expected Knowledge of Students } \\
\text { Other Knowledge of Students }\end{array}$ & 38 & $11.8 \%$ \\
Total Student Statements & 72 & $22.4 \%$ \\
Expected Knowledge of Teaching & 110 & $34.2 \%$ \\
Other Knowledge of Teaching & 14 & $4.3 \%$ \\
Total Teaching Statements & 156 & $48.4 \%$ \\
\hline
\end{tabular}

\section{Knowledge of Content and Curriculum}

As with the rest of this section, I first introduce the results of the prompts to CGAs from the first cycle of coding, which are compared to the framework, and then I introduce the results for the second cycle under "other."

Table 8

Expected Knowledge of Content and Curriculum Components

\begin{tabular}{llcc}
\hline \multicolumn{1}{c}{ Components } & $\begin{array}{c}\text { Statements } \\
(n=30)\end{array}$ & $\begin{array}{c}\text { Teachers } \\
(n=8)\end{array}$ \\
\hline C1 & $\begin{array}{l}\text { Students should understand the median as a central point. } \\
\text { C2 }\end{array}$ & $\begin{array}{l}\text { Students should have a conceptual understanding of the } \\
\text { mean: fair share, balance point }\end{array}$ & $15(3.3 \%)$ \\
\end{tabular}

(Table Continues) 


\begin{tabular}{|c|c|c|c|}
\hline & & Components & $\begin{array}{c}\text { Statements } \\
(n=30)\end{array}$ \\
\hline $\mathrm{C} 3$ & $\begin{array}{l}\text { Students should understand that mean, median, mode is a } \\
\text { way of representing the data using a single number. }\end{array}$ & $5(16.7 \%)$ & $\begin{array}{l}\text { Teachers } \\
(n=8)\end{array}$ \\
\hline $\mathrm{C} 4$ & $\begin{array}{l}\text { Students should relate the choice of measure of center to the } \\
\text { shape of the distribution and context the data were gathered. }\end{array}$ & $9(30.0 \%)$ & 4 \\
\hline $\mathrm{C} 5$ & $\begin{array}{l}\text { Students should make connections between measures of } \\
\text { center and variability through IQR and MAD. }\end{array}$ & $0(0.0 \%)$ & 4 \\
\hline
\end{tabular}

As shown in Table 8, there were 15 comments that discussed the second category $\mathrm{C} 2$ students should have a conceptual understanding of the mean, through fair share or balancing point. When asked about how to make connections between a procedure and the concept of measure of center, Brenda said: "The end goal is for everyone to have the same amount." To the same question, other teachers answered: "You are looking for the point where there is an even distribution of data" (Jennifer), and "I think I would have to link to through sharing things equally" (Monika), "So by them sharing their dollars, they averaged their money together" (Miranda). Similarly, Jonathan answered the same question, saying: "When finding the mean, we are finding if everyone put their items in a pile how much would each person get equally when redistributed."

The evidence for the third category, C3-students should understand that mean, median, mode is a way of representing the data using a single number - was mostly found when teachers were answering the question of "What challenges, have you seen, or do you expect your students will have in learning the content (measures of center)?" To this question, Angela answered, "mean and mode show the measures of center in different ways," and Kasy said "That the idea of center takes on many forms." Similarly, Brenda said: "I usually try to emphasize the measures of center can give different types of information with the same data," and "they are all, in some 
way, an average." However, Jennifer said, "When each of the measures of center would make the most sense in describing a set of data."

With respect to the fourth category, $\mathrm{C} 4$-relating the choice of center to the shape of the distribution and context of the data gathered —only half of the teachers (for a total of nine comments) discussed the concept. Comments coded as $\mathrm{C} 4$ also came from the question about challenges that students have with the measures of center. Here, Angela said: "I would also like them to understand when there are extreme values as well in the data set." Brenda said, "However, one measure might work better for particular types of data," and Jonathan said, "Which measure of central tendency best describes data if there are outliers.".

This category (C4) was also elicited when asking about the kind of response the teacher would give to a comment by a student when he was confused about if we always use the mean. Angela wrote: "I would tell Joey the best time to use the mean is when there are no outliers in the data set." This was a case in which the response was double coded because the teacher was also talking about her teaching strategy to a student question: direct teaching. Angela continues, without apparent direction, to make statements coded as C4: "It is best to use the median when there are outliers," and "using the median will eliminate numbers that would exaggerate or throw off the measure of central tendency."

When commenting on how to help a student with her or his conception Susan said, "Joey needs to understand that there are outliers and using an outlier in the mean can significantly skew your data." Similarly, Susan also responded, "I would talk with Sallie about the outlier and how that can help you choose which measure of central tendency is the best," and "I would talk to Joey about the outlier in the group and how that might skew the mean." 
As seen in Table 8, the results indicated that only one teacher made one comment about the need for students to understand the median as a central point in the data. This comment was given by Angela when asked about the major ideas she wanted the students to come away with: "Some of the major ideas I want my students to understand is finding the center or middle value of the data set." Another category that teachers did not report was the idea that students should make connections between measures of center and variability through the IQR and MAD; as seen from Table 8, there were no comments made in this category.

Table 9

Components of Curriculum Other

\begin{tabular}{lcc}
\hline \multicolumn{1}{c}{ Components } & $\begin{array}{c}\text { Statements } \\
(n=12)\end{array}$ & $\begin{array}{c}\text { Teachers } \\
(n=7)\end{array}$ \\
\hline Students should understand differences between measures of center & $2(16.7 \%)$ & 2 \\
Students should understand the terminology & $7(58.3 \%)$ & 5 \\
Students should understand how to use measures of center & $3(25.0 \%)$ & 2 \\
\hline
\end{tabular}

Other ideas related to curriculum. In the second cycle of coding, when looking at Curriculum Other, there were a total of 12 statements, these statements were coded within knowledge of content and students because most of these comments were answers to the second pre-survey question, which was designed to get teachers discuss their knowledge of content and students. With more than half of them (7) discussing Students should understand the terminology, three statements made about using measures Students should understand how to use measures of center, and two statements made about Students should understand differences between measures of center. When answering the question on what difficulties students have with measures of center, the following comment from Jonathan was coded as Students should 
understand the terminology: "Math is a foreign language. You must understand the terminology first." When asked what ideas the teacher wanted students to get out of the class, Susan replied, "Mean, Median, Mode, Range, IQR."

The comments coded as students should understand differences between measures of center came from a question on what major ideas teachers would want students to get out of the class. Jonathan answered, "The difference between them all," and Monika said, "I think that getting students to actually understand the difference of each is major." These responses were coded this way because even though they are discussing measures of center, the comments were too general to be coded within the framework. Responding to the same question, Angela answered, "I also want them to be comfortable using mean, median, mode, and range," and Jennifer answered, "When to use mean, median, mode and range"; both comments were coded as Students should understand how to use measures of center. That last comment could have been coded as C4 - Students should relate the choice of measure of center to the shape of the distribution and context the data were gathered, however, the response did not make the choice of measure dependent on characteristics of the data, but was just a general idea.

\section{Knowledge of Content and Students}

The analysis of KCS reveals that most teachers mentioned most of the categories identified in the framework, except for the sixth and the second category, as seen in Table 10. Comments were coded as KCS when the teachers were commenting on the students' responses, thinking, or struggles. 
Table 10

Knowledge of Content and Students

\begin{tabular}{|c|c|c|c|}
\hline & Components & $\begin{array}{l}\text { Statements } \\
\quad(n=36)\end{array}$ & $\begin{array}{c}\text { Teachers } \\
(n=8)\end{array}$ \\
\hline S1 & $\begin{array}{l}\text { Students tend to think of minimums and maximums } \\
\text { as outliers. }\end{array}$ & $14(38.9 \%)$ & 6 \\
\hline $\mathrm{S} 2$ & $\begin{array}{l}\text { Students tend to ignore } 0 \text { in the data set when } \\
\text { computing measures of center. }\end{array}$ & $0(0.0 \%)$ & 0 \\
\hline S3 & $\begin{array}{l}\text { Students tend to not order data before finding the } \\
\text { median. }\end{array}$ & $7(19.4 \%)$ & 4 \\
\hline S4 & $\begin{array}{l}\text { Students tend to use the mode in the beginning to } \\
\text { represent typicality. }\end{array}$ & $3(8.3 \%)$ & 2 \\
\hline S5 & $\begin{array}{l}\text { Students tend to ignore mean when it is not part of the } \\
\text { data. }\end{array}$ & $8(22.2 \%)$ & 5 \\
\hline S6 & $\begin{array}{l}\text { Students tend to have difficulty calculating weighted } \\
\text { means. }\end{array}$ & $1(2.8 \%)$ & 1 \\
\hline S7 & Students tend to only know the mean procedurally. & $3(8.3 \%)$ & 3 \\
\hline
\end{tabular}

The first subcategory under KCS, S1-students tend to think of minimum and maximums as outliers. Of the eight teachers, six of them mentioned students' struggle with thinking of minimum and maximum as outliers, for a total of 14 statements. Most of the comments coded as S1 came from comments made in respond to the prompts of two different videos, the second and seventh videos. In the second video, a student comments that he wants to throw away the outlier (maximum) and then find the mean, and another student wants to eliminate both min and max as outliers. To the first prompt of which student is struggling, Angela responded, "The students who seem to be struggling are the ones who just want to throw out the outliers without considering using mode, median, or mean." Two teachers said: "Joey is taking what he thinks is the outlier out of the data and using the rest of the data" (Susan), and "Eric - doesn't understand that data can have outliers" (Monika). Commenting on a different prompt from the same question, Monika also comments: "Sallie is thinking that you automatically take out the largest and smallest." 
Similarly, other teachers commented: "Eric is eliminating data because he feels it is not relevant" (Miranda), and "Eric is not correct by just throwing out the 11.5 because it is an adult size shoe" (Angela).

In response to the seventh video, students making a decision on which measure of center represents the data; Susan commented, "Brian-He uses the median because he doesn't want to include the outlier in the data set." Also commenting on Brian's response, Brenda said: "I don't think any of these answers would be wrong per-se. However, I would say Brian has the best answer with median and his comment about the extreme is great." Angela also responded, "I would also tell him we cannot just ignore the outlier of $\$ 30 . "$

The fifth subcategory, S5-students tend to ignore mean when it is not part of the datawas identified in eight comments. These comments came from prompts for video three and video seven. In both instances, the mean is not represented in the data, and the students are struggling with choosing a measure of center to represent the data. Jennifer recognizes the struggle of the student: "Eric doesn't seem to understand that the mean will not always be a number in your data set and wants to use the mode just because it appears the most." Following with comments for Eric, Monika said, "Eric — actual mean is not listed in data — seems to want only data from list," and "perhaps he has not made the connection that the mean is not always one of the original data points." Susan also comments that "Eric uses the mode and doesn't seem to understand that it's alright to have a number not in the data set.".

The third subcategory, S3—-students tend to not order data when finding the medianhad comments from four participants who were able to identify the struggle. Only one of the teachers stated that "His misconception is that the numbers are in order when presented" (Jonathan), identifying a misconception that students have when finding the median. The 
majority of the participants commented on a video in which Brian correctly identified the median as the needed measure of center but forgot to order the data. Comments ranged from "Brian is struggling because he did not order the data set from greatest to least" (Angela) to "he needs to first put the data set in order from greatest to least or least to greatest" (Angela). Similarly, another teacher, Brenda, stated that: "He also failed to line the data points up in order from least to greatest when finding the median," and "he used the method of the median but did not organize the numbers from least to greatest" (Brenda). Brenda was the only participant to identify this struggle when asked about challenges students have with the content: "They also usually struggle to realize the data has to be in numerical order."

An issue arose with the fourth subcategory, $\mathrm{S} 4$ - students tend to use the mode in the beginning to represent typicality — when only two of the teachers mentioned it with a total of three statements; even in those cases, mode was not specifically recognized as the beginning but just an easy thing for students to do. In this case, one teacher, Angela, mentioned: “Joey's thinking about the mean is using a mode method. He did a nice job placing the numbers on each side of the initial numbers," and "Brian is looking at finding the mode. He wants to use the data for what he thinks most students get for allowance." The other teacher, Kasy, stated: “Joey's thinking about mean assumes that all the boxes have the same number of pencils." These comments show that teachers know that mode is an easy representative of the data that students readily identify.

The last component of KCS, S7—students know the mean only procedurally-was only coded three times from three different participants. These comments were in response to Joey commenting on two different situations: "Don't we always use the mean?" and "I am confused, when do we use the mean and when do we use the median?" In response to the first question, 
Jonathan commented, "Joey knows how to find the measure of central tendency, but does not understand how outliers might throw off the data too." Susan responded: "Joey found the mean and doesn't understand that the mean isn't always the best representation of data." In response to the second situation, Angela responded: "Joey would use the average or mean. He has a good grasp of finding the mean.”

For the sixth element in KCS, S6-students tend to have difficulty calculating weighted means - only one teacher made one comment about students struggling with weighted means. Susan said, "Eric added one male and one female. He did not find the average age because there are more men than there are women." In this comment, Susan recognizes that the student could not find the mean because of the differing number of males and females, and she also recognizes the mistake that the student made when he took the average of the averages as if there was only one male and only one female. Even though there was a video (3) that was constructed around the misconception that students tend to ignore 0 in calculating the mean when part of data, no comments were coded as S2.

Other ideas about students. Student Other was a category in which the teacher was commenting on a student's thinking, comments, or work, but the comments made could not be coded using the original framework. However, unlike Curriculum Other, this category made up almost two thirds of the comments that the teachers made about their students. This category was further analyzed to see if there would be any codes that could be attributed to the teachers' comments and see if there were any prevailing ideas. So, on the second cycle of coding, Student Other had three different codes (as seen in Table 11). 
Table 11

Components of Student Other

\begin{tabular}{lcc}
\hline \multicolumn{1}{c}{ Components } & $\begin{array}{c}\text { Comments } \\
(n=52)\end{array}$ & $\begin{array}{c}\text { Teachers } \\
(n=8)\end{array}$ \\
\hline Teachers explaining students' conception of average & $40(55.0 \%)$ & 8 \\
Students tend to have issues with outliers & $8(11.0 \%)$ & 5 \\
Students' struggles with other concepts of measures of center & $24(33.0 \%)$ & 8 \\
\hline
\end{tabular}

As Table 11 shows, the first category_Teachers explaining students' conception of average - was the most dominant category with more than half of the comments. Included in this code were all the ways that the teachers explained the students' conception of average, without being specific about their meaning or direction or without relating the explanation to their students or what should be done in the classroom. Within this code, the participants explained the students' thinking of average as balance point, fair share, or mode. Explaining the students' conception of average as a balance point, Angela said, "Her data set had the same amount of digits on either side of the median center," and Jennifer said, "Sallie did a good job thinking about how to keep everything balanced and equal to still have an average of 15." These types of answers were solicited in the sixth video when the students create distributions with a predesigned average of 15 . Answering the same prompts from the sixth video, Susan said, "Sallie understood that if 15 is in middle and if she branched out each direction that the mean of the two numbers would be $15 . "$

On the conception of average as mode, as part of Teachers explaining students' conception of average, Jonathan stated: “Joey's thinking is typical. The numbers must be the same. I think that is a great place to start with this type of problem." Miranda stated: "Joey's thinking is correct. If the average is 15 all 7 boxes could have 15 pencils in them," and "Joey 
knows the average would be about the number in each so he knew that regardless of the actual number statistically they could all be 15." Monika said, "I could be the easy way, or maybe he thinks all new boxes of pencils have the same amount," and Angela stated that "Eric has a good point about using the mode the most common number in the data set." On conceiving the average as fair share, Miranda explained: "Sallie is thinking more about the way to create an average of $15.12+18$ would average to 15 , and so on with the rest of the numbers."

Under Teachers explaining students' conception of average, there were some comments in which participants just tried to explain what the student was thinking or doing. When explaining students' thinking Angela said: "She knew that 34 was the most common number in the word problem and that the average would be close to that," and "Brian is correct that you cannot find the mean without knowing the exact numbers." Both comments were given when the students were having issues with finding weighted average. Answering a different prompt, Angela explains: "Sallie is doing well thinking of using the median. There is an outlier of 30 and that increases the range of the data set; therefore, Sallie is correct in wanting to use the median." Brenda explained, "Both of these students recognize the data might be skewed, but I see no reason as to why they should be eliminated." Similarly, Jennifer explains, "He understands the concepts, he would just need to work on when to use mean, median, and mode. He asked a good question at the end."

Relating the students' work in the video to the participants' own students, one teacher commented: "Some of my students prefer to count from each end to determine the middle" (Miranda). When explaining what her students do when finding median, Susan said: "Then someone else will start crossing off numbers from the ends until we end up with a middle or 2 middle numbers." Monika explains Sallie's use of symmetry in creating the distribution with a 
mean of 15: "I feel like this is the way we teach it, so I'm not sure how much is just following a pattern and how much is truly her own thoughts." In a separate issue, Susan explained: "I think Brian understands that 30 is the outlier and can skew the mean."

The code Students' struggle with other concepts of measures of center was given when a teacher identified a struggle that students have without attempting to explain the students' thinking. Some of the statements coded as struggle came from one of the first questions about struggles that participants had encountered with their own students. Answering that first question, Angela said: "The challenges that I have seen students experience are not fining both the mean and median when working with the measure of center." Brenda commented: "They tend to have difficulty with understanding an odd data count for median," and "some students have difficulty recalling which measure is which (vocabulary)." Jennifer commented: "My kids have a hard time remembering the difference between the measures center," and "the vocabulary is difficult for my students to remember." Jonathan explained: “The next challenge is finding measures of central tendency in forms other than a list of numbers (i.e., a frequency table)." Monika said, "Students tend to blend these together- they don't see what sets each apart," and Susan said, "Finding mean, median, mode if a number in the data set is not given."

For Angela, the next time that she discussed students' struggle came from the last (seventh) video when the prompt asked specifically about which student was struggling. Angela said: "Joey is struggling with trying to best represent the data," "Eric is not understanding finding average," and "he [Brian] is not just embracing the data set and using math to find the measure of center." Answering the same prompt, Jonathan said, "Joey is struggling. Don't we always use the mean? He is trying to realize when is it okay to use another measure of central tendency." On an earlier question, Miranda explained, "Typical weight of the shoes is the 
average and Brian is struggling with the understanding how to determine the average." Monika commented: "Brian—confusing meaning of mean and median—not confident of the definitions."

Students tend to have issues with outliers encompassed comments the teachers made about the students struggling with the conception of outliers or the impact that outliers can have on averages without specifying or connecting it to minimum and maximum. Recognizing the issue, teachers commented: "She needs to work more on what outliers are" (Jennifer), "Brian seems to struggle with the mean. He seems to be taught or coached about outliers" (Jonathan), "Sallie does not understand the concept of outliers" (Kasy), "Sallie—doesn't seem to understand what an outlier actually is" (Monika), and "she doesn't understand that there doesn't have to be outliers" (Susan). Susan also commented on the impact that an outlier has on average "Joey needs to understand that there are outliers and using an outlier in the mean can significantly skew your data," and "I would talk with Sallie about the outlier and how that can help you choose which measure of central tendency is the best." That last statement was also coded as Teaching Other because Susan is also commenting on her teaching style: talking to or direct instruction.

\section{Knowledge of Content and Teaching}

The last component of PCK that the framework helped analyze was the KCT. The categories that made up this knowledge were devised such that teachers could show their knowledge by commenting on strategies that they used to teach the content to their students. As can be seen from Table 12, the last category—using technology effectively—was not represented in the data collected from the main data collection instrument. The first category was the use of the investigative process to teach statistics as recommended by the GAISE report (Franklin et al., 2007). There were four subcategories in case a teacher showed knowledge of one aspect of the 
process and did not show appreciation for the others. One teacher discussed the investigative process, specifically: "I give students a print out of shoes sizes from an imaginary shoe store, I have them find the mean, median, and mode and ask them to use that data to determine what sizes to buy" (Kasy).

Table 12

Components of Knowledge of Content and Teaching

\begin{tabular}{llcc}
\hline & \multicolumn{1}{c}{ Components } & $\begin{array}{c}\text { Statements } \\
(n=14)\end{array}$ & $\begin{array}{c}\text { Teachers } \\
(n=8)\end{array}$ \\
\hline T1 & Teach statistics through the investigative process. & $1(7.1 \%)$ & 1 \\
& T1a - Formulate Questions & $0(0.0 \%)$ & 0 \\
T1b - Collect Data & $2(14.3 \%)$ & 1 \\
T1c - Analyze data & $0(0.0 \%)$ & 1 \\
& T1d - Interpret results & $1(7.1 \%)$ & 2 \\
T2 Connect statistics to other areas in mathematics. & $1(7.1 \%)$ & 1 \\
T3 & Relying on exploration of real data. & $9(63.9 \%)$ & 6 \\
T4 & Making effective use of technology and assessment. & $0(0.0 \%)$ & 0 \\
\hline
\end{tabular}

Within that one statement, Kasy gave evidence not only of being aware of the investigative cycle but also of most of the components of the cycle. She explained how she gave students the data; hence, the students are not coming up with the questions nor are they collecting data for the investigation. However, Kasy’s students are analyzing the data, interpreting the results, and making recommendations based on data. On the other hand, Monika discussed: "I collect data from my students so that it means something to them-we also talk organizing the data and predict things about it." In that statement, Monika shows that she is also aware of the investigative cycle and that she uses most of the stages. Like Kasy, Monika does not feel comfortable getting the students to decide what question will be investigated; however, 
unlike Kasy, she does allow students to collect the data, organize it, and interpret the results. Similarly, Susan explains: "We then typically survey the students on their shoe size and find the mean," which again shows the teacher being comfortable with the collection of data.

The second component of the KCT was the connection of statistics to other areas of mathematics. This was a very elusive subject because only one teacher made only one comment that was categorized as "connecting to mathematics." The comment was: "The other example would use fractions or decimals" (Jonathan). This comment was made in response to the first video in which the teacher was asked to comment on similarities or differences from the animated teacher and their own teaching. The prompt on that fist CGA was designed to get teachers talking about their teaching, soliciting their knowledge of content and teaching.

The next component, KCT, was better represented, with six of the eight teachers making at least one statement that discussed relying on active learning and exploration of read data. Most teachers made comments about the use of real-world data: "I would provide several examples that would have a real-world word problem connected" (Angela), "It may be helpful ... to go over different real world data sets and graphs" (Jennifer), “Through projects and activities, and Real World [sic] experiences" (Kasy), and "I like to use real world data, like student shoe size" (Miranda). Several also included comments about active learning through hands on activities: "This would be a good time to use hands-on activities (perhaps using less boxes to start)" (Monika), "I try to use activities that require the students not only to compute the measure, but to also use them to describe situations" (Monika), and "Use data that students have an interest in (music length of favorite songs, etc)" (Jonathan). 
Other ideas about teaching. The category of Teaching Other included statements in which participants discussed some teaching aspect, questions to ask students, activities used to teach, and strategies employed in the classroom that did not make it to the framework. The reason why these statements were not coded within the framework was because most of them were not specific enough and did not pertain to statistics. This category was the one that encompassed more than $90 \%$ of all the statements made about teaching (156 of 170). However, after an extensive look at the categories, it came to my attention that none of those comments were pertinent to statistics. As seen in Table 13, the categories were such that they could have been under any content in mathematics. Hence, I do not include the comments made under Teaching Other in this study. However, as an example of teaching by using discussion, Brenda said, "It would be discussion and further examples," and Jennifer explained, "I would also have a conversation with him about good mathematicians always trying a problem even if they aren't sure where to start." Under teaching using direct/individual instruction, Brenda responded: "Brian requires further clarification on what the median is and does. I would show him the proper way to work the problem and explain why." Similarly, Miranda stated: "Also in class I implement stations allowing for one-on-one instruction with the teacher and fluency practice of the skill."

\section{Table 13}

Components of Teaching Other

\begin{tabular}{lcc}
\hline \multicolumn{1}{c}{ Components } & $\begin{array}{c}\text { Statements } \\
(n=156)\end{array}$ & $\begin{array}{c}\text { Teachers } \\
(n=8)\end{array}$ \\
\hline $\begin{array}{l}\text { Teaching through activities not related to real data } \\
\text { Teaching using direct/individual instruction }\end{array}$ & $\begin{array}{c}17(11.0 \%) \\
73(47.0 \%) \\
\text { (Table Continues) }\end{array}$
\end{tabular}




\begin{tabular}{lcc}
\hline \multicolumn{1}{c}{ Components } & $\begin{array}{c}\text { Statements } \\
(n=156)\end{array}$ & $\begin{array}{c}\text { Teachers } \\
(n=8)\end{array}$ \\
\hline Teaching by using discussion & $23(15.0 \%)$ & 8 \\
Teaching procedures backwards & $11(7.0 \%)$ & 6 \\
Teaching using questions as a strategy & $32(20.0 \%)$ & 7 \\
\hline
\end{tabular}

\section{Summary}

In the coding for the CGA responses, it was important to mention that the first cycle of coding sifted through the data with the purpose of trying to see how much of what the teachers discussed was indicative of what the research and literature say teachers should discuss. The framework was designed so that all the evidence from research, curriculum, and policy documents were included. After the data were sorted out, there were a lot of discussions that did not completely fit within the framework; hence, a second cycle of coding was needed to understand the rest of the statements made from the participating teachers. All the responses were taken together as a group so that I could discuss the knowledge that the teachers exhibited. In the following section, I discuss the knowledge that three of these teachers exhibited, not only in their CGA answers but also in the individual interview. The questions that were asked in the interviews were informed by the CGA responses as a group and individually.

\section{Three Teachers' Profiles}

In this section, I profile the PCK of each of the three teachers who participated in the semi-structured interviews. I profile the participating teachers' PCK by first giving some background information solicited from the initial survey. I continue by introducing responses that were coded within the framework, I will the introduce responses that were coded under the 
category Other, later I will use the interview responses to augment the teacher's profile. As a reminder, the Other responses were coded during the second cycle of coding when I took all comments that were not coded under any components of the framework, and I started to look for patterns in the data. The comments that were deemed to discuss curriculum (for example), but were not discussing a specific component from the framework, were further analyzed to find patterns within the data.

\section{Jonathan's PCK}

Curriculum. Jonathan is a middle school teacher in a school district in the Midwest. He has taught statistics before he responded to the CGA prompts and the semi-structured interview. In this first section, I will display the results to both his CGA prompts and the interview, as they pertain to his knowledge of Curriculum. Jonathan had only three statements, during the CGA, that were coded under knowledge of curriculum: two were coded as C2 and one as C4. The first statement, C2 - Students should have a conceptual understanding of the mean: fair share, balance point, was: "When finding the mean, we are finding if everyone put their items in a pile how much would each person get equally when redistributed", and "I would use this in finding the mean." This last statement was made in connecting an activity of fair share to the mean. The statements coded as C4 - Students should relate the choice of measure of center to the shape of the distribution and context the data were gathered, came during the initial survey asking for major ideas to which Jonathan responded: "The difference between them all. Which measure of central tendency best describes data if there are outliers." From the whole response only the second sentence was coded under C4. The first sentence was coded under Curriculum Other because to Jonathan they are two different thoughts (his own punctuation of finishing a thought). 
Jonathan made two comments about curriculum that were outside the framework: "The difference between them all" which, as seen in previous paragraph, was part of the initial survey question asking for major ideas. The second statement was made when the initial survey asked the participants to talk about the challenges their students encountered: "Math is a foreign language. You must understand the terminology first." I want to point out that this second question was asked with the intent of getting participating teachers to talk about their students' knowledge, yet Jonathan kept talking in general terms without including his experiences with his students. Interestingly enough, when the same questions were brought up in the interview, and after being reminded of his previous answers, Jonathan did not have anything that he wanted to add to his previous statement. When further probed about the meaning of "The difference between them all", Jonathan responded "I mean that understanding the meaning of them, one how to find them, and two how to use that knowledge to better understand that data."

Because there was a part of the framework that did not produce any comments, C5 Students should make connections between measures of center and variability, I specifically asked all three interviewees about Mean Absolute Deviation (MAD) and Inter Quartile Range (IQR). Jonathan was asked if he had heard the term (MAD) and if he had used it in his class, he responded: "I have not". And when asked if he had used the IQR, Jonathan responded, "No I have not used that one." Jonathan was also asked about weighted means, he responded that he does ask questions about weighted means, but that he did not remember the types of content that he used to introduce the problem of weighted means.

Students. When it comes to Jonathan's knowledge of content and students, he only had two statements that were coded using the framework: "[the student's] misconception is that the numbers are in order when presented" (S3 - Students tend to not order data before finding the 
median) and "Joey knows how to find the measure of central tendency, but does not understand how outliers might throw off the data" (S7- students tend to only know the mean procedurally.) Jonathan also made five statements that were not coded within the framework, three statements about students' struggle with other concepts of measures of center. From the initial survey, Jonathan stated the following: "The next challenge is finding measures of central tendency in forms other than a list of numbers (i.e. a frequency table.)", "For most students, the idea of mean is always the right answer", and "Joey is struggling. Don't we always use the mean? He is trying to realize when is it okay to use another measure of central tendency." Jonathan also commented on issues with outliers when he stated, "Brian seems to struggle with the mean. He seems to be taught or coached about outliers."

During the survey, Jonathan was asked "What challenges, have you seen, or do you expect your students will have in learning the content?". In the CGA prompts Jonathan responded with a statement about how mathematics was a different language and that terminology was very important. In the interview, he was asked to elaborate on his answer and if he wanted to add any other challenges that his students encounter with the subject:

"The hardest part is basically, if we have an average what are some possible data, understanding that concept, make sure they understand that the sum divided by how many items, trying to get that concept down. That would be one problem, if I give the information in table form or in a histogram, what is my average what is my mode based on that information?"

When asked about the misconceptions that his students displayed Jonathan said, "that they are all the same thing [mean, median, mode], if we say center but you know they do have 
different meaning. And that is one thing that they have trouble understanding that there is a difference between them [mean, median, mode], and that is the part that we must understand."

Teaching. With respect to his knowledge of content and teaching, Jonathan was the only teacher that commented on $\mathrm{T} 2$ - Connect statistics to other areas in mathematics. $\mathrm{He}$ commented "One example is just like the one she used (teacher in CGA 1, traditional teaching of procedure). The other example would use fractions or decimals." The first part of this response was codded under Teaching Other because of its generality, however the second sentence eluded to using fractions or decimals (topics in mathematics) when teaching statistics, hence this sentence was coded under T2. The only other comment made that involved the framework was solicited when asked about the challenges students have with the content. He stated that he used, "data that students have an interest in (music length of favorite songs, time spent on phone in a day, etc.)" This last statement was coded as T3-Relying on exploration of real data because Jonathan gave examples of real data he uses in the classroom to make the students more interested in his teaching, displaying his teaching style.

Under the "teaching-other" category, Jonathan made comments that were coded as: direct instruction, discussions, questions, activities. On similarities or differences to the teacher in CGA 1, Jonathan responded: "I say my technique is very similar. I would do at least two examples", "In general I teach median the same way. I first give the definition (middle number)", and "Very similar techniques, show the definition, and look at examples. The difference would be that I try to show bi- or tri-modal problems along with when there is no mode." All these comments were coded under Teaching using direct/individual instruction because in all of them Jonathan mirrored, and confirms using, the direct instruction of the CGA teacher. 
For Teaching by using discussion, Jonathan stated that he would: "Discuss each child's reasoning and have students debate which is correct", "Discuss the outlier. What are the items weighed", "[discuss] measuring what is being said to be true", and "Have students discuss ... why are they both 5?" In this last statement, Jonathan was referring to a student comment on the seventh CGA where the mean and median of two different distributions was 5. When it comes to the types of questions (Teaching using questions as a strategy) that Jonathan used, he mostly concentrated on gathering information: "What was the sum of all those 15's you wrote?", "Make a list like you did? Is 11 on that list?", "if we have an average what are some possible data?", "If the mean is 8 , what are some possibilities of money each student has?". He also had some probing questions: "Do we really need to know everyone's age?", "Did the number of blocks we used change?", and two reflection questions: "If you remove 15, what ideas do you have to keep that sum the same?" and "explain why your answer works."

When asked about improving the students' conception of the measures of center in the CGA prompts Jonathan responded:

"I turn this problem into pay rates at different jobs. I try to make sure the mean is $\$ 15$, the mode is $\$ 10$, and the median is $\$ 11$. Before we look at measures of central tendency, how much do you expect to get paid when you start your job. What does this outlier do to your mean? As the president of the company, I advertise the mean to get people to apply for my company to work. As a worker, what number do you want to know?" This is an activity (Teaching through activities not related to real data) that he uses to get students to think about which measure of center to use. Other activities that Jonathan identified consisted of: "Next we will do a list of numbers with two middle numbers and try to discover how to find the middle of two numbers (i.e. 6 and 8,11 and 12)." 
During the CGA prompts, Jonathan was asked, "How have you, or how do you plan to address the challenges students have with the content?" He answered, "Provide problem solving opportunities to better understand mean, median, mode and use data that students have an interest in." During the interview, Jonathan was asked how he would introduce measures of center, what activities he would use and why. He responded:

"I usually have some sort of a survey on the board, how many pets, how many tv's, something like that. I use the definition of statistics—collecting, organizing, and interpreting data. So, I collected it, now we must start interpreting it. One way of doing it is by using the measures of central tendency."

As to the reason why he uses these activities:

"I want them to go through the process of doing that 'definition of statistics'. We have to collect data, how do we collect it, do we have to be specific? We get into misleading statistics later on. Are you biased in your information? Let's say you have a favorite baseball team, did you ask mainly people in your survey that were Cubs fans or Cardinal fans, where the case may be, or did you ask all girls or all boys? So we get into that biased information and how that changes everything."

Close to the end of the interview I asked Jonathan, "what does that process (investigative process) mean to you and how do you introduce it to the students?" He responded: "I start with, statistics is a chapter in our book, so I use that definition. Like collecting data, we have all these numbers that mean nothing to us. So now how do we organize them? ... We have frequency tables, line plots, those are the two that we talk about a lot. So now we start making some sense 
out of it, then we start looking at the measures of central tendency. Then how to present that information." During the interview, I made the comment that Jonathan seemed to always start the investigative process with gathering data, and sometimes allowing the students to gather that data. But, did he ever ask his students to come up with the questions to investigate as a way of involving the students and giving them ownership of the process? He responded: "No, and that is something that I need to get better at. I would like the students to come up with the questions. That would be great, but I cannot say honestly that I have done that."

Table 14

Jonathan's Profile Summary Chart

\begin{tabular}{|c|c|c|c|}
\hline Code & Components & $\begin{array}{l}\text { CGA } \\
\text { Protocol }\end{array}$ & Interview \\
\hline $\mathrm{C} 2$ & $\begin{array}{l}\text { Students should have a conceptual understanding of the mean: } \\
\text { fair share, balance point }\end{array}$ & $\checkmark$ & \\
\hline $\mathrm{C} 3$ & $\begin{array}{l}\text { Students should understand that mean, median, mode is a way } \\
\text { of representing the data using a single number. }\end{array}$ & & + \\
\hline $\mathrm{C} 4$ & $\begin{array}{l}\text { Students should relate the choice of measure of center to the } \\
\text { shape of the distribution and context the data were gathered. }\end{array}$ & $\checkmark$ & + \\
\hline $\mathrm{CO}$ & $\begin{array}{l}\text { Students should understand differences between measures of } \\
\text { center }\end{array}$ & $\checkmark$ & \\
\hline $\mathrm{CO}$ & Students should understand the terminology & $\checkmark$ & \\
\hline $\begin{array}{l}\text { S1 } \\
\text { S3 }\end{array}$ & $\begin{array}{l}\text { Students tend to think of minimums and maximums as outliers. } \\
\text { Students tend to not order data before finding the median. }\end{array}$ & $\checkmark$ & \\
\hline S6 & Students tend to have difficulty calculating weighted means. & & \\
\hline S7 & Students tend to only know the mean procedurally. & $\checkmark$ & + \\
\hline $\mathrm{SO}$ & Teachers explaining students' conception of average & $\checkmark$ & \\
\hline SO & Students tend to have issues with outliers & $\checkmark$ & \\
\hline SO & Students' struggles with other concepts of measures of center & $\checkmark$ & \\
\hline
\end{tabular}




\begin{tabular}{|c|c|c|c|}
\hline Code & Components & $\begin{array}{c}\text { CGA } \\
\text { Protocol }\end{array}$ & Interview \\
\hline & T1a - Formulate Questions & & + \\
\hline & T1b - Collect Data & & \\
\hline & T1c - Analyze data & & + \\
\hline & T1d - Interpret results & & + \\
\hline $\mathrm{T} 2$ & Connect statistics to other areas in mathematics. & $\checkmark$ & \\
\hline $\mathrm{T} 3$ & Relying on exploration of real data. & $\checkmark$ & + \\
\hline TO & Teaching through activities not related to real data & $\checkmark$ & \\
\hline TO & Teaching using direct/individual instruction & $\checkmark$ & \\
\hline TO & Teaching by using discussion & $\checkmark$ & \\
\hline TO & Teaching using questions as a strategy & $\checkmark$ & \\
\hline
\end{tabular}

Summary. Table 14 shows the summary of Jonathan's discussions during the CGA and the interview. Some of the components of the framework did not show up in the CGA responses but were discussed during the interview. Within this section, I have introduced the evidence of Jonathan's knowledge of content and teaching (KCT), knowledge of content and student (KCS), and his knowledge of curriculum. Of the five identified components of the knowledge of curriculum, Jonathan only commented on fair share and relating the choice of measure of center to the distribution of the data. He did not discuss the other components of knowledge of curriculum: median as central point, mean median and mode as a way of representing the data with a single number, and make connections between measures of center and variability. Jonathan gave additional evidence of his knowledge of content and curriculum through his statements under Curriculum Other. These statements equally concentrated on the students' need to see differences between measures of center and their need to know the terminology. 
On KCS, Jonathan commented on his students ignoring 0 when finding the mean (S2), students' lack of ordering data when finding the median (S3), and the tendency of students to know the mean procedurally and not conceptually. However, Jonathan did not comment on S1 students tend to think of minimum and maximum as outliers, even though that was the major idea for one of the CGA's. He also did not comment on other component of KCS, even though the opportunity arose several times in the CGA's and in the semi-structured interview. Other comments on knowledge of content and students concentrated on explaining students' conception of measures of center as well as highlighting students' issues with outliers and struggles with other concepts of measures of center.

Jonathan discussed during the CGA prompts some of the components of KCT that were identified by the framework, however his comment on $\mathrm{T} 3$ - Connecting statistics to other areas of mathematics was too fleeting to be considered a component of the knowledge that this teacher has. When discussing reliance on real data, Jonathan mentioned some of the data that he would be able to use (something students were interested in), also in a later example used data from salaries to create an activity. In the interview, he discussed what he thought of as the "definition of statistics", to include some more components of the investigative process by gathering, displaying and interpreting data. It should be mentioned that he also did not feel comfortable allowing the students to come up with the questions to investigate, something that teachers are expected to do (Franklin et al., 2007), and a concept that can and should be taught in the classroom. Jonathan also provided some additional evidence of his teaching through his comments under Teaching Other. Jonathan showed that he taught mostly through questioning and discussion. 


\section{Kasy's Profile}

Kasy is a middle school teacher who has taught in a school district in the Midwest for the last 20 years. The Fall semester, when the survey and interview took place, was her first semester in a mathematics education Ph.D. program in a university in the Midwest. She has taught statistics in her career, she has had the opportunity to take both content and methods courses through here studies in the teaching of statistics, and she has had professional development geared towards teaching statistics in middle school. In this first section, I will present the results to both her CGA responses and interview, as they pertain to her knowledge of content and curriculum.

Curriculum. The answers to the CGA prompts were not very indicative of her knowledge of curriculum because she concentrated on the teaching aspect of the questions, hence there were only three comments that were coded as components of knowledge of curriculum from the framework. When responding to the initial survey "asking for major ideas" Kasy said: "That the idea of center takes on many forms" which was codded as C3 - Students should understand that mean, median, mode is a way of representing the data using a single number. When contrasting her teaching to the first CGA Kasy responded: "I give students in the class different numbers of popsicle sticks. Then they trade off until every student has the same amount," was coded as C2 - Students should have a conceptual understanding of the mean as fair share, balance point. Later, when asked as to what concept she would connect a fair share activity to she just responded "Average", which also was coded as C2. During the CGA responses Kasy did not have any statements that were codded under Curriculum Other.

When asked in the interview to elaborate and add to response about what major ideas she wanted student to walk away with, Kasy said: 
“So, ... mean, let's say you have popsicles, you have $5 \mathrm{I}$ have 7, but if you are going to do fair sharing than we have 6 a piece. But that does not necessarily work with discreet number. So, if I wanted to know about shoe size... I would think of the mode. With the median you might try to line up kids to know who is in the middle .... So, different situations would call for different measures of center."

When pressed more: "the big one that different measures of center are appropriate for different types of data", she then included an example with salaries and how outliers need to be considered in the measure of center you use. When responding to my inquiry about, C5 Students should make connections between measures of center and variability, Kasy said that she does uses MAD with her $8^{\text {th }}$ graders to discuss variability. IQR received the same answer that she does introduce it to her $8^{\text {th }}$ grade students.

Students. When answering CGA prompts, Kasy's knowledge of content and students was comparable to her knowledge of Curriculum, very few comments were coded as knowledge of content and students. There was one comment under S4 - Students tend to use the mode in the beginning to represent typicality: "Joey's thinking about mean assumes that all the boxes have the same number of pencils." Under S7 - Students tend to only know the mean procedurally Kasy commented: "I want students to understand ideas and form meaning and not just perform calculations to get an answer". Under Students Other Kasy had made comments about Students tend to have issues with outliers: "Sallie does not understand the concept of outliers" and under Teachers explaining students' conception of average Kasy commented: "Joey is struggling with these ideas because he doesn't equate the numbers with their meanings."

When asked about IQR, in the semi-structured interview, Kasy responded that students had issues with finding IQR when it was an even number of pieces of data "Some of the 
misconceptions like if it is an even number of numbers." During the interview when asked to elaborate on challenges encountered through her teaching she responded: "Well one big misconception ... is that when you are finding the median the numbers are in order", "Just getting across to them that mean mode and median are still forms of centering data. Some students do not immediately grasp that idea without examples." She then goes on to say that in a high stakes test there is always the same question about students being give six pieces of data and then asked what the seventh piece needs to be for the average to be a certain number. She identifies the misconception as: "Students would just find the average of the 6 scores." During the interview, she also mentioned that:

"One thing that I learned early in my teaching experience, my students tend to be more kinesthetic and so it's easier, more advantageous to do things where they are tactile. They learn better with tactile kinds of experiences. They also learn better when they see something prior to explaining, prior to the formal explanations. they already have some kind of understanding of what I am getting to so when they actually do the math, they understand why."

When asked about the choice of one of her activities, popsicle sticks for fair share, she explains that: "they have an idea of what average means. By the time students get to 6th grade they generally know how to calculate the average. So, they have some understanding of it as a computation but not as a conceptual idea, the first time I taught 6th grade I realized that at least $50 \%$ of my students did not have a real conceptual understanding of what average was. So, this [popsicle activity] brings it home, that activity makes it clear." Later, when reacting to the third video ( 11 scores mean of 5 , then two more scores need to keep the same mean), the teacher said 
"Initially half of them just find a new average, half do not necessarily relate the average and the total."

Teaching. Knowledge of content and teaching was more visible with Kasy, she made a lot of comments in her responses to CGA prompts and in the interview about the way that she taught. During the CGA prompts, she brought up different activities, popsicle sticks, data gathering on height and weight, that she uses with her students during her teaching. Coded as T1 - Teach statistics through the investigative process, Kasy used data, shoe sizes, and asked her students to analyze the data by finding mean median and mode, and then she asked them to decide as to which measure of center to use. Then, with that data and measure of center in mind, she asked the students to make a recommendation to the store owner as to what shoe size he should buy.

As $\mathrm{T} 3$ - relying on active learning and exploration of real data, Kasy responded to "how do you address challenges that students have?" with "Through projects and activities, and Real World experiences." One of the projects discussed was her use of popsicle sticks to get students to understand fair share. She would give students different number of popsicle sticks and ask them to go around the classroom and trade until they all had the same number of popsicle sticks. When asked how did she know the students were done, the teacher answered: "I notice that eventually it gets quiet because everybody they run into has the same number." She also uses books from the library, where she asks a number of students to make stacks with their library books. She then asks them to share until they all have the same number of books, then she changes the stacks and asks the students "now my average will be different, right?" and the students reaction: "and they will look at me like I am stupid and say, 'Miss. it is the same number of books so it will still be the same average.'" 
Under Teaching Other, Kasy made comments that fell under all the identified themes. There were four comments that were coded under Teaching procedures backwards: "Remember to have an average of 34 the total will always be the same." This comment was made when Kasy was discussing how she would help students with the weighted mean question, where four men had an average of 34. Later she explains that: "I would ask him to determine how many pencils TOTAL I have in the same boxes and then how many pencils could be in each box.” This comment was in response to a question about students creating a distribution when given the mean. Another category that had similar number of comments was Teaching using questions as a strategy. Under this category Kasy commented: "There are 4 men with an average age of 34. What would the total be of these ages. What ages could the men have?" and "I would ask again, how many students are there and can we discard that student just because they don't have any pets."

During the interview I asked Kasy about the investigative process, and her modus operate which was to give students data and then ask to analyze and then make a recommendation, I asked her as to why she did not allow the students to come up with statistical questions to investigate. She responded that "No. And I will give you a reason why", she then went to explain that she had tried once to ask the students for a question to investigate, and the response that she received was too far out of the norm that she did not feel comfortable allowing the students to explore that part of the investigative process. She added: "I think that those kinds of "turning over the learning to students' is possible in maybe high school with older students who have some idea of the purpose of their education."

When asked as to how she would handle misconceptions, "I think that when students discover their own misconceptions, that is the whole idea behind tasks selection, is that part of 
your teaching is to present problems where they will have an opportunity to encounter these misconceptions and then discus. Now once you have had your instruction then you give an appropriate task then you still have some students that do not understand it. Then you might need to explicitly state it, but to me that is always the last resort."

Table 15

Kasy's Profile Summary Chart

CGA

Code

Component

Protocol Interview

C2 Students should have a conceptual understanding of the mean: fair share, balance point

C3 Students should understand that mean, median, mode is a way of representing the data using a single number.

C4 Students should relate the choice of measure of center to the shape of the distribution and context the data were gathered.

S3 Students tend to not order data before finding the median.

S4 Students tend to use the mode in the beginning to represent typicality.

S7 Students tend to only know the mean procedurally.

SO Teachers explaining students' conception of average

SO Students tend to have issues with outliers

T1 Teach statistics through the investigative process.

T1b - Collect Data

T1c - Analyze data

T3 Relying on exploration of real data.

TO Teaching through activities not related to real data

TO Teaching using direct/individual instruction

TO Teaching by using discussion

TO Teaching procedures backwards

TO Teaching using questions as a strategy 
Summary. Table 15 displays the summary of Kasy's discussions during the CGA and the semi-structured interview. Kasy's answers concentrated mostly on the teaching aspect of the CGA's; hence, there were only three comments that were coded as components of curriculum knowledge from the framework, $\mathrm{C} 3$ - representing the data using a single number, and $\mathrm{C} 2-$ Students should have a conceptual understanding of the mean as fair share. When asked in the semi-structured interview to elaborate and add to her response about what major ideas she wanted student to learn, Kasy reiterated how outliers need to be considered in the measure of center that you use. During the interview, Kasy used a situation in which she would include outliers for the purpose of getting students to understand that different measures are appropriate at different times. She also commented that she wanted her students to understand that mean, median, and more are forms of centering the data.

During the CGA prompts, Kasy's KCS was comparable to her knowledge of curriculum: very few comments were coded as KCS. There was one comment under about students using mode at the beginning (S4), and one comment about students knowledge of the mean only procedurally (S7). Under Student Other, Kasy had three different statements about the struggles students have with other concepts of measures of center. During the interview when asked to elaborate on challenges encountered through her teaching, she responded that her students assumed that data were ordered when finding the median. Kasy added evidence of her knowledge of content and students with a couple of statements under Students Other, one explaining students' conception of average and one statement discussing issues students have with outliers.

KCT was more visible with Kasy: she had a lot of comments in her responses to the CGA prompts and in the interview about the way that she taught. During the CGA, she brought up 
different activities, popsicle sticks and data gathering on height and weight, that she uses with her students during her teaching. Kasy also commented that she used real-life data to the question about reacting to student struggles. One of the projects was her use of popsicle sticks to get students to understand fair share. She also uses books from the library for another project. Overall, Kasy's knowledge of teaching was well balanced with activities and discussions about concepts of average; however, there were instances in which she did revert to direct instruction when the concept was more complicated: weighted means and finding the distribution when given the mean. With this last situation of finding possible data points when given the mean, Kasy went directly to the calculation and explained how if there were 10 observations and the average would be 5 , then whatever the observations were they had to add to 50. Additionally, Kasy had multiple comments coded under Teaching Other, those comments were concentrated mostly on using questioning and discussion as a teaching tool.

Overall, Kasy's comments and evidence of her PCK reveal that she concentrated on the teaching aspect of her pedagogy. There were a lot of comments on how she taught and what her students would do in various situations. She was very comfortable discussing activities that she has used in her classroom and activities that she has used to get students to actively engage in the lesson. She commented on some of her students' misconceptions and she has identified some areas where they might struggle with the measures of center. Her knowledge of curriculum was intertwined with her knowledge of students and teaching; hence, it might not have been as clear cut as other teachers, but her comments showed that her knowledge of teaching was more prevalent. 


\section{Monika's Profile}

Monika is a middle school teacher somewhere in the Midwest, she reported during the survey that she had previously taught statistics to her middle school students for the last 20 some years. Monika also reported that she has had classes both in content and methods courses in the teaching of statistics through her scholastic career, and she also has had professional development courses where statistics was discussed. She took the survey within the first week of November, and we conducted the interview within the first week of December of 2016, the interview was a Skype interview.

Curriculum. Responding to CGA prompts, Monika's knowledge of curriculum was limited to only a handful of comments that did not have a specific direction, but were scattered through the spectrum. As far as the framework is concerned, Monika only had two comments that were coded as C2 - Students should have a conceptual understanding of the as fair share, "I think I would have to link to through sharing things equally", and "I think this connects to mean - average money." Both comments were made from a prompt asking on what would a fair share activity could be related to, and how would it be related. When asked about the major ideas she wanted her students to take away from her class Monika she said: "I think that getting students to actually understand the difference of each is major."

When asked, during the interview, if there were any other major ideas that she wanted her students to come away with, Monika said: "No do not think so, with the CCSSM they brought a lot of statistics down to 7 th grade that was covered in high school, so just the basic understanding." When asked if she was familiar with MAD, Monika said that she was and that she was not able to cover MAD during statistics time but she use it during her Algebra 2 class. She also said that she is not able to make a lot of connections because she is not very 
comfortable with the curriculum. When asked about IQR and how has she used it, Monika said: "Yes to know what it is but I have never had any application with it", and "Yes, my students can make box and whisker's plot, but I do not know how to relate that to real life, where do they use that." When asked about weighted means "Not with the term weighted means, that is a new term to me. One thing I do, I have a list of basketball and baseball players' heights. But I do not compare them to each other we just find the average of them. Now I wander if that activity is totally messed up. I'm going to go with NO, sorry."

Students. Monika's knowledge of content and students was evident in a lot of her comments, when asked as to major struggles her students have with the comment she answered: "Students tend to blend these together - they don't see what sets each apart." With respect to the framework Monika made comments about two of the categories under students. One of the comments was coded as S1 - Students tend to think of min and max as outliers, saying: "Eric doesn't understand that data can have outliers." She also commented on S5 - Students tend to ignore mean when it is not part of the data, "Eric - actual mean is not listed in data - seems to want only data from list.", and "Perhaps he has not made the connection that the mean is not always one of the original data points."

The rest of the CGA comments pertaining to students were categorized under "StudentOther". In this category, Monika had most of her comments about how Students' struggles with other concepts of measures of center, she also had comments about issues with outliers. Under issues with outliers Monika commented: "Eric - doesn't understand that data can have outliers", "Sallie - doesn't seem to understand what an outlier actually is, she is over-generalizing the outlier", and "so when they get to seventh grade they have no idea what to do with those things (outliers)." Comments under struggles with other concepts of measures of ceter: "Brian - 
confusing meaning of mean and median - not confident of the definitions", "He is using mean and median interchangeably and needs help understanding the difference", "So they do not understand that median means something different than mean", and "I think the hardest part is getting kids to understand the difference between the mean, median and mode, and that they represent different ideas."

There were comments that were coded as explaining students' conception of average, or just acknowledging what the student was thinking. When responding to a prompt about a student's thinking of the mean, Monika answers: "Joey has a good point - while most of us might think this is the 'easy' way, I would want to ask him why he thinks that", and continues with "I could be the easy way, or maybe he thinks all new boxes of pencils have the same amount." On the same video asked about a different student's thinking: "I feel like this is the way we teach it, so I'm not sure how much is just following a pattern and how much is truly her own thoughts." On the third student's thinking she acknowledges that the student has a good grasp of the content: "since his box is gone - love his thinking - he is showing great insight into the problem."

During the interview when asked for the meaning of "understand the difference of each" Monika answered: "When you say which one is the better measure they do not know how to come up with anything but the average (mean), because that is what they are used to." When reminded of the comments about outliers, in the survey, and asked to elaborate, Monika answered: ". Yes, it seems that that is anywhere in our curriculum, some teachers before me say just ignore them, they do not address them within our curriculum." When asked to elaborate on the statements "students tend to blend those together", and "they do not see what sets each apart", Monika answered: "I think that I struggle with that because I was never taught it well. So, then I think they struggle because of that. I think it is something that I feel I need work on.” 
When asked about other struggles, Monika responded: "statistics is always that last unit. It is always left off, if there is something that does not get to statistics, so every class is different."

Lastly, when asked about a comment on a student's thinking, "Brian is showing great insight" Monika responded: "what I was thinking was that he understands the math behind what they are looking for, so he has insight into what mathematics needs to be done." When urged to differentiate between Brian's insight on concept or procedure: "More about the procedure, yes. Usually the ones that I thought were doing good were very well spoken. They could communicate the math, and I think that communicating the math shows understanding."

Teaching. Monika's knowledge of content and teaching when responding to CGA prompts was displayed by a couple of comments that were coded within the framework, but a lot of comments were coded as "teaching-other". For T1 - teach statistics through the investigative process, Monika commented: "I collect data from my students so that it means something to them - we also talk organizing the data and predict things about it." With T3 - Relying on active learning and exploration of real data, Monika commented: "I would help Joey by building a model with him - this would be a good time to use hands-on activities" and later "I think that he needs to see how he can manipulate the change."

The comments under "teaching-other" were mostly concentrated on Teaching through activities not related to real data, and comments that show Teaching using direct/individual instruction. On activities not related to real data Monika commented: "I try to use activities that require the students not only to compute the measure, but to also use them to describe situations", "I would also love to give him to it to find possible ages for the men and women." When commenting about similarities or differences with the teacher in the first video, Monika responds: "There are similarities here - I think that the information that I present is the same", 
"As I watch this, I'm wondering if I should assume this is all there is? The information that is presented is the same as what I do, but I give lots of examples - 2 modes, no modes" and comments that show that the teacher will use direct/individual instruction: "Eric - need more instruction and possible examples" and "she needs practice with data that doesn't include these (outliers), as well as more instruction."

The rest of the teaching comments were scattered through the categories with single statements that do not give a clear picture of a pattern. Single comments on reflective questions: "What does it mean when we have a part of a pet?", or gathering information questions "How does that get reported in our findings?", or probing comment "I would encourage her to justify why she thought 2 or 3 would be a correct answer."

During the semi-structured interview, I asked Monika if there were any other ways, excluding the survey, that she uses to help her students with measures of center, Monika responded: "I try to do activities where they have to look at real life materials, and where it might be applicable. I struggle with that myself. I try to do the common core approach of working within themselves and coming up with ideas on their own." The next question was about how she introduces measures of center to her classes, "In the beginning, I try to relate it to things that they have already done. Where they have used averages before. They come to me with that basic knowledge, but then I try to use an activity where we are looking at real life numbers, to try to see the differences that each one is." When asked if there were any other activities that she uses she responded that "with statistics I feel like I have to have it written down."

On the first part of the semi-structured interview CGA, students struggle with the idea that two different data sets have the same mean and median. When prompted as to how she helps 
students in this situation Monika responds: "well usually I throw it back at my kids, because I work hard with the mathematical practices for them to communicate it. So, we actually throw it back at them and brake them up in smaller groups, and list what their ideas are, before I narrow it down with what the truth is." When prompted to clarify Monika responds: "I think that I would probably tell them that each set of data is different, and that while they can have the same median and mean, that is why we look at the entire set of data." In the second part of the video when the tables are turned and the students are asked to come up with the data, when given the mean, Monika recognizes that she does not use this as a statistical question. She uses the situation as an algebra activity with the purpose of "if they can talk someone else through it than that is huge" and "also a way to get to that part of your brain that stimulates the thought process differently."

As with the other interviews, I asked Monika about the investigative process and how she implements it in her classroom. She responds: "I was blessed to be part of the 'Model Math Curriculum' team from Illinois, so the Model Math materials that are on the ISBE website I was able to help create those, and we created a couple of activities and I used those." When prompted to talk about the lack of student questions for investigation Monika responds: "I have to be honest again that is the part that gets left out. It depends on if I have time or not, I am sorry to have to admit that to you." At the end of the interview the teacher asked me about my work, and after a little "elevator pitch" about my work she responds: "I have taught a long time and of all the professional development I have had, statistics is absolutely the weakest, and for that same reason it is the last thing on the textbook. I was lucky enough that when I had statistics questions I could ask a high school teacher." 
Table 16

Monika's Profile Summary Chart

\section{CGA}

Code Component Protocol Interview

C2 Students should have a conceptual understanding of the mean: fair share, balance point

C3 Students should understand that mean, median, mode is a way of representing the data using a single number.

C4 Students should relate the choice of measure of center to the shape of the distribution and context the data were gathered.

$\checkmark$

(1)

CO Students should understand differences between measures of
center

CO Students should understand differences between measures of
center

S1 Students tend to think of minimums and maximums as outliers.

S5 Students tend to ignore mean when it is not part of the data.

S7 Students tend to only know the mean procedurally.

SO Teachers explaining students' conception of average

SO Students tend to have issues with outliers

SO Students' struggles with other concepts of measures of center

T1d - Interpret results

T3 Relying on exploration of real data.

TO Teaching using direct/individual instruction

TO Teaching by using discussion

TO Teaching procedures backwards

TO Teaching using questions as a strategy

Note.

$\checkmark$ Means that the teacher discussed the component during the CGA protocol

+ Means that the teacher discussed the component during the Interview

Summary. Table 16 displays the summary of Monika's responses during the CGA and the interview. During the CGA, Monika's knowledge of curriculum was limited to only a handful of comments that did not have a specific direction but were scattered through the 
spectrum. As far as the framework is concerned, Monika only had two comments that were coded as C2-students should understand the mean as fair share — both comments were made from a prompt asking what concept of measures of center a fair share activity could be related to and to which concept it be related. During the interview, she said that she is not able to make a lot of connections because she is not very comfortable with the content. She also commented that students needed to see differences between measures of center and that teachers needed to be cautious throwing out terms like "outliers," instead of looking at the whole data. When asked about IQR and how has she used it, Monika said that she uses the procedures but that she did not make a lot of connections to real-world problems. Hence, with respect to curriculum, Monika did not make a lot of comments, which prompts me to say that she showed a low knowledge of curriculum when compared to the expected knowledge advocated by curriculum documents and research.

Monika showed a fair amount of knowledge of her students in comparison to the expected knowledge from the research. When asked about major struggles that her students have with the content, she answered that students did not see differences and tended to blend the measures of center. With respect to the framework, Monika made comments about three of the categories under students. One of the comments was coded as S1-students tend to think of min and max as outliers and S5-students tend to ignore mean when it is not part of the data. The rest of Monika's CGA comments pertaining to students were categorized under Student Other. With respect to issues with outliers, Monika identified struggling students having issues recognizing outliers.

The comments made show Monika's KCT could be considered low to fair compared to the expected components from the framework. These findings were evident by a couple of 
comments that were coded with the framework, but a lot of comments were coded as Teaching Other. For T1-teach statistics through the investigative process-Monika commented that she collected data from her students to make it more relatable, and then she had a discussion with her students about organizing and making predictions from the data. With $\mathrm{T} 3$ - relying on active learning and exploration of real data-Monika commented that she would help a student by building a model with him using real data and hands-on activities. She did not go into detail about how this was going to be accomplished. The comments under Teaching Other were mostly concentrated on activities that she uses in the classroom and comments that show how teacherheavy, direct instruction, her teaching was. When commenting about similarities or differences with the teacher in the first video, Monika responds that she teaches the same way. The rest of the teaching comments were scattered through the categories with single statements that did not show a clear pattern. 


\section{CHAPTER V: CONCLUSIONS AND RECOMENDATIONS}

\section{Introduction}

In this final chapter, I introduce the central finding of this study in understanding what potential components of PCK looks like with middle school teachers when teaching measures of center in statistics. I start by summarizing the study itself and then introduce some of the primary findings. I then describe the contributions to existing research and the study's implications. I also introduce some of the limitations, followed by recommendations for future research in the same area. I conclude the chapter with a discussion of whether I need to add or omit any of the elements of the conceptual framework developed and, finally, by describing the study's significance.

\section{Summary of the Study}

Statistics has been growing as a field of study (Shaughnessy, 1992) in the last 30 years, and as such, it has gained acceptance within curriculum documents (NCTM, 1989, 2000, 2006; NGA \& CCSSO, 2010). However, as mentioned by Shaughnessy (1992) and Batanero et al. (1994), the preparation of pre-service teachers as well as PD for in-service teachers, has not caught up with the new developments in curriculum. Within the last 10 years there have been some publications to help with teacher preparation that have made recommendations for teaching statistics (Franklin et al., 2007) and for preparing teachers to teach statistics (Franklin et al., 2015). However, as I have outlined in previous chapters, the research on teachers' knowledge for teaching statistics is lacking (Batanero et al., 1994; Franklin et al. 2007; Shaughnessy, 1992, 2007). 
Although there is a growing body of research on PCK within mathematics (e.g., Ball \& Bass, 2003; Ball \& Hill, 2005; Ball et al., 2008; Hill \& Lubienski, 2007; Hill et al., 2008; Shulman, 1986, 1987), the research within statistics has been mostly limited to frameworks and models of PCK. The existing research has concentrated on mapping what PCK should look like (Burgess, 2007; Godino, Batanero, Roa, \& Wilhelmi, 2008; Groth, 2007, 2013; Watson et al., 2008; Watson \& Nathan, 2010) with limited research on what PCK does look like with in-service teachers outside of the United States (Burgess, 2009a, 2009b; Estrella et al., 2015; Ijeh, 2013; Wessels, 2014) and very limited research within the United States concentrating on PSTs (Groth, 2014; Sorto \& White, 2004).

Since its introduction in 2010, the Common Core State Standards for Mathematics (NGA \& CCSSO, 2010) have been adopted by most states (within the United States) as their primary curriculum document. While NCTM $(1989 ; 2000 ; 2006)$ had advocated for statistics to be included as early as the first grade continuing to $12^{\text {th }}$ grade, CCSSM deviated from that precedence and introduced statistics concepts in the sixth grade continuing to 12 grade. This change became the impetus behind this study and its concentration in the introduction of measures of center. Research has shown that students have issues with the conception of measures of center and which measure of center best represents the data (Mokros \& Russell, 1995; Russell \& Mokros, 1990; Leon \& Zawojewski, 1990; Watson \& Moritz, 2000). Hence, teachers should know how to use the given curriculum, what conceptions or misconceptions their students come in with, and what the best way to introduce statistics (Batanero et al., 1994; Franklin et al. 2007; Shaughnessy, 1992, 2007).

Although statistics has been gaining momentum within curriculum and standards documents, published to suggest how statistics should be taught, there has been little research 
with in-service teachers in the United States to understand what knowledge they have with respect to teaching statistics. For these reasons, I designed a study to examine teachers' knowledge with respect to teaching statistics in middle school. For this study, after examining several frameworks that were put forth by research, I found it necessary to create my own framework to adhere to the intersection of PCK and the topic of measures of center. I looked at existing research and curriculum documents, and I expanded on Hill et al. (2008) conceptualization of PCK by giving specific components to each of their three major ideas of pedagogy.

When looking at the studies conducted in the 1990's (Even, 1993; Even \& Tirosh, 1995; Wilson, 1994) researchers were using classroom observation to get a glimpse of what knowledge teachers demonstrated. From observations researchers evolved their thinking on how to understand teacher knowledge. While observations have not lost their appeal and are still used today, researchers have adventured into creating assessment instruments to understand teacher knowledge especially pedagogical content knowledge (Ball et al., 2008; Hill et al., 2008; Hill \& Lubienski, 2007; Watson, 2001). In this study, the adventure of creating assessment instruments has evolved into the use of animations (comics) to understand teachers' knowledge. This methodology, as and argued by different researchers (Chazan \& Herbst, 2012; Herbst \& Chazan, 2015; Herbst, Chazan, Chen, Chieu, \& Weiss, 2011; Herbst \& Kosko, 2014) presents an opportunity in understanding teacher's knowledge. Following Herbst and his colleagues' recommendations, I have used Computer-Generated Animations as the main instrument to analyze the characteristics of participating teachers' knowledge when teaching measures of center in middle school. 
To do what Herbst and his colleagues' advocated I seven Computer-Generated Animations (CGA's), whose content was taken directly from research and curriculum documents and asked the teachers to answer prompts designed to elicit evidence of their knowledge as it related to teaching statistics. The creation of the CGAs was started by first writing seven different vignettes that introduced different ideas, struggles, and concepts about measures of center as well as prompts designed to solicit participants' knowledge of pedagogy. Once the vignettes were written, the CGAs were created using a web-based design program. After that, a web-based platform was created on which the teachers could view the CGAs and answer the corresponding prompts. The end-product was piloted three times and improved on for ease of viewing and information solicited.

There were eight teachers who participated in the study, all of whom had taught statistics in middle school at least once during their career. Three of the teachers participated in semistructured interviews that were designed to further probe their thinking and to clarify any vague comments made in the CGAs. The interview questions were informed by an initial analysis of the data received in the CGAs, and an additional CGA was designed specifically for the interviews so that the teachers would not have to review all previous CGAs. The data were analyzed in two cycles. In the first cycle, the data gathered from the CGAs was analyzed using the codes from the conceptual framework. In the second cycle, the statements without codes were analyzed for emerging patterns and themes and were further categorized as other ideas of content, students, and teaching. Lastly, the three teacher interviews were used as supplemental data to better understand their pedagogical content knowledge. 


\section{Discussion on Teacher's Pedagogical Content Knowledge}

This study had one major research agenda about the PCK teachers exhibit when teaching statistics in middle school. That agenda was further divided into three specific questions:

1. What characteristics of knowledge of content and curriculum do middle school mathematics teachers exhibit when reflecting on teaching measures of center?

2. What characteristics of knowledge of content and students do middle school mathematics teachers exhibit when reflecting on teaching measures of center?

3. What characteristics of knowledge of teaching do middle school mathematics teachers exhibit when reflecting on teaching measures of center?

Table 17 gives a visual of the level of response that each component of the framework was discussed by the participating teachers. The following sections will discuss how the three research questions were answered by the findings of this study.

Table 17

Expected Statistical Knowledge for Teaching Measures of Center 2

\begin{tabular}{llc}
\hline Code & \multicolumn{1}{c}{ Component } & $\begin{array}{c}\text { Level of } \\
\text { response }\end{array}$ \\
\hline C1 & $\begin{array}{l}\text { Students should understand the median as a central point. } \\
\text { C2 }\end{array}$ & $\begin{array}{l}\text { Students should have a conceptual understanding of the mean: fair } \\
\text { share, balance point }\end{array}$ \\
C3 & $\begin{array}{l}\text { Students should understand that mean, median, mode is a way of } \\
\text { representing the data using a single number. }\end{array}$ & $12.5 \%$ \\
C4 & $\begin{array}{l}\text { Students should relate the choice of measure of center to the shape of } \\
\text { the distribution and context the data were gathered. }\end{array}$ & $57.5 \%$ \\
C5 & $\begin{array}{l}\text { Students should make connections between measures of center and } \\
\text { variability. }\end{array}$ & $50.0 \%$ \\
S1 & Students tend to think of minimums and maximums as outliers. & $0.0 \%$ \\
& & (Table Continues)
\end{tabular}




\begin{tabular}{llc}
\hline Code & \multicolumn{1}{c}{ Component } & $\begin{array}{c}\text { Level of } \\
\text { response }\end{array}$ \\
\hline S2 & $\begin{array}{l}\text { Students tend to ignore 0 in the data set when computing measures of } \\
\text { center. }\end{array}$ & $0.0 \%$ \\
S3 & Students tend to not order data before finding the median. & $50.0 \%$ \\
S4 & Students tend to use the mode in the beginning to represent typicality. & $25.0 \%$ \\
S5 & Students tend to ignore mean when it is not part of the data. & $62.5 \%$ \\
S6 & Students tend to have difficulty calculating weighted means. & $12.5 \%$ \\
S7 & Students tend to only know the mean procedurally. & $37.5 \%$ \\
& & $12.5 \%$ \\
T1 & Teach statistics through the investigative process. & $0.0 \%$ \\
& T1a - Formulate Questions & $12.5 \%$ \\
& T1b - Collect Data & $12.5 \%$ \\
& T1c - Analyze data & $25.0 \%$ \\
& T1d - Interpret results & $12.5 \%$ \\
T2 & Connect statistics to other areas in mathematics. & $75.0 \%$ \\
T4 & Relying on exploration of real data. & $0.0 \%$ \\
\hline
\end{tabular}

\section{Knowledge of Content and Curriculum}

The evidence supported by this study's findings point to teachers being comfortable discussing certain components of their knowledge of content ad curriculum. The component that teachers were most comfortable discussing and showed evidence of was C2 - Students should have a conceptual understanding of the mean: fair share, balance point. As evident by table 17, $87.5 \%$ of the teachers made a comment that was coded as $\mathrm{C} 2$. The components that teachers did not show a lot of evidence of, but still discussed, were C3 - Students should understand that mean, median, mode is a way of representing the data using a single number and C4 - Students should relate the choice of measure of center to the shape of the distribution and context the data were gathered. Both categories were discussed by $50 \%$ of the teachers. Lastly one teacher discussed C1 - Students should understand the median as a central point and no teachers 
provided evidence of C5 - Students should make connections between measures of center and variability.

There were only two questions that were the source of most of the codes for curriculum: one in the initial survey that asked about major ideas that the teachers wanted to bring across in their teaching, and one in the fourth CGA that directly asked what concept teachers would connect using a given activity. With respect to the concept of mean as fair share or leveling off data, the teachers made comment about it; however, almost all (14 of 15) comments came after the animated teacher (in CGA 4) demonstrated a fair share activity to the classroom and the prompt asked what concept to connect the activity to and how to use the activity in the classroom.

Thinking of the measures of center as representing the data using a single number, the comments that were offered discussed the idea by mentioning that all measures of center gave different information about the data. As far as relating the choice of the center to the shape and the context of the data, the evidence given was concentrated mostly on singular points (outliers) and did not mention, nor discuss, the shape or the context of the data. The data about knowledge of content and curriculum reveals that teachers exhibit some ideas about measures of center that they keep coming back to. With the idea of the outliers skewing the data, the comments seemed to come back to that concept multiple times; however, there were also four teachers who did not give any evidence of a connection between outliers and their effect on the choice of which measure of center to use. No comments, during the CGAs or the interviews, discussed students making connections between measures of center and variability through IQR or MAD, which is a major recommendation from the CCSSM (NGA \& CCSSO, 2010) in Grade 6. 
Even though the components of the framework were based on curriculum documents and research, participants did not show evidence indicating that their knowledge matched what had been recommended by researchers. Similar findings were observed by Watson (2001), who reported that even though there were a lot of activity-based lesson plans at the primary level, there was almost no evidence a uniformity of curriculum. Watson also found that the major curriculum document, curriculum adopted by most Australian schools, was only used by a quarter of the secondary teachers, a finding that I might speculate could be confirmed by this

study as well, in that most of participating teachers did not provide evidence of knowledge of content and curriculum.

\section{Knowledge of Content and Students}

KCS is the knowledge that teachers have when recognizing what conceptions, misconceptions, and strategies students use in solving statistical questions. This study showed that most teachers are comfortable, gave evidence of, discussing the fact that S1 - Students tend to think of minimums and maximums as outliers. This component of the knowledge of content and students was discussed by $75 \%$ (6) of the teachers, as shown in table 17 . The table also shows that teachers gave some evidence of knowledge of components S3 through S7, but gave no evidence of component S2 - Students tend to ignore 0 in the data set when computing measures of center.

There were numerous prompts that asked teachers to discuss topics that would reveal their knowledge of students. It should be mentioned that one of the initial survey questions asked specifically about challenges that students have, but only half of the teachers specifically identified a challenge that students have that was aslo identified by the research, with three of 
these teachers concentrating on differences between measures of center. Those comments were not about making a choice about which measure of center to use but were about differences, in definition and computational algorithm, between the three measures of center. The other comment about challenges came from one teacher recognizing that students do not see the need to have ordered data when finding median. The rest of the comments were about vocabulary, with one teacher deviating completely to division in mathematics, without making any connections to statistics, and how her students had issue when dividing decimals.

Three participants made at least three comments coded as S1—Students tend to think of minimum and maximum as outliers. Two of those teachers took the acknowledging of an outlier by a student as a given and commented on whether the elimination of said outlier was correct or not. One teacher commented that students should not just eliminate outliers and find the mean, whereas another said that was a good idea, recognizing that the outlier can skew the data. The third teacher acknowledges what the student is doing without passing judgment; interestingly though, this third teacher also recognizes that the students are eliminating what they "thought was an outlier." The third teacher does not seem to agree with the assumption of the students that the min and max are outliers. This misunderstanding about outliers can stem from the lack of emphasis on dealing with outliers in the CCSSM (NGA, CCSSO, 2010); however, there was a good deal of emphasis placed on outliers by Kader, Jacobbe, Wilson, and Zbiek (2013), who did outline why outliers were important as well as how to identify an outlier. In this study, most teachers would readily acknowledge a student's response instead of responding to the solution displayed. Similarly, Watson et al. (2008) reported that, at the low level, teachers were not successful at responding to student work or questions. Similarly Hashweh (1987) found that low 
content knowledge teachers tended to reinforce preconceptions and incorrectly criticized correct student answers.

\section{Knowledge of Content and Teaching}

$\mathrm{KCT}$ is the knowledge that teachers display when deciding which instructional strategy is the most appropriate for a given classroom situation. KCT also incorporates the knowledge teachers have about different representations of a given topic. The one component, about knowledge of content and teaching, that participants gave plenty of evidence about was T3relying on exploration of real data, as evidenced by six participants' comments. Participating teachers did not give a lot of evidence to the rest of the components, as shown by table 17, where at most two teachers commented on T1b-Interpreting results, and no comments were given for T1a-Formulating questions, or T4-making effective use of technology and assessment.

Of the six teachers who commented on T3, only two tried to recognize the actual context of the real data that they were using, and the rest of the teachers merely mentioned the use of real data. From the comments pertaining to $\mathrm{KCT}$, only $8 \%$ corresponded to one of the codes created in the framework; the rest of the comments were attributed to other ideas about teaching. And as previously discussed, the comments made could have pertained to any subject within mathematics and were not specific to statistics.

It was evident that participants mainly employed direct instruction, a finding corroborated by Ijeh (2013), who reported that most teachers taught the topic in a step-wise and mostly procedural fashion. As with Watson et al. (2008), who reported teachers giving generic suggestions to students work, my participants gave such vague suggestions that they did not even pertain to statistics. Similar, to the comments that Monika made (in the interview) that she did 
not feel comfortable teaching because of her missing knowledge, Batanero and Diaz (2010) also reported that their teachers did not feel prepared to help their students. Hashweh (1987) and Carlsen (1993) also reported that teachers with low knowledge of content tended to not deviate from activities presented in books, showing that they were not comfortable teaching the subject.

Overall, the knowledge of content and curriculum that these participants displayed centered on relating the choice of measure of center to a single point in the data, mostly outliers, but not to the shape or context of the data. These teachers also concentrated on the idea that measures of center give different information about the data but did not comment that they are a way of representing the data using a single number. On the KCS, these participants concentrated on students struggling with outliers, ordering data when finding the median, and ignoring the mean when it was not part of the data. Under KCT, participants concentrated on the need for relying on exploration of real data; however, only a couple gave examples of what that data wood look like. It was interesting to note that no teachers seemed comfortable allowing students to formulate their own questions for investigation, a finding that was also confirmed in the interviews.

\section{Limitations}

One of the more prevalent limitations in this study is the fact that I was only able to conduct this study with eight teachers and was only able to interview three of them. If I had had a larger sample of in-service teachers to work with, I might have been able to get more evidence of teachers commenting on more components of the framework. With a larger sample of teachers, I might have been able to further validate my assessment protocol. Another limitation would be the distribution of the prompts that I created. Most of the prompts ask participants to discuss 
their teaching more than their knowledge of curriculum. This distribution of prompts might have contributed to the lack of comments about curriculum; however, I found it hard to create CGAs that would be more inclusive of curriculum knowledge.

\section{Discussion on Extending the Conceptual Framework}

I this section I will discuss the merits of changing or adding components to the conceptual framework, based on the data received. For every type of knowledge that was discussed in the conceptual framework, there were at least three additional categories that teachers commented on. When it comes to knowledge of curriculum, only one category (students should understand the terminology) had enough discussion to merit discussing inclusion in the framework. However, most of the comments were made in passing and did not fundamentally relate to the topic. Teachers only mentioned terminology as words that needed to be used and not as concepts that needed to be understood. So, for knowledge of curriculum, I do not think there is a category that would merit inclusion.

Under the umbrella of KCS, there were four new categories that emerged from the data gathered by the CGAs. Three of these categories each made up around $20 \%$ of the data about students: students tend to struggle with other concepts of measures of center $(21 \%)$, teacher explaining student thinking (19\%), and students tend to struggle with the conception of average $(17 \%)$. For the first category (conceptions of measures of center), I think that this category should be included in the framework. It is important for teachers to know that because the curriculum emphasizes at least two different conceptual models for measures of center, their students have issues conceptualizing measures of center. 
For the category "students tend to struggle with the conception of average," I would advocate for it to not be included in the framework because most of the comments were about how students struggle with the procedure, vocabulary, and recognizing differences in measures. This category was plagued with very general statements about student struggles, and few comments were made about specific misconceptions or conceptions that students have. The last category, "teacher explaining student thinking," does not merit inclusion in the framework because most comments were about what the teacher thought the students was thinking or doing. This is an important category to discuss, but it does not seem feasible to expect that all teachers would explain their students' thinking the same way, and the explaining of student thinking is the underlying expectation of the whole category of KCS.

KCT was a category in which the discrepancy between the framework and the comments made was very wide. In this category, only $8 \%$ of the comments were directed to the framework, and the rest (92\%) were other ideas about teaching. However, because most of the comments did not pertain to statistics, none of the categories merit inclusion in the framework.

\section{Recommendations}

\section{Thoughts on Professional Development}

Because I only interviewed eight teachers, there is not enough information to generalize what PD should look like. However, here are my initial thoughts about what PD could look like based on what my participants did. I think that PD should first advocate for the introduction of median as a central point as well as ways of connecting measures of center to variability. PD should also emphasize that measures of center are all used as ways of representing data using a single number, PD should also emphasize the choice of measure of center to the shape of the 
distribution and the context of the data gathered. Even though the findings suggested that teachers might have a conceptual understanding of measures of center, that does not mean that, as a topic, it should be omitted from the discussion.

As with Carpenter, Fennema, and Franke (1996), exposing teachers to the way that their students think should be beneficial in getting teachers to better understand their students' thinking and strategies that they use. The topics to concentrate on should be the idea that students tend to ignore 0 when calculating the mean and that student seem to have an easier time in the beginning if we start by introducing the mode. Other topics for discussion are the difficulty that students have with weighted means (Gattuso, Mary, 1998; Leavy O'Loughlin, 2006) and the fact that students can compute the mean procedurally without having a conceptual understanding.

An activity that educators could employ would be the analysis of student work (Groth, 2014). This activity would give teachers an idea of how students engage with different problems, giving teachers another insight into their students' thinking. Getting teachers to understand their students' misconceptions might make it easier for teachers to prepare for the inevitable moment when those misconceptions rear their ugly heads. From research (Russell \& Mokros 1990), we know that teachers have similar prevailing ideas about measures of center as do their students. I think that one way to address this would be for PD, as well as university teaching, to create an environment in which the teachers would encounter their own misconceptions and have the chance to see how said misconception should be addressed.

Using investigations to teach statistics has been a topic discussed in numerous curriculum documents (Franklin et al., 2007; NCTM, 1989, 2000, 2006; NGA \& CCSSO, 2010), and this study found that teachers have some gaps in their knowledge. One topic to focus on would be allowing the students to pick the questions for investigation to give them ownership of the 
process. This can be done by having teachers get acquainted with characteristic of good statistical questions. Teachers seemed reluctant to allow student to collect data and always presented them with a set of data, or if data were collected, it was something that students could do in class. The investigation would be richer if students were allowed to pick their data from different sources.

Teachers should also discuss different types of tasks (Smith \& Stein, 1998) that they introduce to their students to understand the progression of tasks as well as the need for higher level tasks to be created and used in the classroom. Tasks should be chosen to make connections to mathematics and other topics within statistics as well as to use technology effectively for teaching statistics. Even though activities were discussed in the study, teachers should be encouraged to come up with activities that highlight differences within measures of center as well as make connections to the types of questions asked and discussion developed in class and the teaching style. However, more research needs to be done with more teachers in order for us to generalize these findings.

\section{Recommendations for Research}

The next logical step in future research would be to further use and improve the CGAs as an assessment instrument, something that has already started with Herbst (2011), who argued that animations could work as well as videos in assessing teacher noticing of mathematics. As I mentioned in the limitations, I think that it would be beneficial to conduct this study again with a larger number of teachers to see if the results can be further refined. Another direction would be to use CGAs in understanding teacher knowledge in other aspects of statistics, such as variability, inferences, and statistical associations. Within the research on PD, it would be 
beneficial to create the PD to include the topics mentioned above and then see how well that PD is helping in-service teachers. The creation of PD was one of the reasons for this study: I wanted to know in what areas PD would be more successful.

\section{Significance and Contributions of the Study}

This study contributes to the existing literature about the PCK that in-service teachers have in teaching statistics in middle school. As previous studies have shown (Batanero et al., 1994; Olfos, \& Mena-Lorca, 2015; Ijeh, 2013; Watson, 2001; Wessels, 2014), I found that teachers do not always display the knowledge that curriculum documents or hypothesized models would expect a teacher to have. Shulman (1986) commented that knowledge of curriculum was lacking with in-service teachers, and I found that only $13 \%$ of the comments made pertained to knowledge of curriculum. As previously discussed by Callingham (1997), teachers have limited understanding of the conceptual meaning of measures of center, as seen in the comments coded as $\mathrm{C} 2$ (students should have a conceptual understanding of the mean: fair share, balance point), and most of those comments came only after the activity was presented in the CGA (4).

This study adds to the KCS literature by reporting on the challenges that teachers know their students struggle with. I discussed how teachers are aware of their students' struggles with outliers, but teachers themselves might have similar misconceptions. Teachers exhibited awareness of student struggles with ordering data when finding median and not wanting to use the mean when it is not part of the data. I also reported that most of these participants were aware that students tend to think of minimum and maximum as outliers and attempt to eliminate perceived outliers when finding the mean. 
This study also adds to information about teachers' KCT, or lack thereof. Most participants did not make use of the investigative process, something that has been advocated for the teaching of statistics from NCTM (1989) to Franklin et al. (2007). This study also adds to the knowledge of how teachers use the investigative process, and the fact that teachers do not feel comfortable allowing students to come up with questions to investigate. Being able to come up with questions to investigate allows the student to take ownership of their learning and allows them to feel part of the learning process (Franklin et al., 2007).

This study also adds to the literature on teacher noticing as well as using CGAs to analyze and find evidence of teacher knowledge. In this study, I used CGAs so that the participating teachers would not be distracted by environmental or student-driven conflicts. This is an innovative approach because the teacher was placed in a comfortable setting (at home) examining someone else's work and hence gave a richer set of responses. Star and Strickland (2008) found that PSTs had issues with noticing tasks and the actual mathematical content being discussed because of classroom distractions. The use of CGAs also contributes to the literature put forth by Herbst et al. (2011) who advocated that comics (animations) could be used to solicit teachers' knowledge of pedagogy. The authors advocated for comics because they could control the narrative and which details the teachers payed attention to.

\section{Concluding Thought}

This study has given me the opportunity to contribute to the research on teacher knowledge as it relates to teaching statistics in middle school. I had the opportunity to create several Computer-Generated Animations to help me gather the data used in this study. I had to establish my own conceptual framework to analyze the data collected. To a pessimist, the data 
gathered paints a rather gloom picture of what pedagogical content knowledge looks like with inservice teachers. However, my main goal was not simply to judge the participating teachers, but to give them an opportunity to write their own narrative, and to give researchers, like me, the data unto which they can create their own arguments and future research. This study give me the opportunity to contribute to the conversation as to how best to help improve teacher preparation, in school as well as professional development. 


\section{REFERENCES}

American Statistical Association \& National Council of Teachers of Mathematics. (2013). Preparing pre-K-12 teachers of statistics: A joint position statement of the American Statistical Association (ASA) and the National Council of Teachers of Mathematics (NCTM). Retrieved from http://www.nctm.org/Standards-and-Positions/Position$\underline{\text { Statements/Preparing-Pre-K-12-Teachers-of-Statistics/ }}$

Ball, D. L., \& Bass, H. (2003). Toward a practice-based theory of mathematical knowledge for teaching. In B. Davis \& E. Simmt (Eds.), Proceedings of the 2002 annual meeting of the Canadian Mathematics Education Study Group / Groupe Canadien d'Étude en Didactique des Mathématiques (pp. 3-14). Edmonton, Alberta, Canada: Canadian Mathematics Education Study Group / Groupe Canadien d'Étude en Didactique des Mathématiques.

Ball, D. L., Bass, H., Sleep, L., \& Hoover, M. (2004, February). Using records of practice to tackle the unsolved problem of teachers' mathematical knowledge. Presentation at California State University-Northridge.

Ball, D. L., \& Hill, H. C. (2005, April). Knowing mathematics as a teacher. Presentation at the annual meeting of the National Council of Teachers of Mathematics, Anaheim, CA.

Ball, D. L., Thames, M. H., \& Phelps, G. (2008). Content knowledge for teaching: What makes it special? Journal of Teacher Education, 59(5), 389-407.

doi: $10.1177 / 0022487108324554$ 
Batanero, C., Burrill, G., \& Reading, C. (Eds.). (2011). Teaching statistics in school mathematics—Challenges for teaching and teacher education: A joint ICMI/IASE study. Dordrecht, the Netherlands: Springer. doi:10.1007/978-94-007-1131-0

Batanero, C., \& Díaz, C. (2010). Training teachers to teach statistics: What can we learn from research? Statistique et enseignement, 1(1), 5-20. Retreived from http://publicationssfds.math.cnrs.fr/index.php/StatEns/article/view/3

Batanero, C., Godino, J. D., Vallecillos, A., Green, D. R., \& Holmes, P. (1994). Errors and difficulties in understanding elementary statistical concepts. International Journal of Mathematical Education in Science and Technology, 25(4), 527-547.

doi:10.1080/0020739940250406

Begg, A., \& Edwards, R. (1999, December). Teachers' ideas about teaching statistics. Paper presented at the combined annual meeting of the Australian Association for Research in Education and the New Zealand Association for Research in Education, Melbourne, Australia.

Begle, E. G. (1979). Critical variables in mathematics education: Findings from a survey of the empirical literature. Washington, DC: Mathematics Association of America; Reston, VA: National Council of Teachers of Mathematics.

Borko, H., Jacobs, J., Eiteljorg, E., \& Pittman, M. E. (2008). Video as a tool for fostering productive discussions in mathematics professional development. Teaching and Teacher Education, 24(2), 417-436. doi:10.1016/j.tate.2006.11.012

Burgess, T. A. (2007). Investigating the nature of teacher knowledge needed and used in teaching statistics (Doctoral thesis, Massey University, Palmerston North, New Zealand). Retrieved from http://mro.massey.ac.nz/handle/10179/534 
Burgess, T. (2009a). Teacher knowledge and statistics: What types of knowledge are used in the primary classroom? The Montana Mathematics Enthusiast, 6(1-2), 3-24.

Burgess, T. (2009b). Statistical knowledge for teaching: Exploring it in the classroom. For the Learning of Mathematics, 29(3), 18-21.

Burgess, T. A. (2011). Teacher knowledge of and for statistical investigations. In C. Batanero, G. Burrill, \& C. Reading (Eds.), Teaching statistics in school mathematics—Challenges for teaching and teacher education: A joint ICMI/IASE study (pp. 259-270). Dordrecht, the Netherlands: Springer. doi:10.1007/978-94-007-1131-0_26

Callingham, R. A. (1997). Teachers' multimodal functioning in relation to the concept of average. Mathematics Education Research Journal, 9(2), 205-224. doi:10.1007/BF03217311

Cai, J. (1998). Exploring students' conceptual understanding of the averaging algorithm. School Science and Mathematics, 98(2), 93-98. doi:10.1111/j.1949-8594.1998.tb17398.x

Capraro, M. M., Kulm, G., \& Capraro, R. M. (2005). Middle grades: Misconceptions in statistical thinking. School Science and Mathematics, 105(4), 165-174. doi:10.1111/j.1949-8594.2005.tb18156.x

Carlsen, W. S. (1993). Teacher knowledge and discourse control: Quantitative evidence from novice biology teachers' classroom. Journal of Research in Science Teaching, 30(5), $471-481$.

Carpenter, T. P., Fennema, E., \& Franke, M. L. (1996). Cognitively guided instruction: A knowledge base for reform in primary mathematics instruction. The Elementary School Journal, 97(1), 3-20. 
Casey, S. A. (2008). Subject matter knowledge for teaching statistical association. Available from ProQuest Dissertations and Theses database. (UMI No. 3353096)

Chatzivasileiou, E., Michalis, I., Tsaliki, C., \& Sakellariou, I. (2011). In service elementary teachers' conceptions of arithmetic mean. In Bulletin of the International Statistical Institute Proceedings of the 58th World Statistical Congress 2011 (pp. 4869-4873). Retrieved from http://2011.isiproceedings.org/papers/950460.pdf

Chazan, D., \& Herbst, P. (2012). Animations of classroom interaction: Expanding the boundaries of video records of practice. Teachers College Record, 114(3).

Cobb, G. W., \& Moore, D. S. (1997). Mathematics, statistics, and teaching. American Mathematical Monthly, 104(9), 801-823. doi:10.2307/2975286

Conference Board of the Mathematical Sciences. (2012). The mathematical education of teachers II. Providence, RI: American Mathematical Society; Washington, DC: Mathematical Association of America.

Cooper, L. L., \& Shore, F. S. (2008). Students' misconceptions in interpreting center and variability of data represented via histograms and stem-and-leaf plots. Journal of Statistics Education, 16(2). doi:10.1080/10691898.2008.11889559

Danielowich, R. M. (2014). Shifting the reflective focus: Encouraging student teacher learning in video-framed and peer-sharing contexts. Teachers and Teaching, 20(3), 264-288. doi:10.1080/13540602.2013.848522

Ernest, P. (1994). An introduction to research methodology and paradigms. Exeter, Devon, England: Research Support Unit, School of Education, University of Exeter. 
Estrella, S., Olfos, R., \& Mena-Lorca, A. (2015). El conocimiento pedagógico del contenido de estadística en profesores de primaria [Pedagogical content knowledge of statistics among primary school teachers]. Educacao E Pesquisa, 41(2), 477. doi:10.1590/S151797022015041858

Even, R. (1993). Subject-matter knowledge and pedagogical content knowledge: Prospective secondary teachers and the function concept. Journal for Research in Mathematics Education, 24(2), 94-116.

Even, R. \& Tirosh, D. (1995). Subject-matter knowledge and knowledge about students as sources of teacher presentations of the subject matter. Educational Studies in Mathematics, 29(1), 1-20.

Franklin, C. (2014). The statistical education of teachers (SET): An American Statistical Association policy document. In K. Makar, B. de Sousa, \& R. Gould (Eds.), Sustainability in statistics education: Proceedings of the Ninth International Conference on Teaching Statistics. Voorburg, the Netherlands: International Statistical Institute. Retrieved from https://iaseweb.org/icots/9/proceedings/pdfs/ICOTS9_1A2_FRANKLIN.pdf

Franklin, C. A., Bargagliotti, A. E., Case, C. A., Kader, G. D., Scheaffer, R. L., \& Spangler, D. A. (2015). The statistical education of teachers. Alexandria, VA: American Statistical Association. Retrieved from www.amstat.org/education/SET/SET.pdf

Franklin, C., Kader, G., Mewborn, D., Moreno, J., Peck, R., Perry, M., \& Scheaffer, R. (2007). Guidelines for assessment and instruction in statistics education (GAISE) report: A preK-12 curriculum framework. Alexandria, VA: American Statistical Association. 
García Cruz, J. A., \& Garrett, A. J. (2008). Understanding the arithmetic mean: A study with secondary and university students. Research in Mathematical Education, 12(1), 49-66.

Gattuso, L., \& Mary, C. (1998, July). Development of the concept of weighted average among high-school children. Paper presented at the fifth International Conference on Teaching Statistics. Retrieved from http://iase-web.org/documents/papers/icots5/Topic6f.pdf

Gaudin, C., Flandin, S., Ria, L., \& Chaliès, S. (2014). An exploratory study of the influence of video viewing on preservice teachers' teaching activity: Normative versus developmental approaches.Form@re,14(2),21-50.doi:10.13128/formare-15126

Gfeller, M. K., Niess, M. L., \& Lederman, N. G. (1999). Preservice teachers' use of multiple representations in solving arithmetic mean problems. School Science and Mathematics, 99(5), 250-257. doi:10.1111/j.1949-8594.1999.tb17483.x

Godino, J. D., Batanero, C., Roa, R., \& Wilhelmi, M. R. (2008). Assessing and developing pedagogical content and statistical knowledge of primary school teachers through project work. In C. Batanero, G. Burrill, C. Reading, \& A. Rossman (Eds.), In C. Batanero, G. Burrill, C. Reading, \& A. Rossman (Eds.), Joint ICMI/IASE study: Teaching statistics in school mathematics. Challenges for teaching and teacher education. Proceedings of the ICMI Study 18 and 2008 ISAE Round Table Conference. Retrieved from http://iaseweb.org/documents/papers/rt2008/T3P1_Godino.pdf

Godino, J. D., Ortiz, J. J., Roa, R., \& Wilhelmi, M. R. (2011). Models for statistical pedagogical knowledge. In C. Batanero, G. Burrill, \& C. Reading (Eds.), Teaching statistics in school mathematics - Challenges for teaching and teacher education: A joint ICMI/IASE study. (pp. 271-282). Dordrecht, the Netherlands: Springer. doi:10.1007/978-94-007-1131-0_27 
González, O. (2016). A framework for assessing statistical knowledge for teaching based on the identification of conceptions of variability held by teachers. In Dani Ben-Zvi \& Katie Makar (Eds.), The teaching and learning of statistics: International perspectives (pp. 315-325). Cham, Switzerland: Springer. doi:10.1007/978-3-319-23470-0_37

Groth, R. E. (2007). Toward a conceptualization of statistical knowledge for teaching. Journal for Research in Mathematics Education, 38(5), 427-437.

Groth, R. E. (2013). Characterizing key developmental understandings and pedagogically powerful ideas within a statistical knowledge for teaching framework. Mathematical Thinking and Learning, 15(2), 121-145. doi:10.1080/10986065.2013.770718

Groth, R. E. (2014). Using work samples from the National Assessment of Educational Progress (NAEP) to design tasks that assess statistical knowledge for teaching. Journal of Statistics Education, 22(3). doi:10.1080/10691898.2014.11889712

Groth, R. E., \& Bergner, J. A. (2006). Preservice elementary teachers' conceptual and procedural knowledge of mean, median, and mode. Mathematical Thinking and Learning, 8(1), 3763. doi:10.1207/s15327833mt10801_3

Hashweh, M. Z. (1987). Effects of subject-matter knowledge in the teaching of biology and physics. Teaching \& Teacher Education, 3(2), 109-120.

Herbst, P., Chazan, D., Chen, C.-L., Chieu, V.-M., \& Weiss, M. (2011). Using comics-based representations of teaching, and technology, to bring practice to teacher education courses. ZDM: The International Journal on Mathematics Education, 43(1), 91-103. doi:10.1007/s11858-010-0290-5 
Herbst, P., \& Chazan, D. (2015). Studying professional knowledge use in practice using multimedia scenarios delivered online. International Journal of Research \& Method in Education, 38(3), 272-287. doi:10.1080/1743727x.2015.1025742

Herbst, P., \& Kosko, K. W. (2014). Using representations of practice to elicit mathematics teachers' tacit knowledge of practice: A comparison of responses to animations and videos. Journal of Mathematics Teacher Education, 17(6), 515-537. doi:10.1007/s 10857-013-9267-y

Hiebert, J., Gallimore, R., Garnier, H., Bogard Givvin, K., Hollingsworth, H., Jacobs, J., . . . Stigler, J. (2004). Teaching mathematics in seven countries: Results from the TIMSS 1999 video study (Rev. ed.). Washington, DC: U.S. Department of Education, National Center for Education Statistics. Retrieved from https://nces.ed.gov/pubs2003/2003013.pdf

Hill, H. C., Ball, D. L., \& Schilling, S. G. (2008). Unpacking pedagogical content knowledge: Conceptualizing and measuring teachers' topic-specific knowledge of students. Journal for Research in Mathematics Education, 39(4), 372-400.

Hill, H. C., \& Lubienski, S. T. (2007). Teachers' mathematics knowledge for teaching and school context: A study of California teachers. Educational Policy, 21(5), 747-768. doi:10.1177/0895904807307061

Hill, H. C., Schilling, S., \& Ball, D. L. (2004). Developing measures of teachers' mathematics knowledge for teaching. Elementary School Journal, 105(1), 11-30. doi:10.1086/428763 
Jacobbe, T. (2008). Elementary school teachers' understanding of the mean and median. In C. Batanero, G. Burrill, C. Reading, \& A. Rossman (Eds.), Joint ICMI/IASE study: Teaching statistics in school mathematics. Challenges for teaching and teacher education. Proceedings of the ICMI Study 18 and 2008 ISAE Round Table Conference. Retrieved from https://www.stat.auckland.ac.nz/ iase/publications/rt08/T2P13_Jacobbe.pdf

Jacobs, V. R., Lamb, L. L. C., \& Philipp, R. A. (2010). Professional noticing of children's mathematical thinking. Journal for Research in Mathematics Education, 41(2), 169-202.

Miles, B. M., Huberman, A. M., \& Saldaña, J. (2014). Qualitative data analysis: A methods sourcebook (3rd ed.). Thousand Oaks, CA: Sage.

Kader, G. K., Jacobbe, T., Wilson, P. S., \& Zbiek, R. M. (2013). Developing essential understanding of statistics for teaching mathematics: Grades 6-8. Reston, VA: National Council of Teachers of Mathematics.

Kersting, N. (2008). Using video clips of mathematics classroom instruction as item prompts to measure teachers' knowledge of teaching mathematics. Educational and Psychological Measurement, 68(5), 845-861. doi:10.1177/0013164407313369

Kersting, N. B., Givvin, K. B., Sotelo, F. L., \& Stigler, J. W. (2010). Teachers' analyses of classroom video predict student learning of mathematics: Further explorations of a novel measure of teacher knowledge. Journal of Teacher Education, 61(1-2), 172-181. doi:10.1177/0022487109347875

Kersting, N. B., Givvin, K. B., Thompson, B. J., Santagata, R., \& Stigler, J. W. (2012). Measuring usable knowledge: Teachers' analyses of mathematics classroom videos predict teaching quality and student learning. American Educational Research Journal, 49(3), 568-589. doi:10.3102/0002831212437853 
Leavy, A., \& O’Loughlin, N. (2006). Preservice teachers understanding of the mean: Moving beyond the arithmetic average. Journal of Mathematics Teacher Education, 9(1), 53-90. doi:10.1007/s10857-006-9003-y

Leon, M. R., \& Zawojewski, J. S. (1990). Use of arithmetic mean: An investigation of four properties issues and preliminary results. In D. Vere-Jones (Ed.), Proceedings of the III International Conference on Teaching Statistics (pp. 302-306). Retrieved from https://www.stat.auckland.ac.nz/ iase/publications/18/BOOK1/A9-2.pdf

Liston, M. (2015). The use of video analysis and the Knowledge Quartet in mathematics teacher education programmes. International Journal of Mathematical Education in Science and Technology, 46(1), 1-12. doi:10.1080/0020739X.2014.941423

Ijeh, S. B. (2013). Pedagogical content knowledge (PCK) development in statistics teaching: What content knowledge does mathematics teachers have and demonstrate during classroom practice? Mediterranean Journal of Social Sciences, 4(14), 191-200 doi:10.5901/mjss.2013.v4n14p191

Makar, K. (2014). Young children's explorations of average through informal inferential reasoning. Educational Studies in Mathematics, 86(1), 61-78. doi:10.1007/s10649-0139526-y

Mathews, D., \& Clark, J. M. (2003). Successful students' conceptions of mean, standard deviation, and the Central Limit Theorem. Unpublished manuscript.

Mercimek, O., \& Erbas, A. K. (2017). Validation of the mathematical knowledge for teaching statistics instrument. Cumhuriyet International Journal of Education, 6(1), 173-184. doi:10.30703/cije.321451 
Mevarech, Z. R. (1983). A deep structure model of students' statistical misconceptions. Educational Studies in Mathematics, 14(4), 415-429. doi:10.1007/BF00368237

Meyer, F., Lampron, R., \& Gazé, M.-A. (2014). Four pedagogical models using video as a tool for learning in a distance teacher training program context. Form@re, 14(2), 75-86. doi:10.13128/formare-15125

Mokros, J., \& Russell, S. J. (1995). Children's concepts of average and representativeness. Journal for Research in Mathematics Education, 26(1), 20-39. doi:10.2307/749226

Mooney, E. S. (2002). A framework for characterizing middle school students' statistical thinking. Mathematical Thinking and Learning, 4(1), 23-63. doi:10.1207/S15327833MTL0401_2

National Commission on Excellence in Education. (1983). A nation at risk: The imperative for educational reform. Washington, DC: U.S. Department of Education.

National Council of Teachers of Mathematics. (1989). Curriculum and evaluation standards for school mathematics. Reston, VA: Author.

National Council of Teachers of Mathematics. (2000). Principles and standards for school mathematics. Reston, VA: Author.

National Council of Teachers of Mathematics. (2006). Curriculum focal points for prekindergarten through Grade 8 mathematics: A quest for coherence. Reston, VA: Author. National Council of Teachers of Mathematics, Commission on Teaching Standards for School Mathematics. (1991). Professional standards for teaching mathematics. Reston, VA: Author. 
National Governors Association Center for Best Practices \& Council of Chief State School Officers. (2010). Common core state standards for mathematics. Washington, DC: Author. Retrieved from http://www.corestandards.org/assets/CCSSI Math Standards.pdf National Mathematics Advisory Panel. (2008). Foundations for success: The final report of the National Mathematics Advisory Panel. Washington, DC: U.S. Department of Education.

Piaget, J. (1952). The child's conception of number. London: Routledge \& Kegan Paul.

Pollatsek, A., Lima, S., \& Well, A. D. (1981). Concept or computation: Students' understanding of the mean. Educational Studies in Mathematics, 12(2), 191-204. doi:10.1007/BF00305621

Porter, A., McMaken, J., Hwang, J., \& Yang, R. (2011). Common Core Standards: The New U.S. Intended Curriculum. Educational Researcher, 40(3), 103-116. Retrieved from http://www.jstor.org/stable/41238917

Russell, S. J., \& Mokros, J. R. (1990). What's typical? Children's and teachers' ideas about average. In D. Vere-Jones (Ed.), Proceedings of the III International Conference on Teaching Statistics (pp. 307-313). Retrieved from https://iaseweb.org/documents/papers/icots3/BOOK1/A9-3.pdf

Santagata, R., \& Guarino, J. (2011). Using video to teach future teachers to learn from teaching. ZDM: The International Journal on Mathematics Education, 43(1), 133-145. doi:10.1007/s11858-010-0292-3

Schoenfeld, A. H. (2007). Method. In F. K. Lester, Jr. (Ed.), Second handbook of research on mathematics teaching and learning (Vol. 1, pp. 69-107). Greenwich, CT: Information Age. 
Shaughnessy, J. M. (1992). Research on probability and statistics: Reflections and directions. In D. A. Grouws (Ed.), Handbook of research on mathematical teaching and learning (pp. 465-494). New York, NY: Macmillan.

Shaughnessy, J. M. (2007). Research on statistics learning and reasoning. In F. K. Lester, Jr. (Ed.), Second handbook of research on mathematics teaching and learning (Vol. 2, pp. 957-1009). Greenwich, CT: Information Age.

Shulman, L. S. (1986). Those who understand: Knowledge growth in teaching. Educational Researcher, 15(2), 4-14. doi:10.3102/0013189X015002004

Shulman, L. S. (1987). Knowledge and teaching: Foundations of the new reform. Harvard Education Review, 57(1), 1-22. doi:10.17763/haer.57.1.j463w79r56455411

Silverman, J., \& Thompson, P. W. (2008). Toward a framework for the development of mathematical knowledge for teaching. Journal of Mathematics Teacher Education, 11(6), 499-511. doi:10.1007/s10857-008-9089-5

Simon, M. A. (2006). Key developmental understandings in mathematics: A direction for investigating and establishing learning goals. Mathematical Thinking and Learning, 8(4), 359-371. doi:10.1207/s15327833mt10804_1

Smith, M. S., \& Stein M. K. (1998). Selecting and creating mathematical tasks: From research to practice. Mathematics Teaching in the Middle School, 3(5), 344-50.

Sorto, A., \& White, A. (2004, July). Statistical knowledge for teaching. Paper presented at the 10th International Congress on Mathematical Education. Retrieved from https://iaseweb.org/documents/papers/icme10/intro.pdf 
Star, J. R., Lynch, K., \& Perova, N. (2011). Using video to improve preservice mathematics teachers' abilities to attend to classroom features: A replication study. In M. G. Sherin, V. R. Jacobs, \& R. A. Philipp (Eds.), Mathematics teacher noticing: Seeing through teachers' eyes (pp. 118-133). New York, NY: Routledge.

Star, J. R., \& Strickland, S. K. (2008). Learning to observe: Using video to improve preservice mathematics teachers' ability to notice. Journal of mathematics teacher education, 11(2), 107-125. doi:10.1007/s10857-007-9063-7

Strauss, S., \& Bichler, E. (1988). The development of children's concepts of the arithmetic average. Journal for Research in Mathematics Education, 19(1), 64-80. doi:10.2307/749111

Tarr, J. E., \& Shaughnessy, J. M. (2007). Student performance in data analysis, statistics, and probability. In P. Kloosterman \& F. K. Lester. Jr. (Eds.), Results and interpretations of the 2003 mathematics assessment of the National Assessment of Educational Progress (pp. 139-168). Reston, VA: National Council of Teachers of Mathematics.

Vygotsky, L. S. (1978). Mind in society: The development of higher psychological processes. Cambridge, MA: Harvard University Press.

Watson, J. M. (2001). Profiling teachers' competence and confidence to teach particular mathematics topics: The case of chance and data. Journal of Mathematics Teacher Education, 4(4), 305-337. doi:10.1023/A:1013383110860 
Watson, J. M., Callingham, R. A., \& Donne, J. M. (2008). Establishing PCK for teaching statistics. In C. Batanero, G. Burrill, C. Reading, \& A. Rossman (Eds.), Joint ICMI/IASE study: Teaching statistics in school mathematics. Challenges for teaching and teacher education. Proceedings of the ICMI Study 18 and 2008 ISAE Round Table Conference. Retrieved from http://iase-web.org/documents/papers/rt2008/T2P10_Watson.pdf

Watson, J., Callingham, R., \& Nathan, E. (2009). Probing teachers' pedagogical content knowledge in statistics: "How will Tom get to school tomorrow?". Crossing divides, 2, $563-570$.

Watson, J. M., \& Moritz, J. B. (2000). The longitudinal development of understanding of average. Mathematical Thinking and Learning, 2(1-2), 11-50. doi:10.1207/S15327833MTL0202_2

Watson, J. M., \& Nathan, E. L. (2010). Biased sampling and PCK: The case of the marijuana problem. In L. Sparrow, B. Kissane, \& C. Hurst (Eds.), Shaping the future of mathematics education. Proceedings of the 33rd annual conference of the Mathematics Education Research Group of Australasia (Vol. 2, pp. 610-617). Fremantle, WA: MERGA.

Wessels, H. (2014). Developing statistical knowledge for teaching of variability through professional development. In K. Makar, B. de Sousa, \& R. Gould (Eds.), Sustainability in statistics education. Proceedings of the Ninth International Conference on Teaching Statistics (ICOTS9). Voorburg, the Netherlands: International Association of Statistics Education. Retrieved from https://iaseweb.org/icots/9/proceedings/pdfs/ICOTS9_7B2_WESSELS.pdf 
Wild, C. J., \& Pfannkuch, M. (1999). Statistical thinking in empirical enquiry. International Statistical Review, 67(3), 223-248. doi:10.2307/1403699

Wilson, M. R. (1994). One preservice teacher's understanding of function: The impact of a course integrating mathematical content and pedagogy. Journal for Research in Mathematics Education, 25 (4), 346-370.

Zawojewski, J. S., \& Shaughnessy, J. M. (1999). Data and chance. In E. A. Silver \& P. A. Kenney (Eds.), Results from the seventh mathematics assessment of the National Assessment of Educational Progress (pp. 235-268). Reston, VA: National Council of Teachers of Mathematics.

Zawojewski, J. S., \& Shaughnessy, J. M. (2000). Mean and median: Are they really so easy? Mathematics Teaching in the Middle School, 5(7), 436-440.

Zazkis, D. (2013). On students' conceptions of arithmetic average: The case of inference from a fixed total. International Journal of Mathematical Education in Science and Technology, 44(2), 204-213. doi:10.1080/0020739X.2012.703338 


\section{APPENDIX A: ANIMATION VIGNETTES}

\section{Video1}

\section{Part 1}

Board $\quad 1,1,2,2,2,2,3,3,3,3,4,4,4,4,4$

Mean $=$ Add the numbers then divide

by how many numbers there are

Teacher: Today we will talk about the mean, median, and mode. concepts in our statistics unit. Here are a set of data that will help us understand these measures:

In order for us to find the mean we just add the numbers and divide by how many numbers there are.

As you can see, we found that the sum is 42 , and because there are 15 numbers we divide 42 by 15 to get 2.8 , hence the mean is 2.8 . Here is a set of data that I want you to practice with before we move on to the median.

Eric: So, when I add the numbers I get 117, and dividing by 9 , I get 13 as the mean.

Prompt: Comment on differences or similarities between the way you introduce the mean and the way the teacher in this video introduced the mean.

\section{Part 2}

Teacher: To find the median we look for the middle number. Since there are 15 pieces of data that means the 8 th number is our median. If we count from the first 1 , we get the 8 th number to be 3. Let's practice finding the median with the data I gave you. 
Sallie: Since there are 9 numbers, that means that the middle number is the fifth one. If I count from the 2 then the fifth number is 13 , that means that 13 is the median.

Teacher: If we have an even number of data then we look at the middle two numbers and add them and divide by 2 to find the median. From our previous data I am taking away the first 1 . So, now we have 14 numbers. The 7th and 8th numbers, which are the two middle numbers, are both 3 , adding them up we get 6 , dividing by 2 we get 3 , hence again the median is 3 . Find the median of you new data. 12, 12, 12,13,13, 14, 17, 21

Brian: Since we now have 8 numbers, the middle two will be the fourth and the fifth ones. So, $13+13=26$, dividing by 2 we still get 13 , our median did not change.

Prompt: Comment on differences or similarities between the way you introduce the mean and the way the teacher in this video introduced the median.

\section{Part 3}

Teacher: Lets go to our original data. To find the mode we just look for the number that shows up the most. As we can see from my data the number that shows up the most is the 4 . Go ahead and find the mode for your original data.

Sallie: From our data, the number 12 shows up three times, so that has to be our mode, 12 .

Prompt: Comment on differences or similarities between the way you introduce the mean and the way the teacher in this video introduced the mode. 


\section{Video 2}

$9.3,9.1,9.2 .9 .2,9.1,9.23,9,9.1,11.5$

Teacher: Yesterday, I weighed the shoes that were on the doorstep, and I got these results in ounces. What is the typical weight of the shoes?

Joey: If I add up all the numbers, I get 85.03, and if I divide by 9, (the number of shoes), then I get 9.45 ounces as the average.

Eric: Since the 11.5 seems too big, maybe they were a grownup's shoes, we take it out, if we add the rest up we get 73.53 , then divide by 8 we get 9.19 ounces as the average.

Sallie: If we eliminate the lowest and largest, because they are always outliers, then add and divide by 7 will give us an average of 9.21 ounces.

Brian: It is true that there seems to be a really large number, the 11.5 , so why not use the median, which can be found by crossing out the first and the last numbers, like 9.3 on the left and 11.5 on the right. then we can eliminate the next two, 9.1 on the left and 9.1 on the right, all the way until there is only one number left. That will give us the median of 9.1 as the average.

Joey: I am confused, do we not always use the mean to represent the typical number of the data?

Prompt 1: Please identify which student/students seem to be struggling with the idea of measures of center, and explain why.

Prompt 2: How would you help these students improve their conception (please talk about each child individually)? 


\section{Video 3}

\section{$0,1,1,1,1,1,2,2,2,2,3,3,3,4,4,4,4$}

Teacher: In my fifth period class the 17 students had this many pets. One of them did not have any, five of them had one pet, 4 had two pets, three had 3, and four of them had 4 pets. If a grownup asked you as to what number represents how many pets a student in fifth grade might have. What would be your answer?

Joey: So, if I add all those numbers up, I get 38, and if I divide by 16, I get the answer as 2.375 . Sallie: How can this mean represent the data, since you can't have 2.375 pets?

Brian: I thought we had 17 numbers for the 17 students, why did you divide by 16 ? Joey: Well. One of those students had no pets. So we do not need to count that. Is that right?

Prompt 1: How would you respond to Sallie's comment?

Prompt 2: How would you respond Joey's question about whether to include 0 in the calculation of the mean?

\section{Video 4}

Teacher: Students, here are some cubes representing your amount of money. James, you have 7 cubes, Sandie you have 6, Tony 10, and you Emma have 9 cubes. Now, stack your cubes to show your individual allowance, and place them in the middle of the table so that we can compare them. I want you to think of a way to distribute the cubes, representing your money, so that you all had the same amount.

Tony: Since I have 10 cubes, I can give one to Sandie, and now both James and Sandie have 7 cubes, and me and Emma have 9 cubes representing our money. 
Emma: Since two of us have 9 cubes and two have 7 cubes, why don't I give a cube to Sandie, that way we both have 8 cubes, and Tony can give one to James, so they also have 8 cubes. Now we all have 8 cubes, so we each have $\$ 8$.

Prompt 1: What concept of measures of center would you connect this activity to?

Prompt 2: Explain how would you make that connection (from previous prompt).

\section{Video 5}

Teacher: In an elevator there are 4 men and 2 women, the average age of the men is 34 years old, and the average age of the women is 38 years old. What is the average age of the people in the elevator?

Eric: Is the average not 36 years old? $34+38$ is 72 , if I divide that by 2 , you get 36 .

Sallie: There are more men in the elevator, shouldn't the average be closer to 34 ?

Brian: Because we do not know the exact age, of each person, how can we find the average?

Prompt 1: How would you respond to Eric's Comment?

Prompt 2: How would you respond to Sallie's Comment?

Prompt 3: How would you respond to Brian's Comment?

\section{Video 6}

Teacher: Assume that I have seven boxes of pencils in my desk, and that I know the mean number of pencils in a box is 15 . I want you to write down seven numbers that could represent the number of pencils in each box, so that the mean amount was still 15.

Joey: I guess I can write the number 15, the number of pencils in a box, seven times. 
Sallie: We can put 15 pencils in the middle, and then go to, 14 and 16,13 and 17,12 and 18 pencils, like one in each side.

Prompt 1: Please comment on Joey's thinking about the mean.

Prompt 2: Please comment on Sallie's thinking about the mean.

Prompt 3: Please comment on Brian's thinking about the mean.

Teacher: Ok, now this next time, I want you to do this again, but we cannot use the number 15 , and the number 11 has to be part of your data.

Joey: If I can't use the 15 pencils seven times, then I have no idea how to do this.

Sallie: Neither can I, since I can't use the 15 pencils in the middle. What number do I use to put the other numbers around? Do I use the 11?

Brian: What if we multiply 15 pencils by 7 boxes to get 105 pencils, then I just have to find seven numbers to add to 105 . Since I have to use the 11, I can have 6 boxes with 11 pencils, and then one box with 39 pencils. Because $11 * 6=66$ and $66+39=105$ pencils.

Prompt 4: How would you help Joey with the second task?

Prompt 5: How would you help Sallie with the second task? 


\section{Video 7}

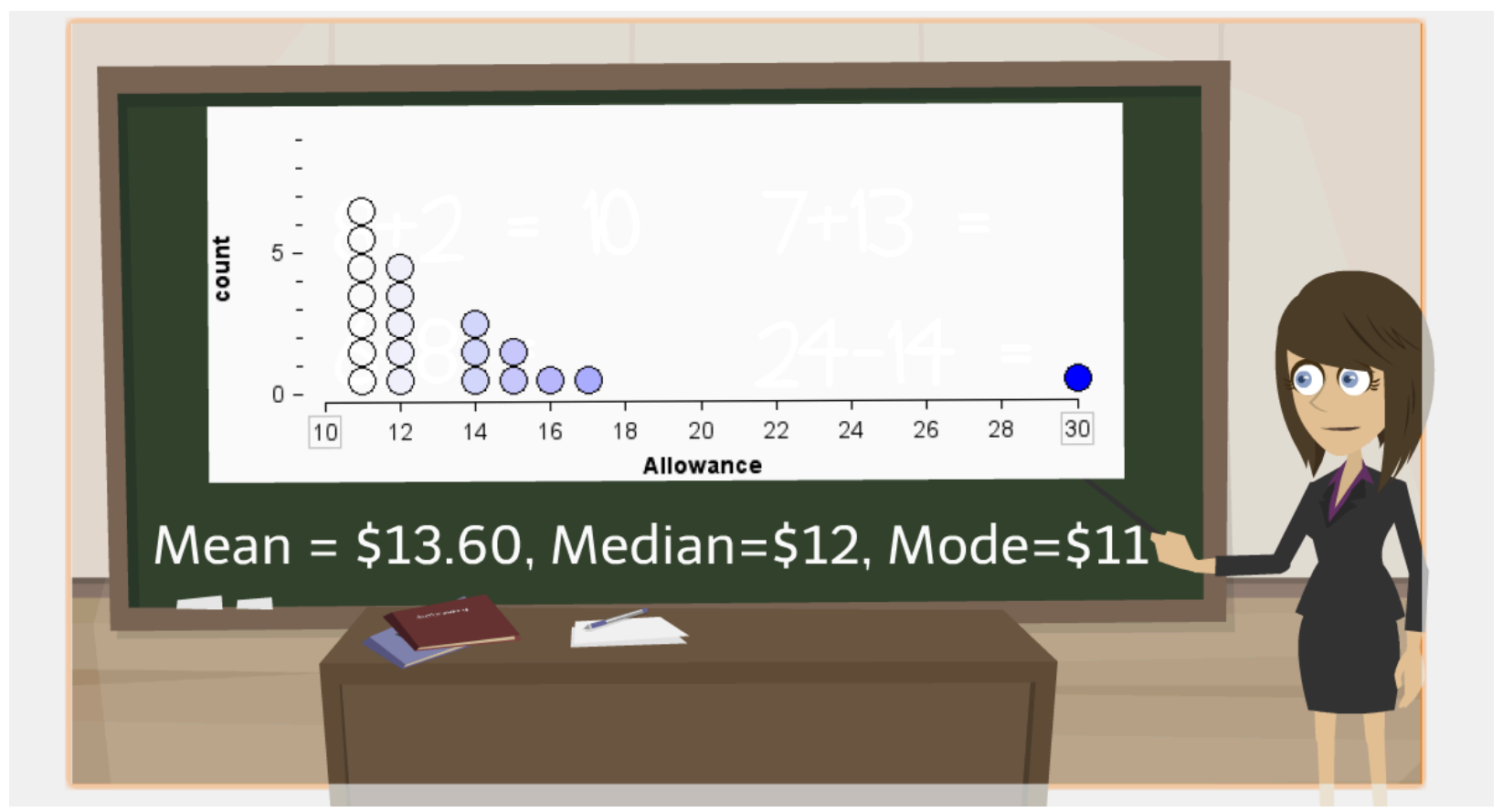

Teacher: The data presented in this graph represents the allowance of 20, 7th graders, and it has a mean of $\$ 13.6$, a median of $\$ 12$ and mode of $\$ 11$. Which one of these measures, mean, median, or mode, would best represent the data? Please explain your answer.

Joey: Well, the mean is the average of the data, so I would use $\$ 13.6$ to represent the data.

Eric: But $\$ 13.6$ is not part of the data, so why not use the mode, $\$ 11$, since that is what most students have?

Sallie: What about the median, since that shows the middle of the data, why not use the median of $\$ 12$ ?

Brian: I think we should use the median. Just because a kid gets $\$ 30$ from his parents does not mean that the average student will. The median is a better measure of center.

Joey: Wait, when should we use the mean, and when do we use the median? 
Prompt 1: Please identify which student/students seem to be struggling with the content, and explain why.

Prompt 2: How would you help these students improve their conception (please talk about each child individually)? 


\section{APPENDIX B: INITIAL SURVEY QUESTIONS}

1. Have you taught data analysis in the middle school at least twice during your career as a teacher?
a. Yes
b. No

2. Have you had any data analysis content courses, during your teacher education?
a. Yes
b. No

3. During your teacher education have you taken any methods courses that included pedagogy in teaching topics in data analysis?
a. Yes
b. No

4. During your career as a teacher have you participated in a professional development program geared towards teaching data analysis at the middle school level?
a. Yes
b. No

5. What major ideas do you want to bring across when teaching measures of center to your students?

6. What challenges, have you seen, or do you expect your students will have in learning the content (measures of center)?

7. How have you, or how do you plan to address those challenges? 